\title{
Inhalts- und Musterübersicht
}

\author{
Mit dem Code vorne im Werk das komplette Werk und alle Muster \\ für die Online-Nutzung freischalten
}

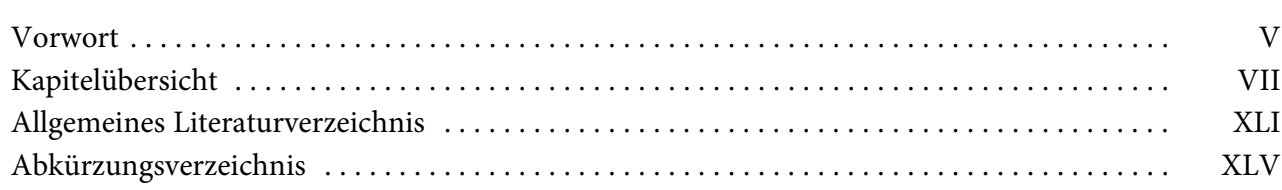

Seite

$\mathrm{V}$

VII

XLI

\section{Erster Teil \\ Individualarbeitsrecht}

\section{Kap. 1 Anbahnung des Arbeitsverhältnisses}

I. Einführung

1. Vorstellungsgespräch

2. Ausschreibung/Einstellungs- und Personalfragebogen $\ldots \ldots \ldots \ldots \ldots \ldots \ldots \ldots \ldots$

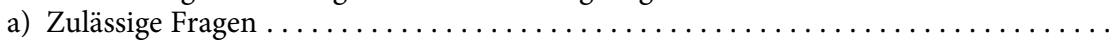

b) Beteiligung des Betriebsrats und Haftungsprivilegierung $\ldots \ldots \ldots \ldots \ldots \ldots \ldots$

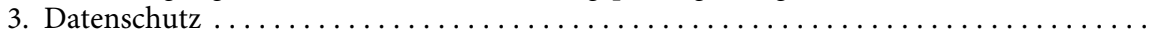

4. Beteiligung des Betriebsrats bei der Einstellung $\ldots \ldots \ldots \ldots \ldots \ldots \ldots \ldots \ldots \ldots \ldots$

5. Aufklärungspflichten des Arbeitgebers bei ungesicherter Beschäftigung des Arbeit-

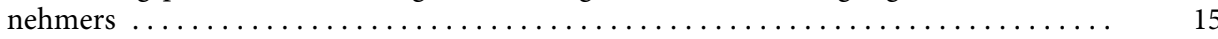

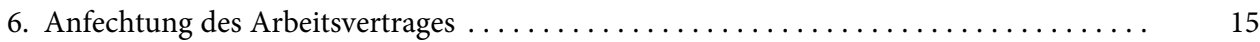

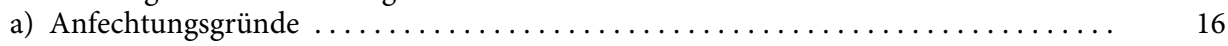

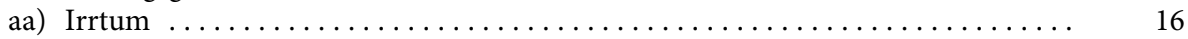

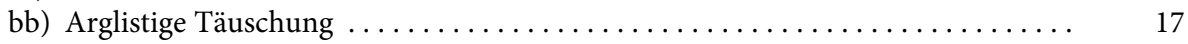

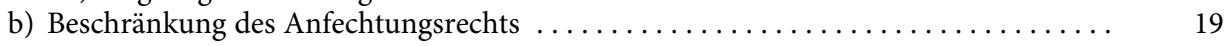

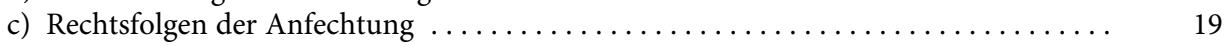

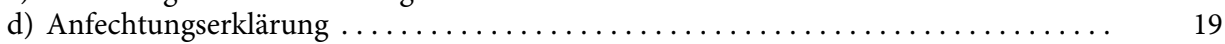

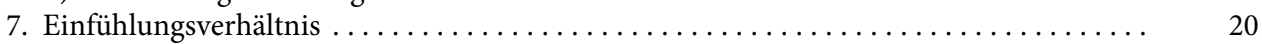

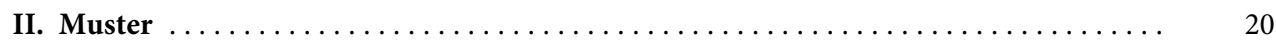

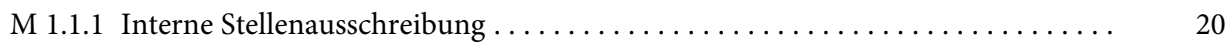

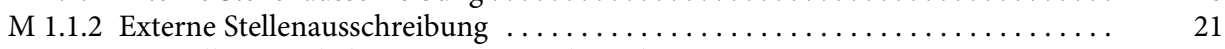

M 1.2.1 Vorstellungseinladung mit Kostenübernahme $\ldots \ldots \ldots \ldots \ldots \ldots \ldots \ldots \ldots . \ldots \ldots$

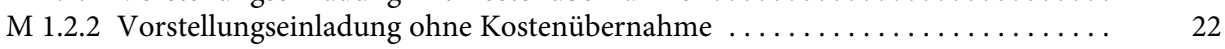

M 1.3.1 Einstellungsfragebogen im Bewerbungsverfahren ................. 22

M 1.3.2 Personalfragebogen nach erfolgter Einstellung $\ldots \ldots \ldots \ldots \ldots \ldots \ldots \ldots \ldots$

M 1.4 Einwilligung in ärztliche Untersuchung/psychologische und graphologische

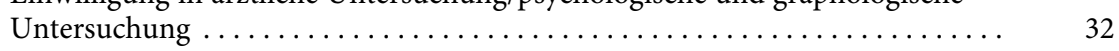

M 1.5 Antrag an den Betriebsrat auf Zustimmung zur Einstellung und Eingruppie-

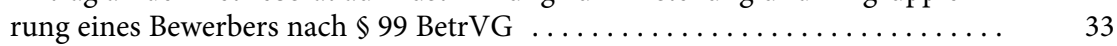

M $1.6 \quad$ Klage auf Erstattung von Vorstellungskosten $\ldots \ldots \ldots \ldots \ldots \ldots \ldots \ldots \ldots \ldots$

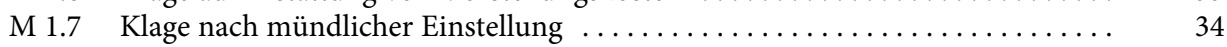

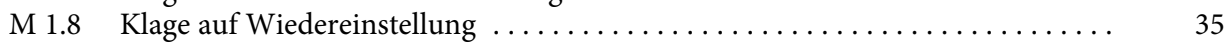

M 1.9 Klage auf Entschädigung wegen Diskriminierung bei der Einstellung . . . . . . 37

M 1.10 Klage des Arbeitgebers auf Schadensersatz und Vertragsstrafe wegen Nicht-

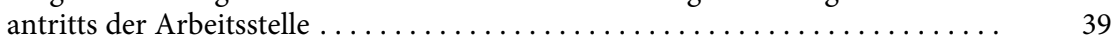


M 1.11 Anfechtung des Arbeitsvertrages wegen arglistiger Täuschung $\ldots \ldots \ldots \ldots \ldots$

M 1.12 Klage des Arbeitnehmers gegen die Anfechtung des Arbeitsvertrages . . . . . . . .

\section{Kap. 2 Verträge mit gewerblichen Arbeitnehmern (Arbeitern)}

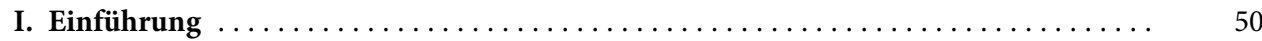

1. Allgemeine Geschäftsbedingungen und Arbeitsvertrag $\ldots \ldots \ldots \ldots \ldots \ldots \ldots \ldots \ldots \ldots$

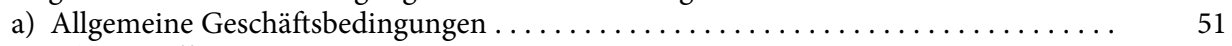

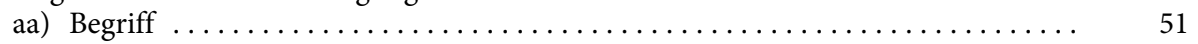

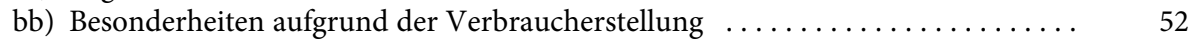

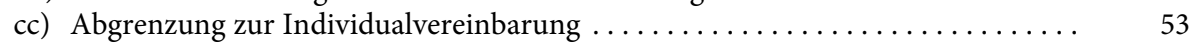

dd) Keine Klauselkontrolle zugunsten des Verwenders . . . . . . . . . . . . 53

ee) Beteiligung des Betriebsrats bei Formularverträgen $\ldots \ldots \ldots \ldots \ldots \ldots \ldots \ldots . \ldots \ldots$

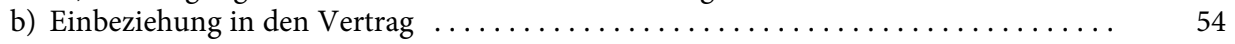

c) Vorrang der Individualabrede/Schriftformklausel $-\S 305 \mathrm{~b}$ BGB $\ldots \ldots \ldots \ldots \ldots \ldots$

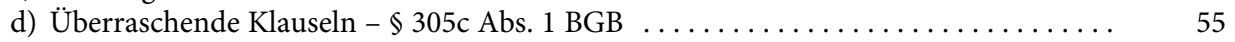

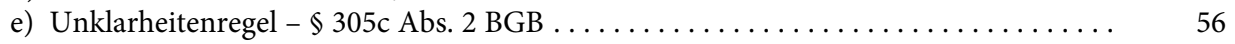

f) Rechtsfolgen bei Nichteinbeziehung und Unwirksamkeit $-\$ 306$ BGB $\ldots \ldots \ldots \ldots$.

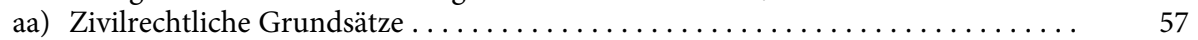

bb) BAG vor Einführung der AGB-Kontrolle/Geltung bei Individualverträgen . . . . 58

cc) BAG nach Einführung der AGB-Kontrolle ...................... 59

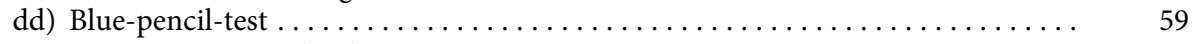

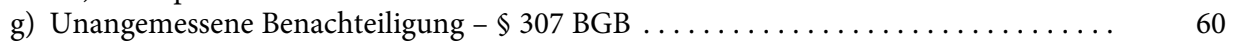

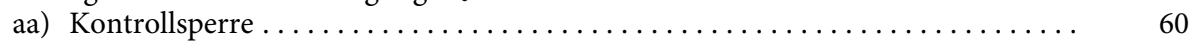

bb) Transparenzgebot $-\$ 307$ Abs. 1 Satz 2 BGB $\ldots \ldots \ldots \ldots \ldots \ldots \ldots \ldots \ldots \ldots \ldots \ldots \ldots \ldots \ldots \ldots$

cc) Inhaltskontrolle - Materiell unangemessene Benachteiligung - $\$ 307$ Abs. 1

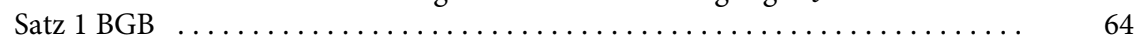

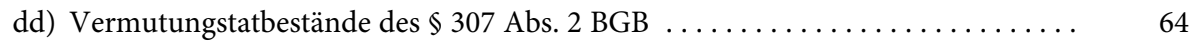

h) Klauselverbote mit Wertungsmöglichkeit $-\S 308$ BGB $\ldots \ldots \ldots \ldots \ldots \ldots \ldots \ldots . \ldots \ldots$

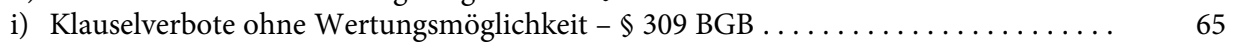

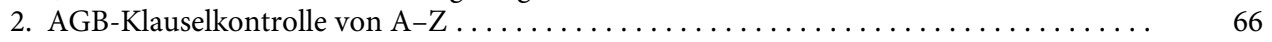

3. Form des Arbeitsvertrages, Nachweisgesetz, Arbeitsbedingungenrichtlinie . . . . . . . 117

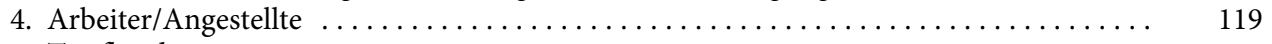

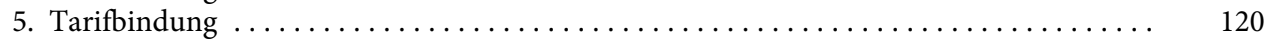

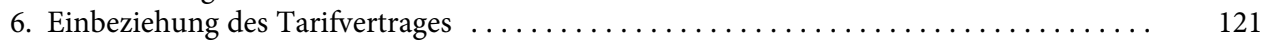

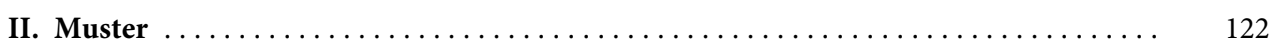

M 2.1a Arbeitsvertrag mit einem gewerblichen Arbeitnehmer ohne Bezugnahme auf

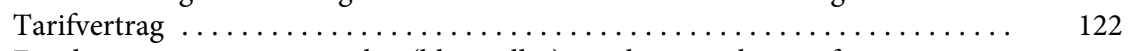

M 2.1b Employment agreement with a (blue collar) employee without reference to a

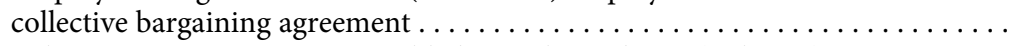

M 2.2 Arbeitsvertrag mit einem gewerblichen Arbeitnehmer (Arbeiter) mit Bezug-

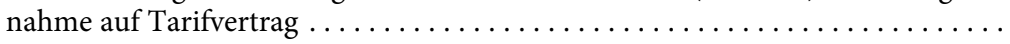

M 2.3 Arbeitsvertrag mit einem gewerblichen Arbeitnehmer (Arbeiter) mit teilweiser Bezugnahme auf tarifvertragliche Regelungen $\ldots \ldots \ldots \ldots \ldots \ldots \ldots$

\section{Kap. 3 Verträge mit Angestellten}

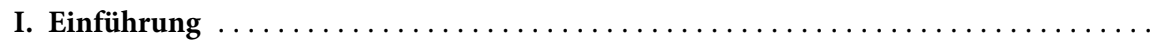

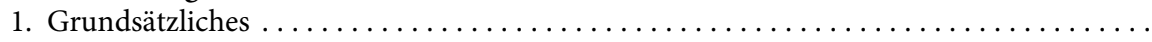

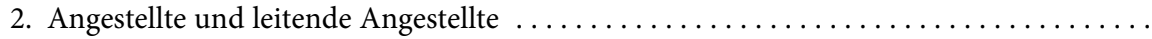

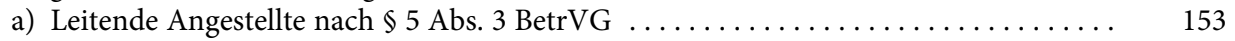

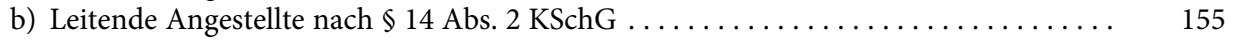

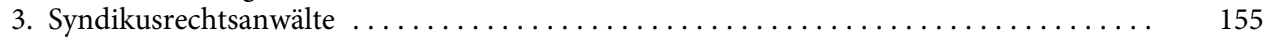




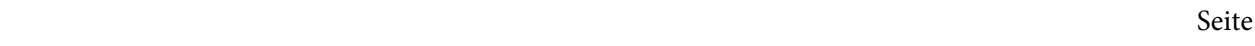

II. Muster . . . . . . . . . . . 156

M 3.1 Ausführlicher Anstellungsvertrag mit einem Angestellten ohne Bezugnahme

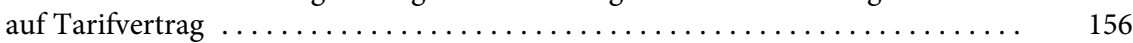

M 3.2 Anstellungsvertrag mit einem Angestellten mit Bezugnahme auf Tarifvertrag ... 176

M 3.3 Anstellungsvertrag mit einem leitenden Angestellten .................. 179

M 3.4 Anstellungsvertrag mit einem Syndikusrechtsanwalt ................ 185

\section{Kap. 4 Dienstvertrag des Geschäftsführers}

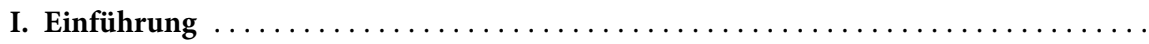

1. Anforderungen an die Person des Geschäftsführers $\ldots \ldots \ldots \ldots \ldots \ldots \ldots \ldots \ldots \ldots \ldots$

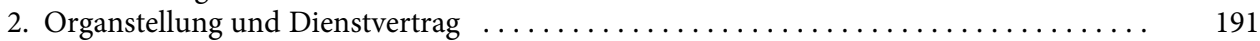

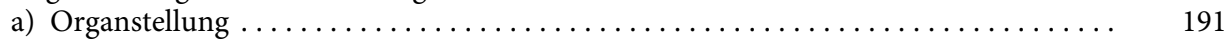

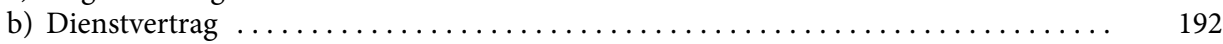

aa) Zuständigkeit für Abschluss und Änderung des Dienstvertrages . . . . . . . . 193

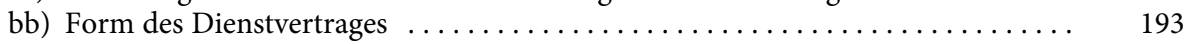

3. Pflichten und Verantwortlichkeiten des Geschäftsführers . . . . . . . . . . . . . 194

4. Arbeits- und sozialversicherungsrechtliche Stellung des Geschäftsführers . . . . . . . . 195

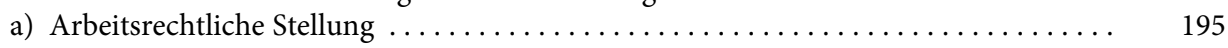

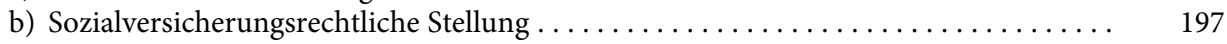

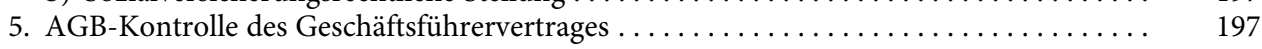

6. Anwendung des VorstAG auf die $\mathrm{GmbH} \ldots \ldots \ldots \ldots \ldots \ldots \ldots \ldots \ldots \ldots \ldots \ldots \ldots \ldots \ldots \ldots \ldots$

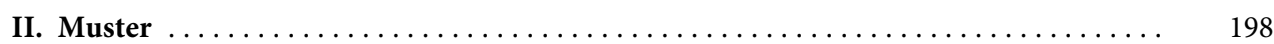

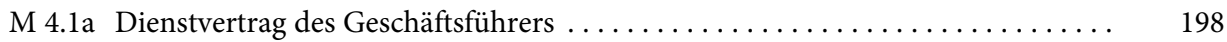

M 4.1b Service Agreement of the Managing Director $\ldots \ldots \ldots \ldots \ldots \ldots \ldots \ldots 214$

\section{Kap. 5 Dienstvertrag des Vorstandsmitglieds}

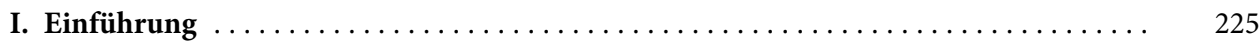

1. Anforderungen an die Person des Vorstandes ........................ 225

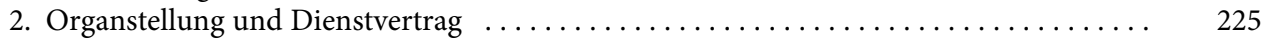

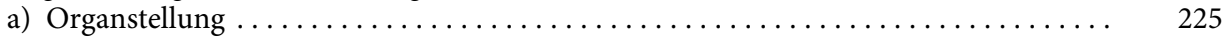

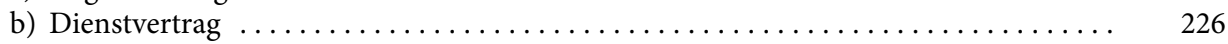

aa) Zuständigkeit für Abschluss und Änderung des Dienstvertrages $\ldots \ldots \ldots \ldots .226$

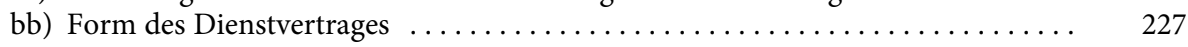

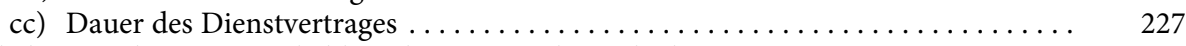

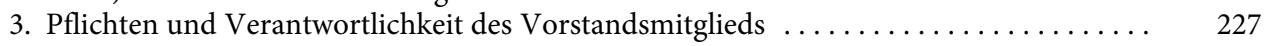

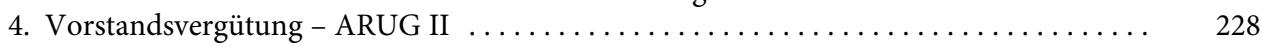

5. Deutscher Corporate Governance Kodex (DCGK) .................... 229

6. Sozialversicherungsrechtliche Stellung des Vorstandsmitglieds $\ldots \ldots \ldots \ldots \ldots \ldots \ldots . \ldots \ldots \ldots$

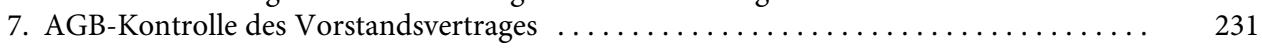

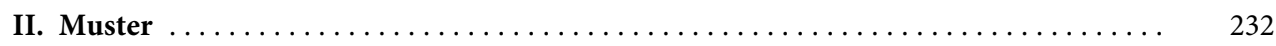

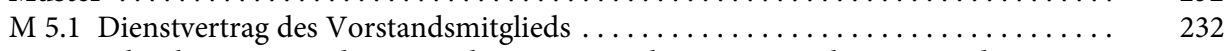

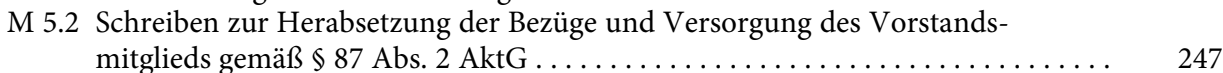

M 5.3 Beschlussfassung des Aufsichtsrats über die Herabsetzung der Bezüge und

Kap. 6 Besondere Arbeitsverträge - Befristung, Telearbeit, Mobile Office

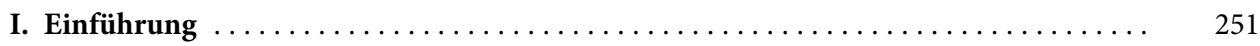

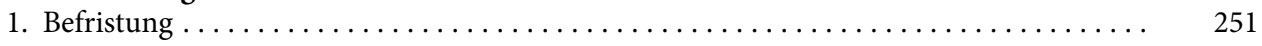


a) Befristung aufgrund eines sachlichen Grundes $\ldots \ldots \ldots \ldots \ldots \ldots \ldots \ldots \ldots$

aa) Befristungsgründe nach $\$ 14$ Abs. 1 Satz 1 iVm. Satz 2 TzBfG im Einzelnen .... .

bb) Kalendermäßige Befristung, $₫ 3$ Abs. 1 iVm. $\$ 15$ Abs. 1 TzBfG (M 6.1.1) . . . . .

cc) Zweckbefristung, $₫ 3$ Abs. 1 iVm. $₫ 15$ Abs. 2 TzBfG (M 6.1.2; M 6.1.5) . . ...

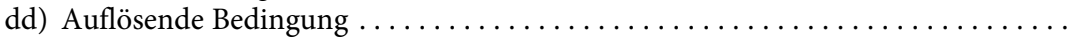

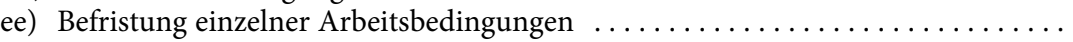

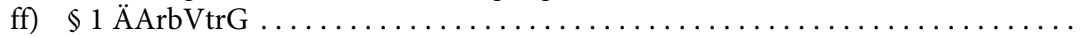

b) Befristung aufgrund gesetzlicher Regelungen $\ldots \ldots \ldots \ldots \ldots \ldots \ldots \ldots \ldots$

aa) $\$ 14$ Abs. 2, 2a, 3 TzBfG - Sachgrundlose Befristung (M 6.1.6; M 6.1.9) . . . . . .

bb) $\$ 21$ BEEG, $\$ 6$ PflegeZG und $\$ 9$ FPfZG $\ldots \ldots \ldots \ldots \ldots \ldots \ldots \ldots \ldots \ldots \ldots$

cc) Befristungen im Hochschulbereich nach WissZeitVG $\ldots \ldots \ldots \ldots \ldots \ldots \ldots$

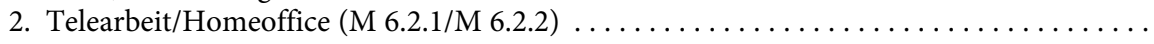

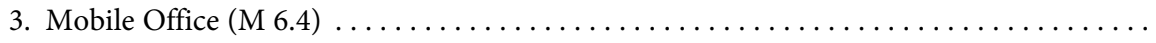

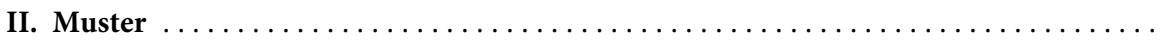

M 6.1.1 Kalendarisch befristeter Arbeitsvertrag aus sachlichen Gründen . . . . . . . .

M 6.1.2 Zweckbefristeter Arbeitsvertrag aus sachlichen Gründen . . . . . . . . . . . . . 278

M 6.1.3.1 Mitteilung der Zweckerreichung nach $₫ 15$ Abs. 2 TzBfG . . . . . . . . ... 279

M 6.1.3.2 Mitteilung des Ablaufs des vereinbarten Befristungszeitraums

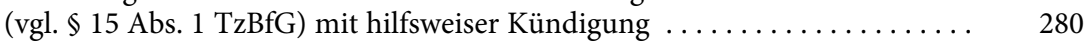

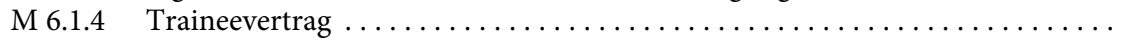

M 6.1.5 Doppelt befristeter Arbeitsvertrag $\ldots \ldots \ldots \ldots \ldots \ldots \ldots \ldots \ldots \ldots \ldots \ldots$

M 6.1.6 Sachgrundlos befristeter Arbeitsvertrag nach $\$ 14$ Abs. 2 TzBfG ..........

M 6.1.7 Probearbeitsverhältnis mit Befristung $\ldots \ldots \ldots \ldots \ldots \ldots \ldots \ldots \ldots \ldots$

M 6.1.8 Verlängerung des Probearbeitsverhältnisses mittels Aufhebungsvertrag . . . . .

M 6.1.9 Verlängerung des sachgrundlos befristeten Arbeitsvertrages nach

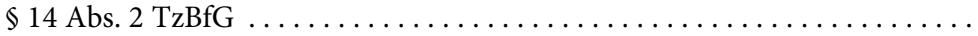

M 6.1.10 Hinausschieben des Beendigungszeitpunktes über die Regelaltersgrenze

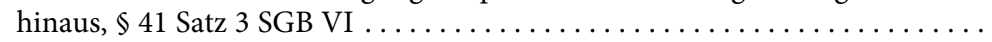

M 6.1.11 Klage auf Feststellung der Unwirksamkeit einer Befristung und Weiter-

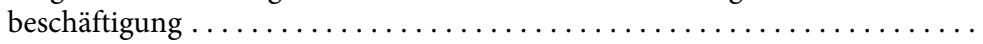

M 6.2.1 Arbeitsvertrag über alternierende Telearbeit/Homeoffice ohne vom Arbeitgeber eingerichteten Arbeitsplatz im Privatbereich $\ldots \ldots \ldots \ldots \ldots \ldots \ldots$

M 6.2.2 Arbeitsvertrag über alternierende Telearbeit/Homeoffice mit vom Arbeitgeber eingerichtetem Arbeitsplatz im Privatbereich $\ldots \ldots \ldots \ldots \ldots \ldots \ldots$

M 6.3 Homeoffice-Klausel für Arbeitsvertrag $\ldots \ldots \ldots \ldots \ldots \ldots \ldots \ldots \ldots \ldots$

M 6.4 Mobile Office-Vereinbarung/Vertrag über mobiles Arbeiten . . . . . . . . . .

\section{Kap. 7 Arbeitszeit, Teilzeit, Altersteilzeit}

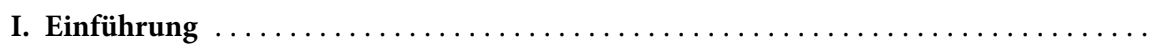

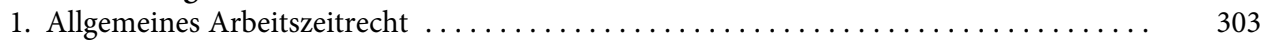

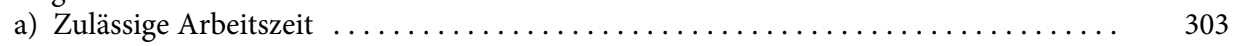

b) Verstöße gegen das ArbZG . . . . . . . . . . . . . . . . . . . . . . . . . . . . . 304

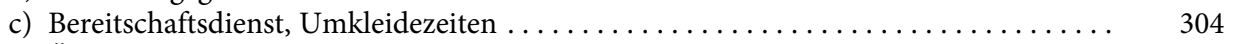

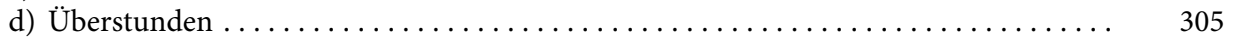

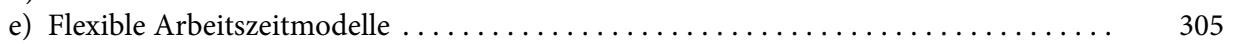

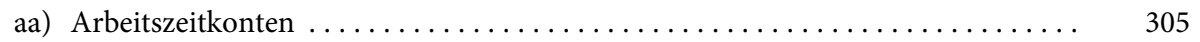

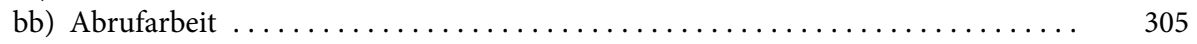

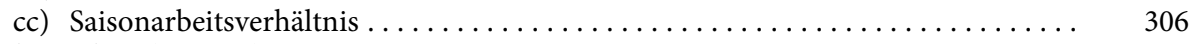

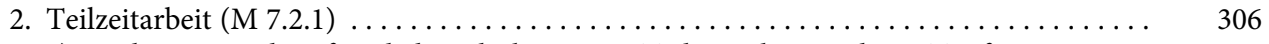

a) Rechtsanspruch auf zeitlich nicht begrenzte Teilzeitarbeit nach $\$ 8$ TzBfG . . . . . . 307

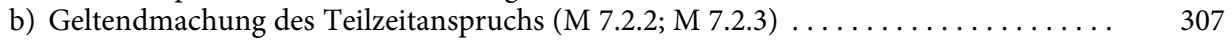


c) Ablehnung des Teilzeitantrags $(M 7.2 .4) \ldots \ldots \ldots \ldots \ldots \ldots \ldots \ldots \ldots \ldots \ldots \ldots \ldots$

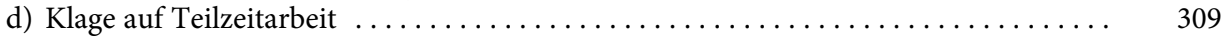

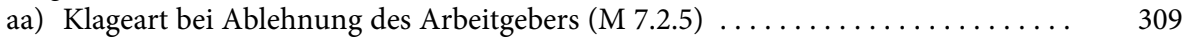

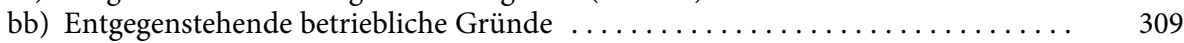

(1) Betriebliche Gründe gegen die gewünschte Verringerung . . . . . . . . 310

(2) Betriebliche Gründe gegen die gewünschte Verteilung . . . . . . . . . . 312

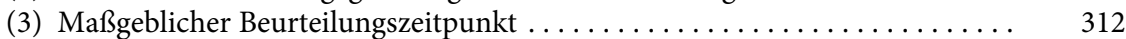

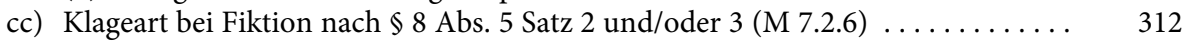

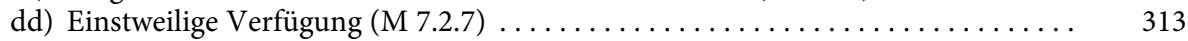

e) Teilzeitanspruch nach $\$ 9$ a TzBfG (Brückenteilzeit) $\ldots \ldots \ldots \ldots \ldots \ldots \ldots \ldots \ldots \ldots$

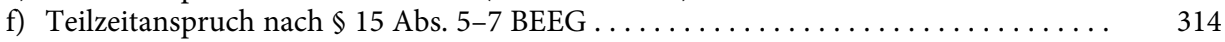

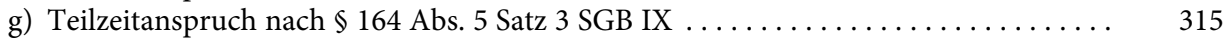

h) Teilzeitanspruch nach $₫ 3$ PflegeZG $(M 17.13) \ldots \ldots \ldots \ldots \ldots \ldots \ldots \ldots \ldots \ldots \ldots$

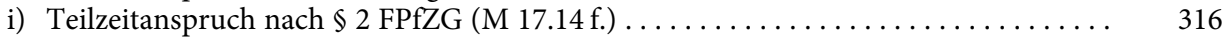

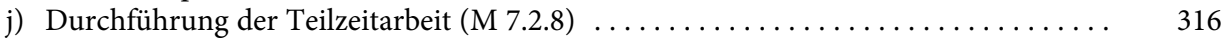

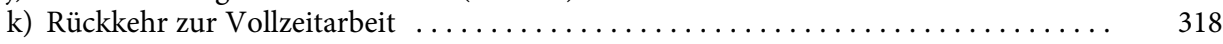

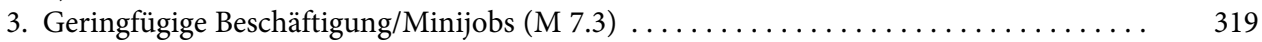

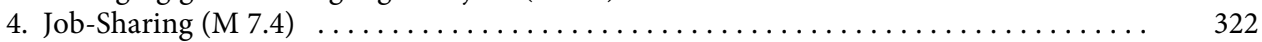

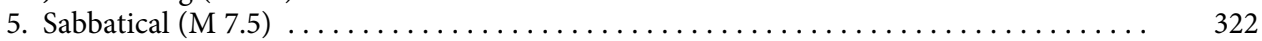

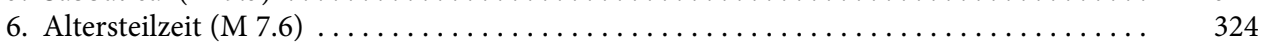

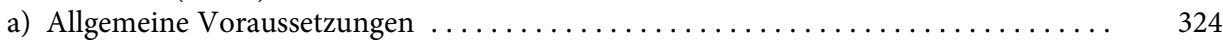

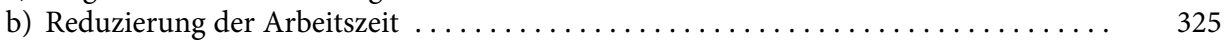

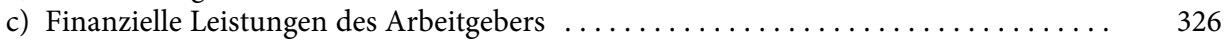

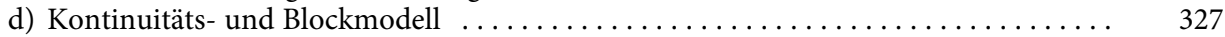

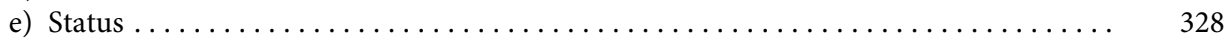

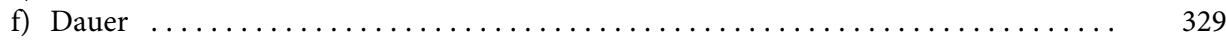

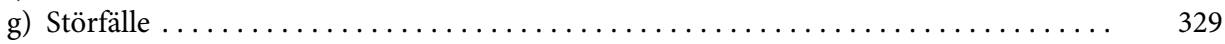

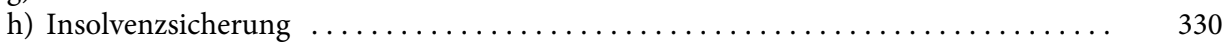

II. Muster $\ldots \ldots \ldots \ldots \ldots \ldots \ldots \ldots \ldots \ldots \ldots \ldots \ldots \ldots \ldots \ldots \ldots \ldots \ldots \ldots \ldots \ldots$

M 7.1.1 Klausel zur regelmäßigen Arbeitszeit und Befugnis zur Anordnung von

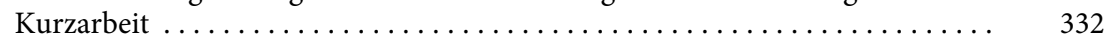

M 7.1.2 Klausel zur Anordnung von Überstunden . . . . . . . . . . . . . . . 333

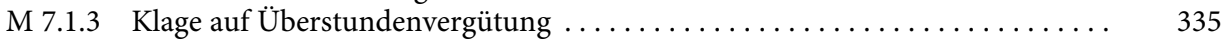

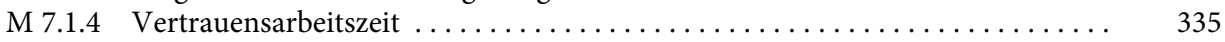

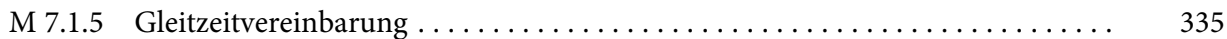

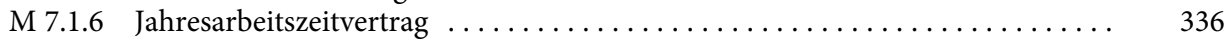

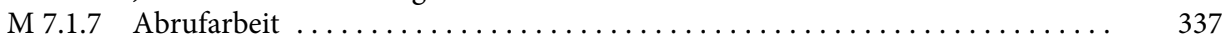

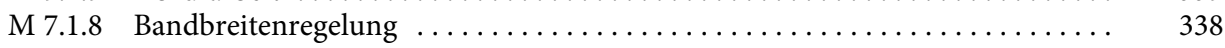

M 7.1.9 Klage des Arbeitnehmers auf Anerkennung/Vergütung der Umkleidezeit als

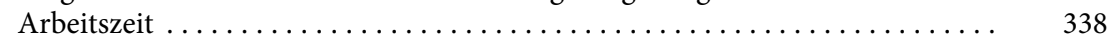

M 7.2.1 Teilzeitarbeitsvertrag $\ldots \ldots \ldots \ldots \ldots \ldots \ldots \ldots \ldots \ldots \ldots \ldots \ldots \ldots \ldots \ldots \ldots$

M 7.2.2 Antrag auf Reduzierung der Arbeitszeit . . . . . . . . . . . . . . . . . . . 341

M 7.2.3 Schreiben bei verspätetem Antrag auf Reduzierung der Arbeitszeit . . . . . . . 342

M 7.2.4 Ablehnung des Antrags auf Reduzierung der Arbeitszeit . . . . . . . . . . . . . 342

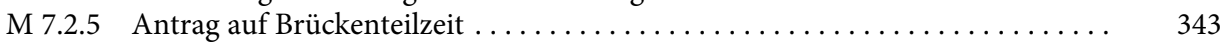

M 7.2.6 Schreiben bei verspätetem Antrag auf Brückenteilzeit . . . . . . . . . . . . . 344

M 7.2.7 Ablehnung des Antrags auf Brückenteilzeit . . . . . . . . . . . . . . . . . . . . . . . 344

M 7.2.8 Klage auf Zustimmung zur dauerhaften Reduzierung der Arbeitszeit . . . . . . 345

M 7.2.9 $\begin{aligned} & \text { Klage auf Zustimmung zur vorübergehenden Reduzierung der Arbeitszeit } \\ & \text { (Brückenteilzeit) } \ldots \ldots \ldots \ldots \ldots \ldots \ldots \ldots \ldots \ldots \ldots \ldots \ldots \ldots \ldots \ldots \ldots \ldots \ldots \ldots \ldots \ldots \ldots \ldots \ldots \ldots \ldots \ldots \ldots \ldots\end{aligned}$

M 7.2.10 Klage auf Feststellung der reduzierten Arbeitszeit $\ldots \ldots \ldots \ldots \ldots \ldots \ldots \ldots$ 
M 7.2.11 Einstweilige Verfügung auf Reduzierung der Arbeitszeit $\ldots \ldots \ldots \ldots \ldots \ldots$

M 7.2.12 Änderungsvertrag zur Reduzierung der Arbeitszeit . . . . . . . . . . . .

M 7.3.1 Teilzeitvertrag mit geringfügiger Beschäftigung (Minijob) $\ldots \ldots \ldots \ldots \ldots$

M 7.3.2 Antrag auf Befreiung von der Rentenversicherungspflicht bei einer geringfügig entlohnten Beschäftigung nach $\$ 6$ Abs. $1 \mathrm{~b}$ SGB VI $\ldots \ldots \ldots \ldots \ldots \ldots$

M 7.4.1 Job-Sharing-Arbeitsvertrag mit einem Job-Partner $\ldots \ldots \ldots \ldots \ldots \ldots \ldots \ldots$

M 7.4.2 Job-Sharing-Arbeitsvertrag mit allen Job-Partnern . . . . . . . . . . . . .

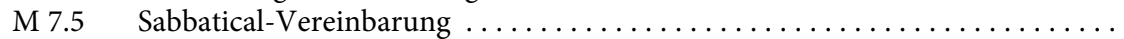

356

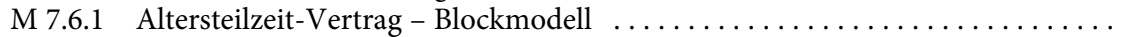

M 7.6.2 Klage auf Abschluss eines Altersteilzeitvertrages . . . . . . . . . . . .

\section{Kap. 8 Ausbildungs- und Fortbildungsverträge}

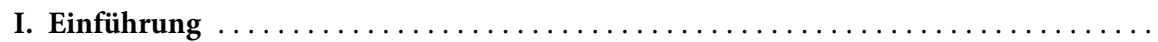

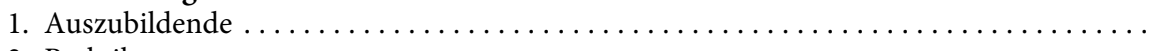

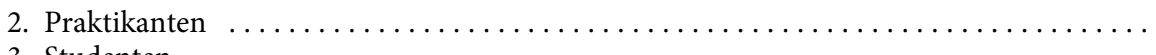

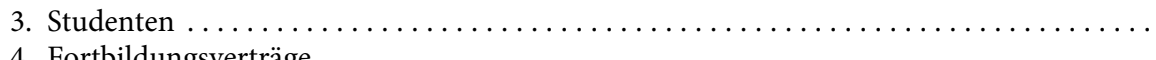

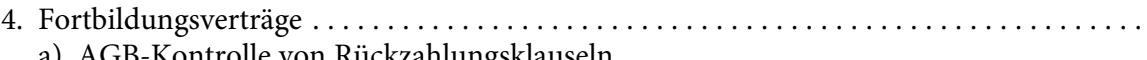

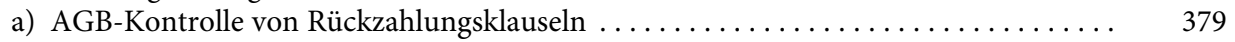

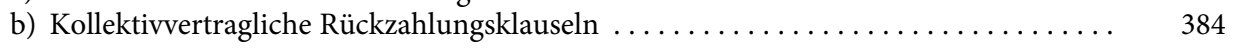

II. Muster $\ldots \ldots \ldots \ldots \ldots \ldots \ldots \ldots \ldots \ldots \ldots \ldots \ldots \ldots \ldots \ldots \ldots \ldots \ldots \ldots \ldots$

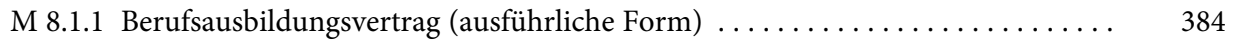

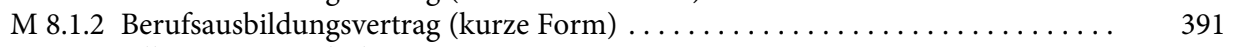

M $8.2 \quad$ Allgemeiner Praktikantenvertrag . . . . . . . . . . . . . . . . . . . . 395

M 8.3 Praktikantenvertrag für Schüler und Studenten (Pflichtpraktikum) . . . . . . . 398

M 8.4 Werkstudentenvertrag $\ldots \ldots \ldots \ldots \ldots \ldots \ldots \ldots \ldots \ldots \ldots \ldots \ldots \ldots \ldots \ldots . \ldots \ldots$

M 8.5 Traineevertrag . . . . . . . . . . . . . . . . . . . . . . . . . . . 404

M 8.6 Fortbildungsvertrag mit Rückzahlungsklausel . . . . . . . . . . . . . . . . . . . 404

\section{Kap. 9 Dienstverträge außerhalb des Arbeitsverhältnisses}

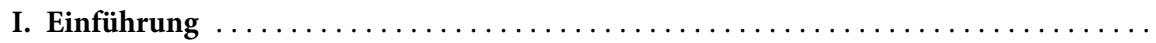

1. Abgrenzung freier Mitarbeiter/Arbeitnehmer $(\mathrm{M} 9.1 .1-9.1 .4) \ldots \ldots \ldots \ldots \ldots \ldots$

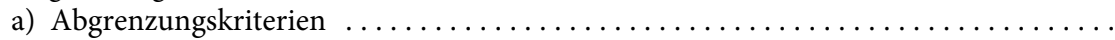

b) Sozialversicherungsrechtliche Besonderheiten $\ldots \ldots \ldots \ldots \ldots \ldots \ldots \ldots \ldots$

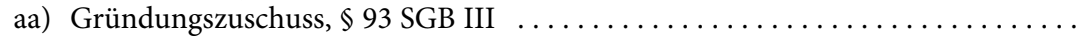

bb) Arbeitnehmerähnliche Selbständige, $₫ 2$ Satz 1 Nr. 9 SGB VI . . . . . . . . . . .

cc) Anfrageverfahren, $₫ 7$ a SGB IV (Statusfeststellungsverfahren) $\ldots \ldots \ldots \ldots \ldots$

c) Folgen eines fälschlich als freie Mitarbeit eingeordneten Anstellungsverhältnisses ...

2. Beratervertrag ( $\mathrm{M} 9.2) /$ Interimsmanagement $(\mathrm{M} 9.3) \ldots \ldots \ldots \ldots \ldots \ldots \ldots \ldots \ldots \ldots$

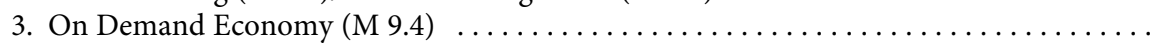

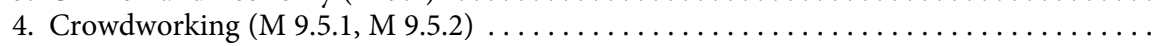

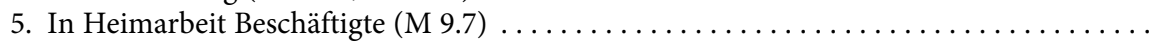

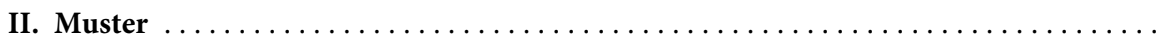

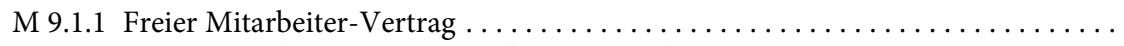

M 9.1.2 Freier Mitarbeiter-Vertrag (Rahmenvertrag) $\ldots \ldots \ldots \ldots \ldots \ldots \ldots \ldots \ldots$

M 9.1.3 Werkvertrag mit einem Subunternehmer - Softwareentwicklung . . . . . . . . .

M 9.1.4 Vereinbarung über die Miete von Betriebsmitteln - hier: Nutzung von PC ....

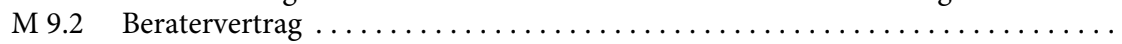

M 9.3 Vertrag mit einem Interimsmanager $\ldots \ldots \ldots \ldots \ldots \ldots \ldots \ldots \ldots \ldots \ldots$

M 9.4 On Demand Economy - Rahmenvertrag für Kurierfahrer mit Auftragserteilung über APP 
M 9.5.1 Crowdworking - Rahmenvertrag mit Auftragserteilung über APP .......... Seite

M 9.5.2 Allgemeine Geschäfts- und Nutzungsbedingungen zum Crowdworking -

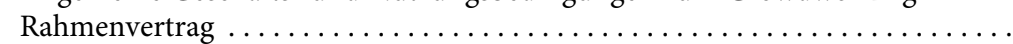

M 9.6 Statusklage wegen Bestehens eines Arbeitsverhältnisses (Scheinselbständigkeit)

M 9.7 Heimarbeitsvertrag . . . . . . . . . . . . . . . . . . . . . . .

\section{Kap. 10 Arbeitnehmerüberlassung}

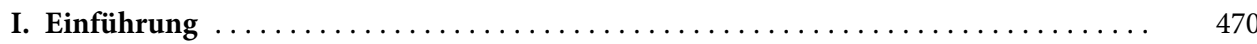

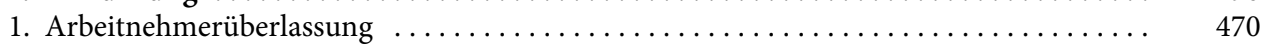

2. Abgrenzung zu Dienst- und Werkverträgen $\ldots \ldots \ldots \ldots \ldots \ldots \ldots \ldots \ldots \ldots \ldots \ldots \ldots \ldots \ldots \ldots \ldots$

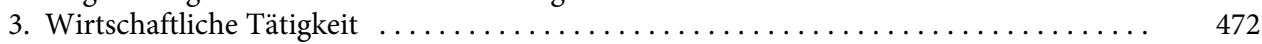

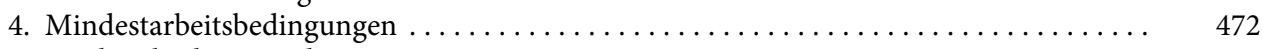

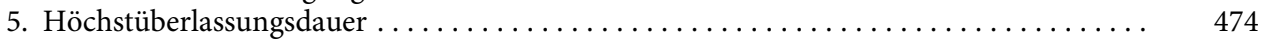

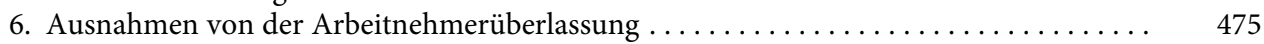

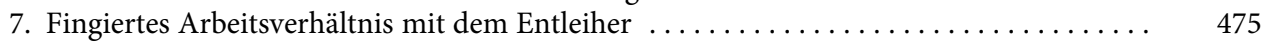

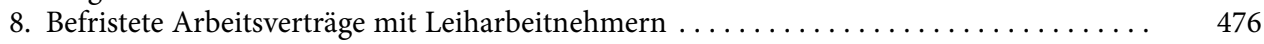

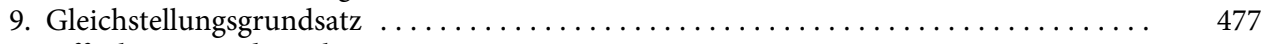

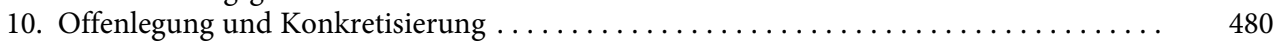

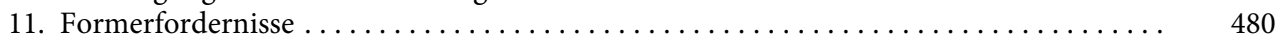

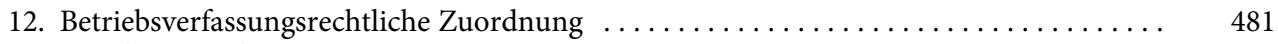

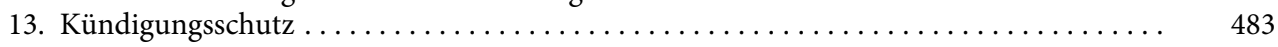

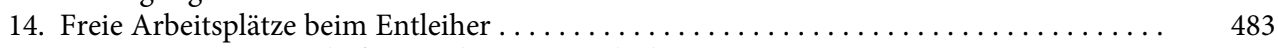

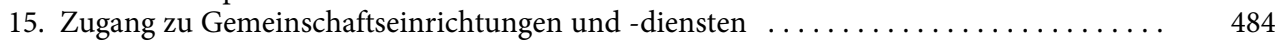

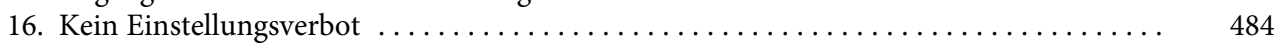

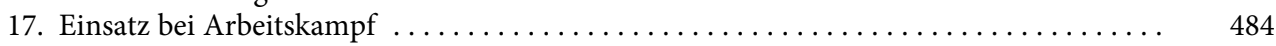

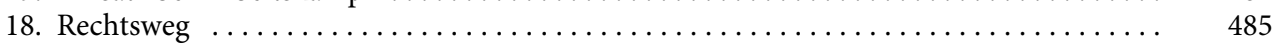

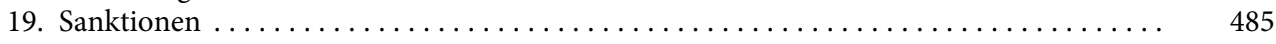

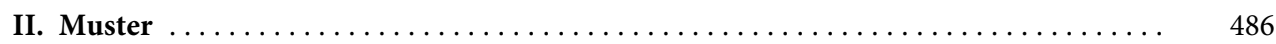

M 10.1.1 Anstellungsvertrag zwischen Leiharbeitnehmer und Verleiher ohne Bezugnahme auf einen Tarifvertrag $\ldots \ldots \ldots \ldots \ldots \ldots \ldots \ldots \ldots \ldots \ldots \ldots \ldots \ldots \ldots \ldots \ldots$

M 10.1.2 Anstellungsvertrag zwischen Leiharbeitnehmer und Verleiher mit Bezug-

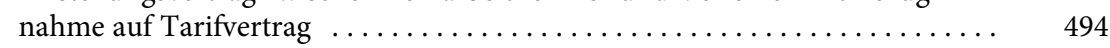

M 10.2 Arbeitnehmerüberlassungsvertrag - Vertrag zwischen Verleiher und

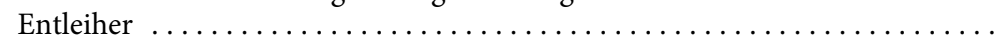

M 10.3 Rahmenvertrag zur Arbeitnehmerüberlassung zwischen Verleiher und

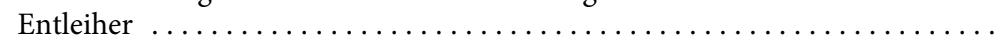

\section{Kap. 11 Auslandseinsatz}

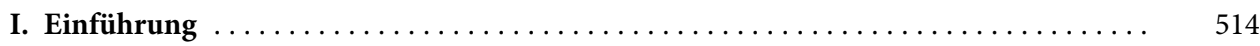

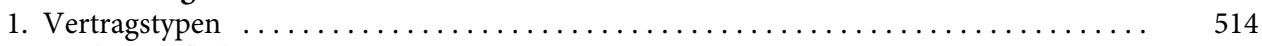

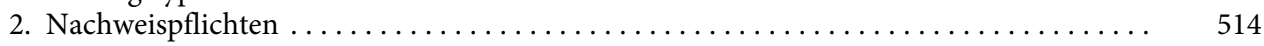

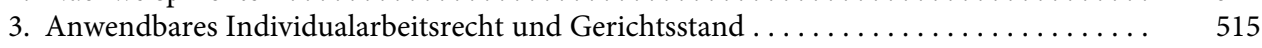

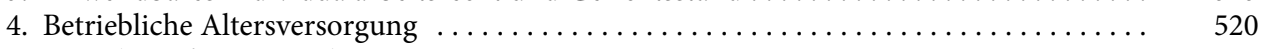

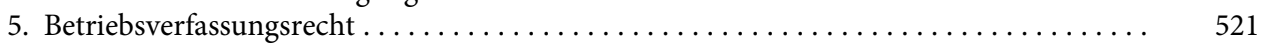

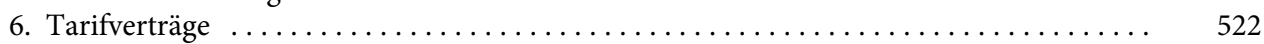

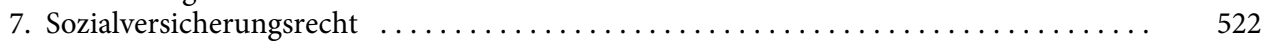

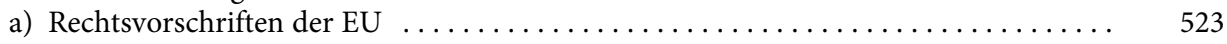

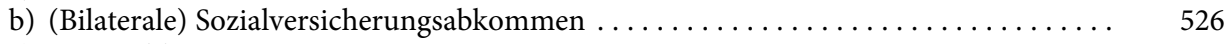

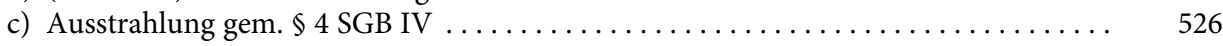

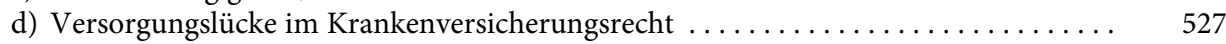

e) Freiwillige Versicherung/Versicherung auf Antrag $\ldots \ldots \ldots \ldots \ldots \ldots \ldots \ldots \ldots$ 
8. Steuerrecht $\ldots \ldots \ldots \ldots \ldots \ldots \ldots \ldots \ldots \ldots \ldots \ldots \ldots \ldots \ldots \ldots \ldots \ldots \ldots \ldots \ldots \ldots \ldots$

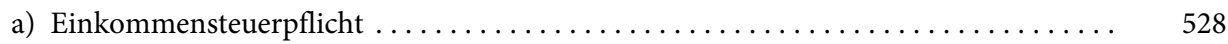

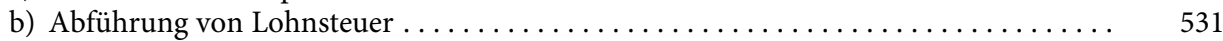

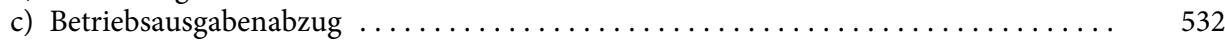

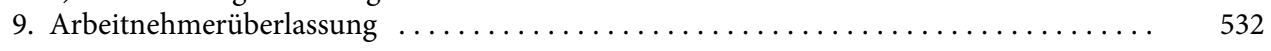

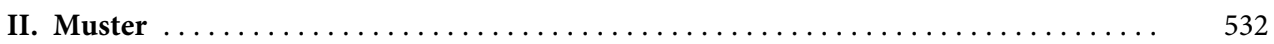

M $11.1 \quad$ Entsendung $\ldots \ldots \ldots \ldots \ldots \ldots \ldots \ldots \ldots \ldots \ldots \ldots \ldots \ldots \ldots \ldots \ldots$

M 11.2.1 Versetzung Auslandsvertrag - Anstellungsvertrag mit dem ausländischen

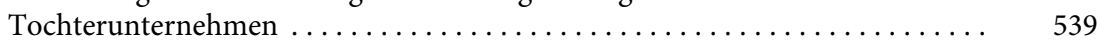

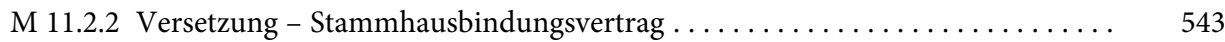

\section{Kap. 12 Vergütung}

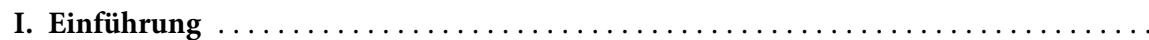

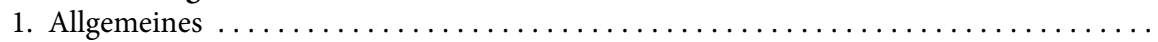

2. Freiwilligkeit, Widerruflichkeit und Anrechenbarkeit der Vergütung . . . . . . . . . . 554

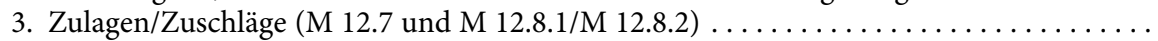

5. Provisionsvereinbarung für einen angestellten Handelsvertreter $(\mathrm{M} 12.11) \ldots \ldots$

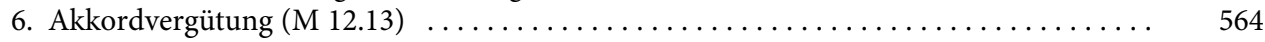

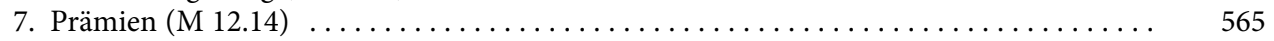

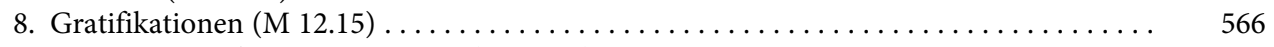

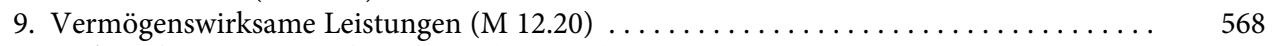

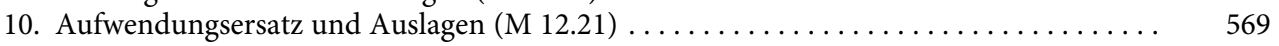

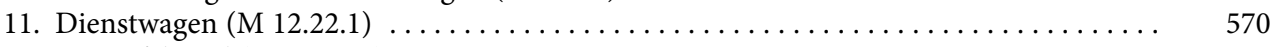

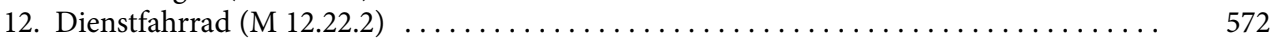

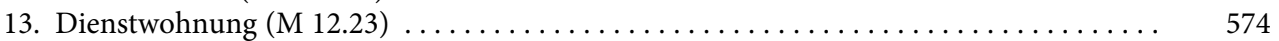

14. Arbeitgeberdarlehen $(\mathrm{M} 12.24) \ldots \ldots \ldots \ldots \ldots \ldots \ldots \ldots \ldots \ldots \ldots \ldots \ldots \ldots \ldots$

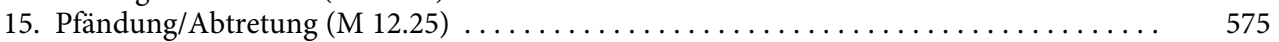

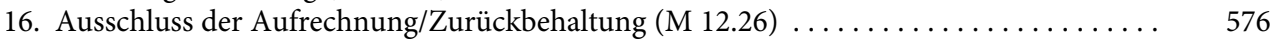

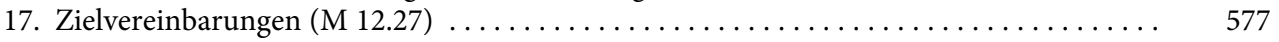

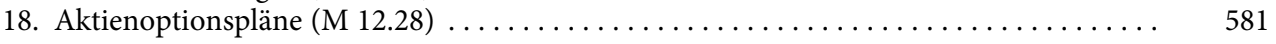

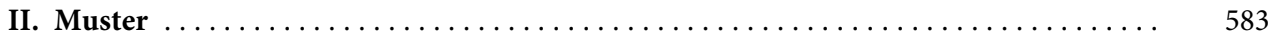

M 12.1.1 Gewerbliche Arbeitnehmer ohne Tarifbindung $\ldots \ldots \ldots \ldots \ldots \ldots \ldots \ldots$

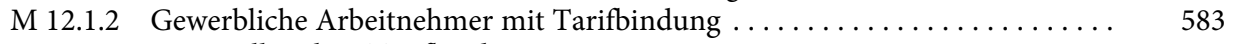

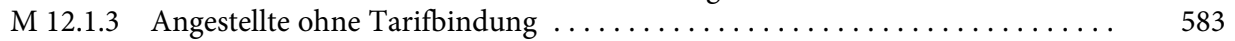

M 12.1.4 Angestellte mit Tarifbindung $\ldots \ldots \ldots \ldots \ldots \ldots \ldots \ldots \ldots \ldots \ldots \ldots \ldots \ldots . \ldots \ldots$

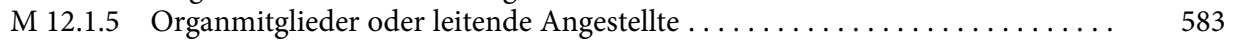

M $12.2 \quad$ Einstweilige Verfügung auf Gehaltszahlung $\ldots \ldots \ldots \ldots \ldots \ldots \ldots \ldots \ldots \ldots \ldots$

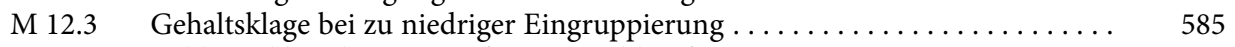

M $12.4 \quad$ Zahlungsklage bei zweistufiger Ausschlussfrist $\ldots \ldots \ldots \ldots \ldots \ldots \ldots \ldots \ldots . \ldots$

M $12.5 \quad$ Gehaltsklage wegen Ungleichbehandlung/Diskriminierung $\ldots \ldots \ldots \ldots . . \quad 588$

M 12.6 Klage im Urkundenprozess auf Geschäftsführervergütung nach fristloser

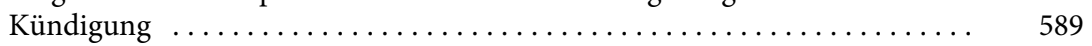

M 12.7.1 Übertarifliche Zulage $\ldots \ldots \ldots \ldots \ldots \ldots \ldots \ldots \ldots \ldots \ldots \ldots \ldots \ldots \ldots \ldots \ldots \ldots . \ldots . \ldots 2$

M 12.7.2 Widerrufs- und Anrechnungsvorbehalt für die übertarifliche Zulage . . . . . 592

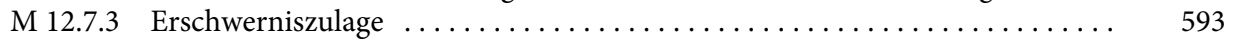

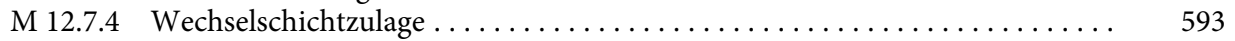

M 12.7 .5 Auslandszulage $\ldots \ldots \ldots \ldots \ldots \ldots \ldots \ldots \ldots \ldots \ldots \ldots \ldots \ldots \ldots \ldots \ldots \ldots \ldots . \ldots \ldots$

M 12.7.6 Leistungszulage $\ldots \ldots \ldots \ldots \ldots \ldots \ldots \ldots \ldots \ldots \ldots \ldots \ldots \ldots \ldots \ldots \ldots \ldots \ldots$

M 12.7.7 Sozialzulage $\ldots \ldots \ldots \ldots \ldots \ldots \ldots \ldots \ldots \ldots \ldots \ldots \ldots \ldots \ldots \ldots \ldots \ldots \ldots$ 
M 12.8.1 Überstundenzuschläge $\ldots \ldots \ldots \ldots \ldots \ldots \ldots \ldots \ldots \ldots \ldots \ldots \ldots \ldots$

Seite

M 12.8.2 Nachtarbeits-, Sonn- und Feiertagszuschläge $\ldots \ldots \ldots \ldots \ldots \ldots \ldots \ldots \ldots$

M $12.9 \quad$ Klage auf Überstundenvergütung $\ldots \ldots \ldots \ldots \ldots \ldots \ldots \ldots \ldots \ldots \ldots$

M 12.10.1 Tantieme/Bonus für leitenden Angestellten oder Geschäftsführer einer $\mathrm{GmbH}$

M 12.10.2 Ermessenstantieme für einen leitenden Angestellten . . . . . . . . . . .

M 12.10.3 Klage auf Ermessenstantieme/Ermessensbonus . . . . . . . . . . . .

M 12.10.4 Tantieme/Bonus für Vorstand einer Aktiengesellschaft . . . . . . . . . . .

M 12.11 Provisionsvereinbarung für einen angestellten Handelsvertreter . . . . . . . . . .

M 12.12 Stufenklage wegen Abrechnung und Zahlung von Provision . . . . . . . . .

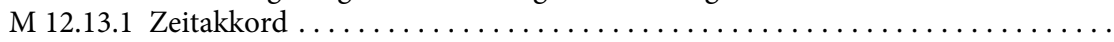

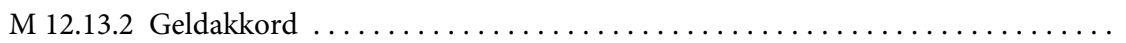

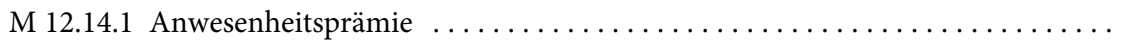

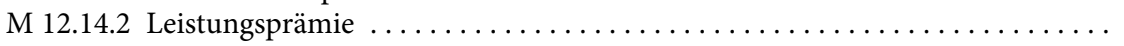

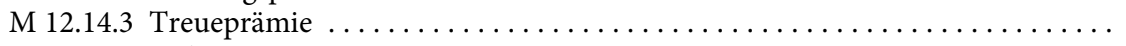

M 12.14.4 Halteprämie/Retention Bonus $\ldots \ldots \ldots \ldots \ldots \ldots \ldots \ldots \ldots \ldots \ldots \ldots \ldots$

M 12.15.1 Sonderzuwendung mit Freiwilligkeitsvorbehalt $\ldots \ldots \ldots \ldots \ldots \ldots \ldots \ldots$

M 12.15.2 Sonderzuwendung und Bindungsklausel $\ldots \ldots \ldots \ldots \ldots \ldots \ldots \ldots \ldots \ldots$

M 12.16 Sonderzuwendung nach Ermessen (Ermessensgratifikation) . . . . . . . . . .

M 12.17 Klage auf Sondervergütung wegen Benachteiligung von Teilzeitbeschäftigten

M 12.18 Klage auf Ausgabe von Belegschaftsaktien wegen betrieblicher Übung .....

M 12.19 Klage wegen Widerrufs/Teilkündigung von Sonderleistungen . . . . . . . . .

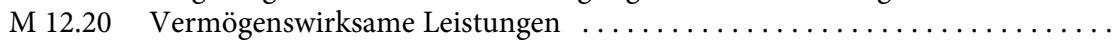

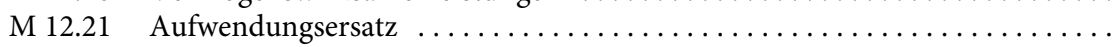

M 12.22.1 Dienstwagenüberlassungsvertrag $\ldots \ldots \ldots \ldots \ldots \ldots \ldots \ldots \ldots \ldots \ldots \ldots$

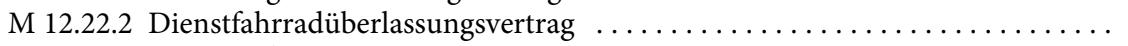

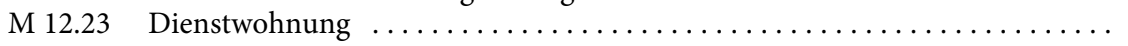

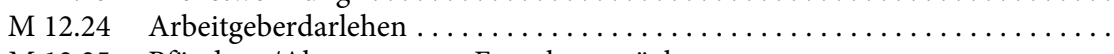

M 12.25 Pfändung/Abtretung von Entgeltansprüchen $\ldots \ldots \ldots \ldots \ldots \ldots \ldots \ldots \ldots$

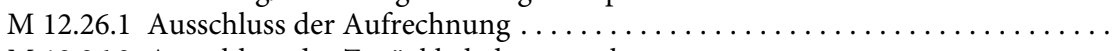

M 12.26.2 Ausschluss des Zurückbehaltungsrechts $\ldots \ldots \ldots \ldots \ldots \ldots \ldots \ldots \ldots$

M 12.27 Rahmenvereinbarung für eine Zielvereinbarung $\ldots \ldots \ldots \ldots \ldots \ldots \ldots \ldots$

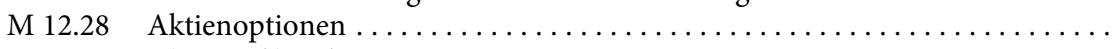

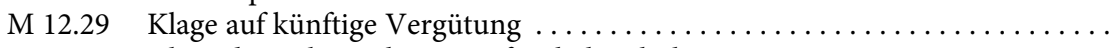

M $12.30 \quad$ Klage des Arbeitnehmers auf Gehaltserhöhung $\ldots \ldots \ldots \ldots \ldots \ldots \ldots \ldots \ldots$

M 12.31 Klage des Arbeitgebers auf Rückzahlung überzahlter Vergütung . . . . . . .

594

595

595

597

598

599

600

601

605

607

607

608

609

610

610

611

612

614

615

616

617

618

618

621

625

629

629

631

631

631

632

633

638

639

641

\section{Kap. 13 AGG, EntgTranspG}

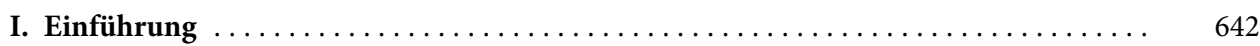

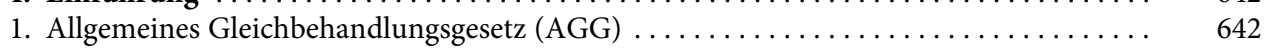

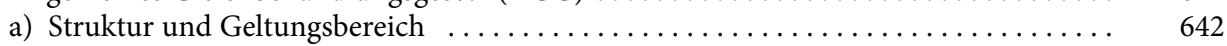

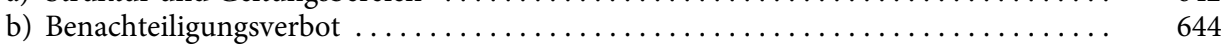

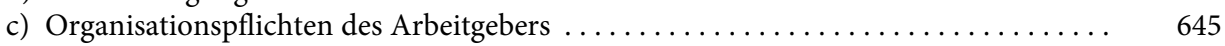

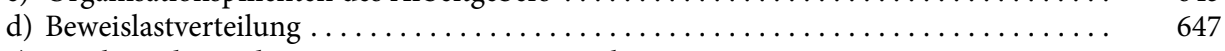

e) Beschwerde- und Leistungsverweigerungsrecht $\ldots \ldots \ldots \ldots \ldots \ldots \ldots \ldots \ldots \ldots \ldots \ldots \ldots \ldots$

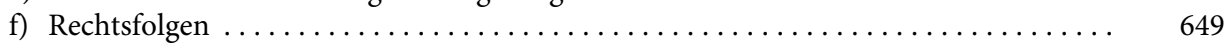

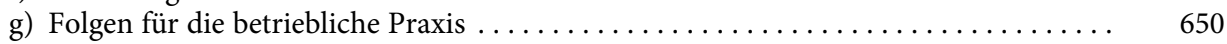

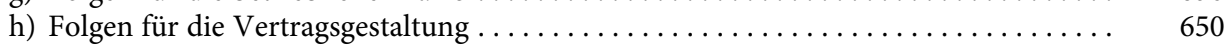

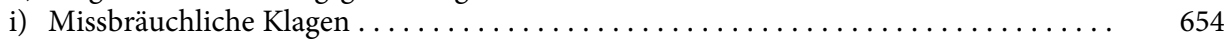

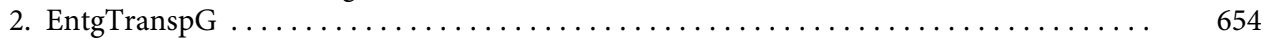

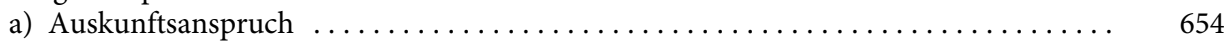

b) Verpflichtung zur Erstellung eines Entgelttransparenzberichts, $\$ 21$ EntgTranspG .. 655 
II. Muster $\ldots \ldots \ldots \ldots \ldots \ldots \ldots \ldots \ldots \ldots \ldots \ldots \ldots \ldots \ldots \ldots \ldots \ldots \ldots \ldots \ldots \ldots$

M 13.1.1 Klage auf Entschädigung wegen Diskriminierung bei der Einstellung . . . . . 655

M 13.1.2 Gehaltsklage wegen Ungleichbehandlung/Diskriminierung . . . . . . . . 655

M 13.1.3 Klage wegen berechtigter Leistungsverweigerung des Arbeitnehmers . . . . . 655

M 13.2.1 Auskunftsverlangen nach EntgTranspG . . . . . . . . . . . . . . . 657

M 13.2.2 Auskunft nach EntgTranspG des tarifgebundenen/tarifanwendenden Arbeitgebers ................................. 658

M 13.2.3 Auskunft nach EntgTranspG des tariffreien Arbeitgebers . . . . . . . . . . . . 659

M 13.2.4 Auskunftsverweigerung des Arbeitgebers nach EntgTranspG . . . . . . . . . . 660

M 13.2.5 Entgelttransparenzbericht $\ldots \ldots \ldots \ldots \ldots \ldots \ldots \ldots \ldots \ldots \ldots \ldots \ldots \ldots \ldots$

\section{Kap. 14 Urlaub}

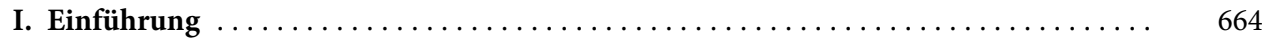

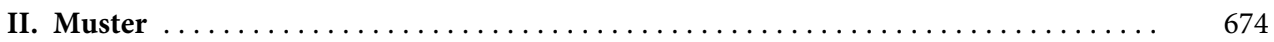

M 14.1 Urlaubsantrag und -bewilligung (Formular) $\ldots \ldots \ldots \ldots \ldots \ldots \ldots \ldots \ldots .674$

M 14.2 Ausführliche Bewilligung von bezahltem und unbezahltem Urlaub (Brief) ... 674

M 14.3 Urlaubsbescheinigung bei Beendigung des Arbeitsverhältnisses ......... 675

M 14.4 Antrag auf Übertragung des Teilurlaubs vor Erfüllung der Wartezeit in das

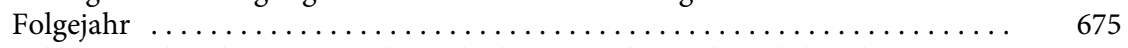

M 14.5 Erklärung über die Kürzung des Urlaubsanspruches während der Elternzeit

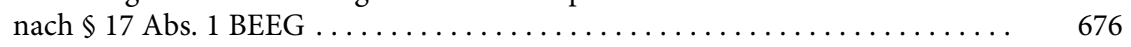

M 14.6 Hinweis- und Aufforderungsschreiben zum Verfall von Urlaubstagen bei

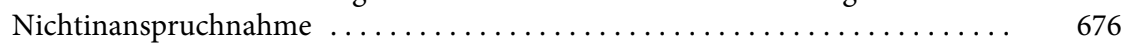

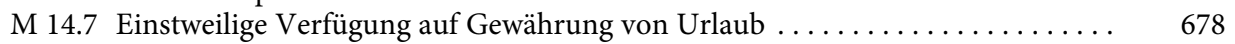

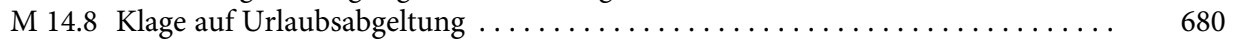

\section{Kap. 15 Krankheit}

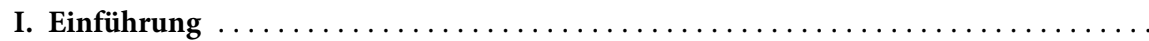

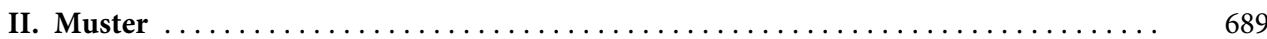

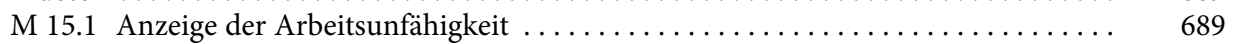

M 15.2 Weisung zum Nachweis einer ärztlichen Bescheinigung .............. 690

M 15.3 Ergänzung zum Arbeitsvertrag zur Kürzung von Sonderleistungen im Krankheitsfall ................................. 690

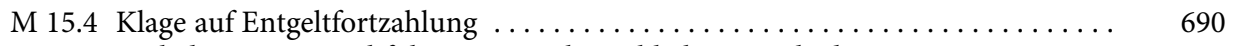

M 15.5 Einladung zur Durchführung eines betrieblichen Eingliederungsmanagements

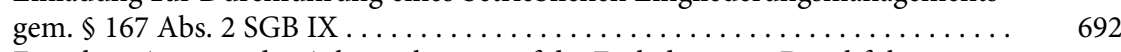

M 15.6 Formlose Antwort des Arbeitnehmers auf die Einladung zur Durchführung eines betrieblichen Eingliederungsmanagements gem. $\$ 167$ Abs. 2 SGB IX ...

\section{Kap. 16 Schwerbehinderte Menschen}

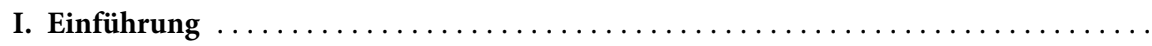

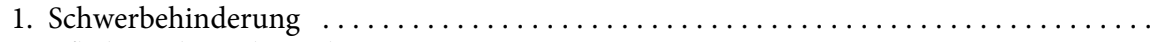

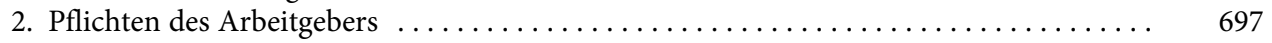

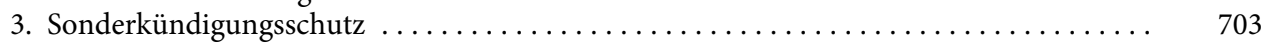

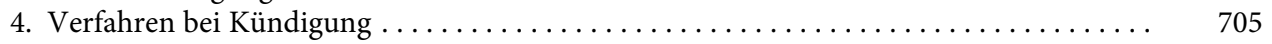

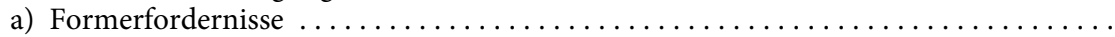

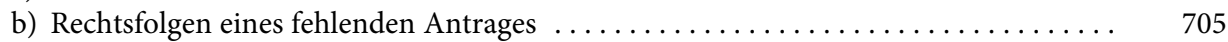

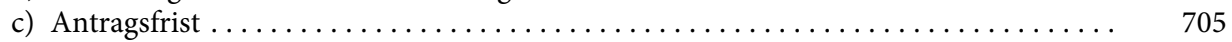

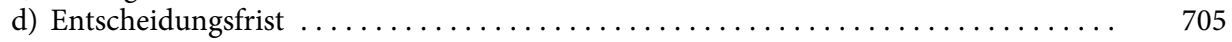




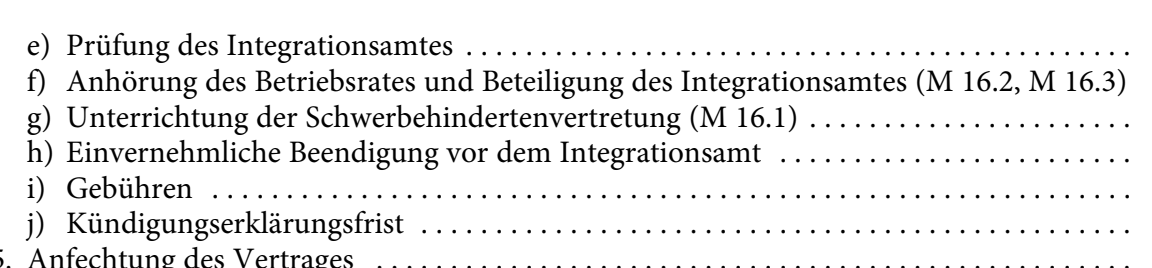

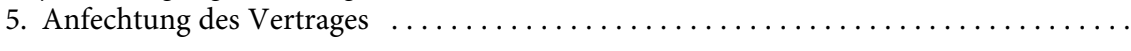

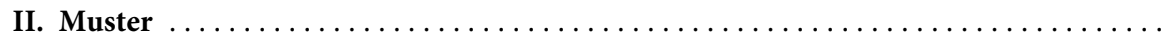

M 16.1 Unterrichtung der Schwerbehindertenvertretung zur außerordentlich fristlosen sowie hilfsweise ordentlich fristgemäßen verhaltensbedingten Verdachtskündigung gem. $₫ 178$ Abs. 2 SGB IX $\ldots \ldots \ldots \ldots \ldots \ldots \ldots \ldots \ldots \ldots \ldots$

M 16.2 Anhörung des Betriebsrats zur außerordentlich fristlosen sowie hilfsweise ordentlich fristgemäßen verhaltensbedingten Verdachtskündigung gem.

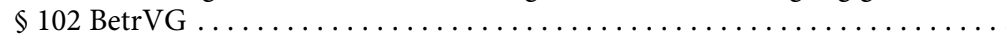

M 16.3 Antrag des Arbeitgebers auf Zustimmung zur Kündigung eines schwerbehinderten Menschen/gleichgestellten behinderten Menschen . . . . . . . . . . . . . .

M 16.4 Widerspruch gegen die Zustimmung des Integrationsamtes $\ldots \ldots \ldots \ldots \ldots$

M 16.5 Klage des Arbeitgebers gegen die Versagung der Zustimmung des Integrations-

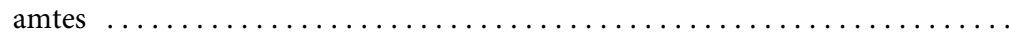

M 16.6 Anfechtung des Arbeitsvertrages wegen Täuschung über Schwerbehinderten-

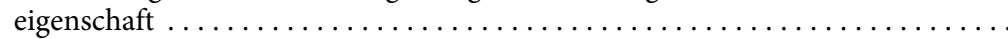

M 16.7 Klage des Arbeitnehmers auf Zuweisung eines leidensgerechten Arbeitsplatzes
Seite

706

706

706

706

707

707

707

708

708

709

710

712

714

715

\section{Kap. 17 Mutterschutz, Eltern- und Pflegezeit}

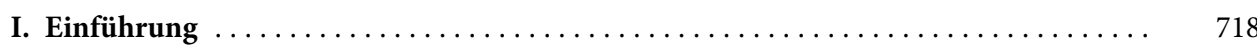

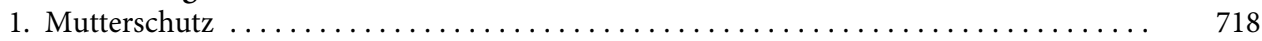

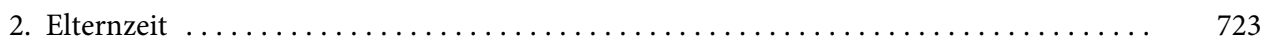

3. Elterngeld und Elterngeld Plus $\ldots \ldots \ldots \ldots \ldots \ldots \ldots \ldots \ldots \ldots \ldots \ldots \ldots \ldots \ldots \ldots \ldots \ldots \ldots \ldots$

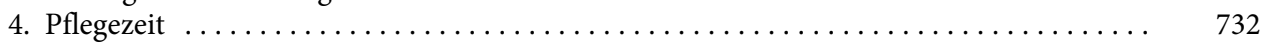

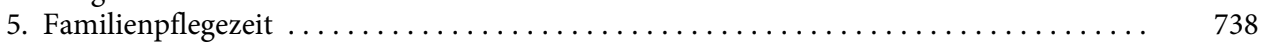

II. Muster $\ldots \ldots \ldots \ldots \ldots \ldots \ldots \ldots \ldots \ldots \ldots \ldots \ldots \ldots \ldots \ldots \ldots \ldots \ldots \ldots \ldots \ldots \ldots \ldots$. 741

M 17.1 Mitteilung der Schwangerschaft nach $\$ 15$ Abs. 1 Satz 1 MuSchG . . . . . . . . 741

M 17.2 Informationsschreiben des Arbeitgebers an die schwangere Mitarbeiterin . . . 742

M 17.3 Antrag auf Ausnahmebewilligung vom Nachtarbeitsverbot . . . . . . . . . . . 742

M 17.4 Antrag auf Elternzeit . . . . . . . . . . . . . . . . . . . . . . . . . . . . . 743

M 17.5 Antwortschreiben des Arbeitgebers . . . . . . . . . . . . . . . . . . . . . 744

M 17.6 Antrag auf Zustimmung zur Kündigung in der Elternzeit . . . . . . . . . . . . . 745

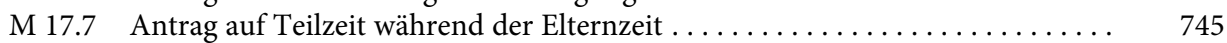

M 17.8 Ablehnung des Antrags auf Teilzeit während Elternzeit . . . . . . . . . . . . 746

M 17.9 Einstweilige Verfügung auf Teilzeitbeschäftigung während der Elternzeit . . . 747

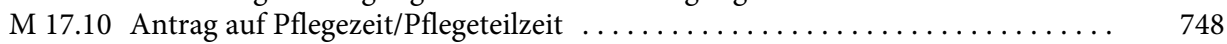

M 17.11 Ablehnung des Antrags auf Pflegeteilzeit . . . . . . . . . . . . . . . . . . . . 749

M 17.12 Einstweilige Verfügung auf Gewährung von Pflegezeit . . . . . . . . . . . . 750

M 17.13 Vereinbarung über eine Teilzeittätigkeit während der Pflegezeit . . . . . . . . 752

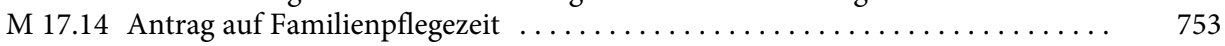

M 17.15 Vereinbarung zur Familienpflegezeit $\ldots \ldots \ldots \ldots \ldots \ldots \ldots \ldots \ldots \ldots \ldots \ldots \ldots \ldots$

M 17.16 Einstweilige Verfügung auf Gewährung von Familienpflegezeit . . . . . . . . 755

M 17.17 Antrag auf Zustimmung zur Kündigung in der Familienpflegezeit . . . . . . . . 757 


\section{Kap. 18 Fehlverhalten, Schadensersatz, Mobbing}

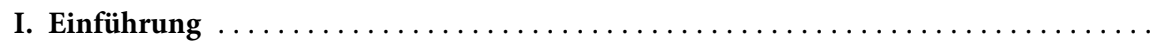

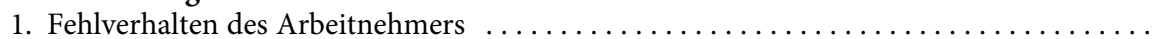

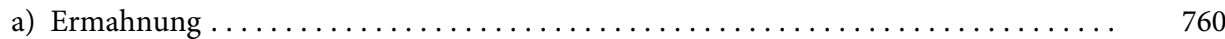

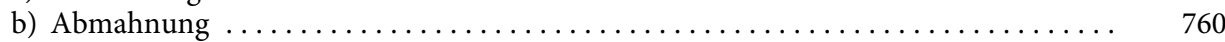

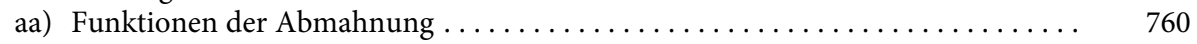

bb) Wirksamkeitsvoraussetzungen der Abmahnung ................... 761

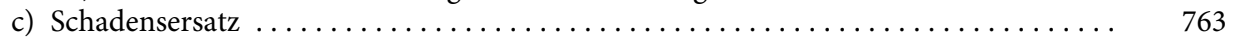

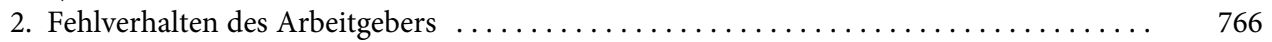

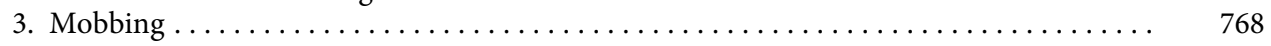

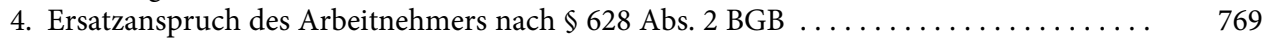

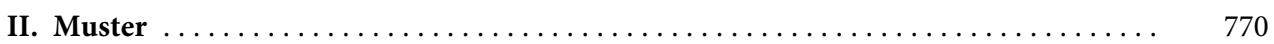

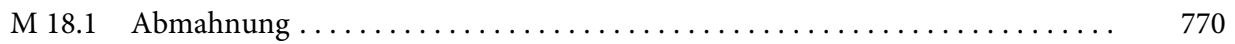

M 18.2 Vorweggenommene Abmahnung als Erklärung an den Arbeitnehmer ....... 771

M 18.3 Vorweggenommene Abmahnung als Aushang ................... 772

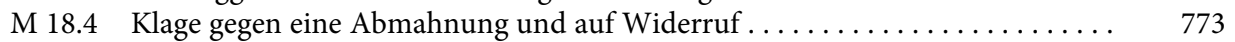

M 18.5 Klage des Arbeitgebers auf Schadensersatz ..................... 775

M 18.6 Klage des Arbeitgebers gegen den Arbeitnehmer auf Mankohaftung . . . . . . $\quad 777$

M 18.7 Arrest und Arrestpfändung wegen Unterschlagung . . . . . . . . . . . . 778

M $18.8 \quad$ Klage des Arbeitnehmers wegen Mobbing ..................... 781

M 18.9 Klage des Arbeitgebers wegen Vertragsbruchs auf Schadensersatz und

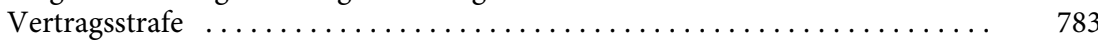

M 18.10 Einstweilige Verfügung auf Unterlassung von Wettbewerbshandlungen .... 783

M 18.11 Klage des Arbeitnehmers auf Freistellung von Ansprüchen Dritter .......... 784

M 18.12 Deklaratorisches Schuldanerkenntnis ........................ 785

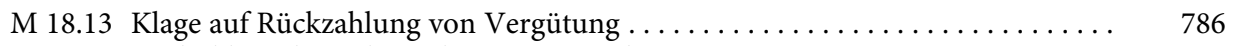

M 18.14 Widerklage des Arbeitgebers wegen Geheimnisverrats ................ 786

\section{Kap. 19 Versetzung}

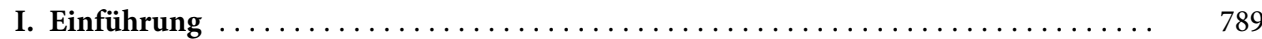

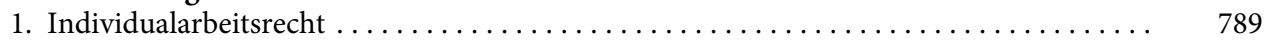

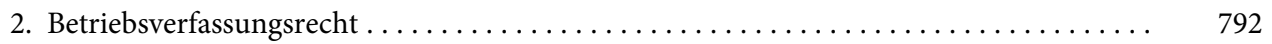

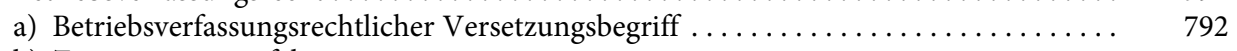

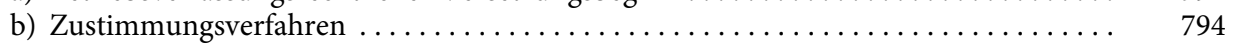

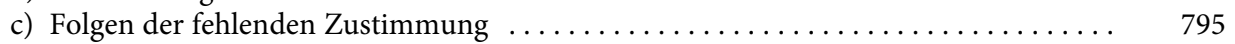

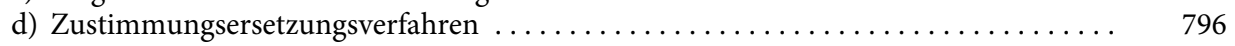

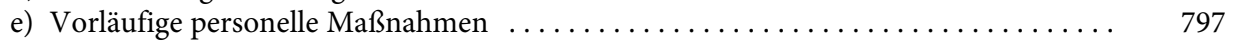

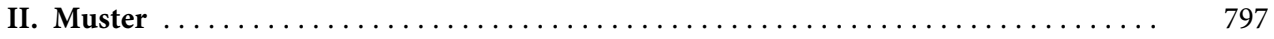

M 19.1 Ausübung des Direktionsrechts und vorsorgliche Änderungskündigung

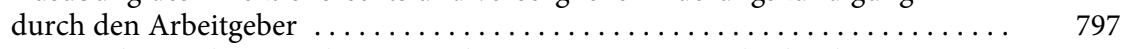

M 19.2 Unterrichtung des Betriebsrates nach $\$ 99$ BetrVG wegen beabsichtigter

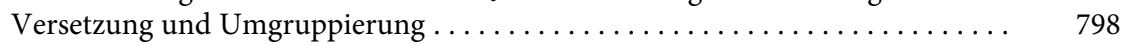

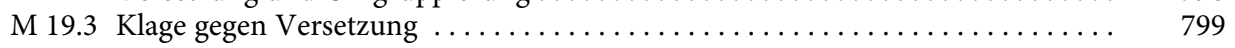

M 19.4 Klage auf Versetzung auf einen leidensgerechten Arbeitsplatz ............ 801

\section{Kap. 20 Änderungskündigung}

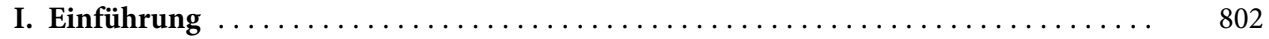

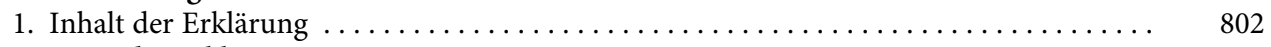

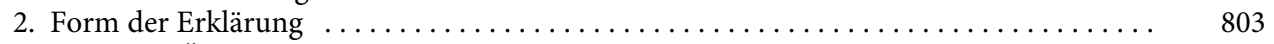

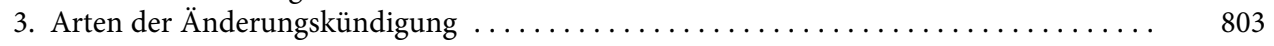


Seite

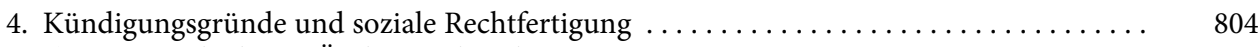

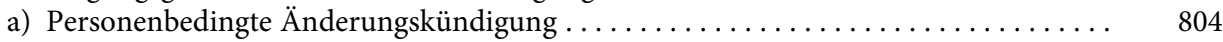

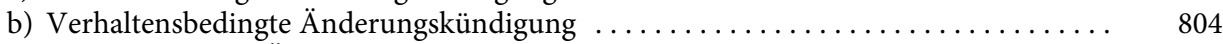

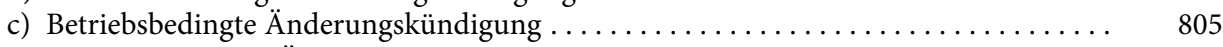

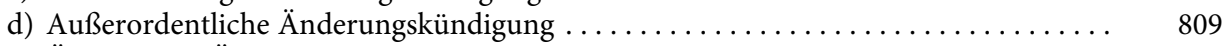

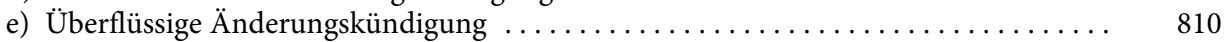

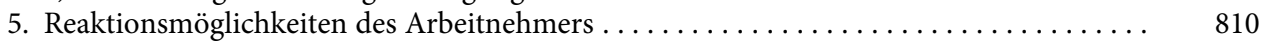

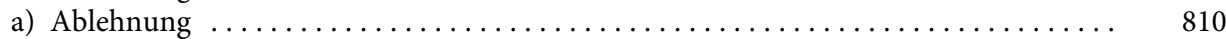

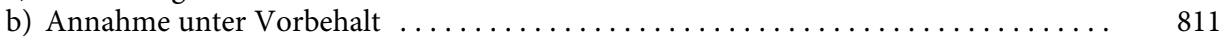

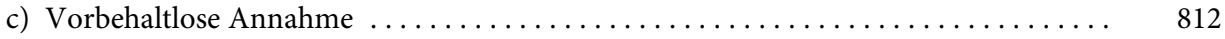

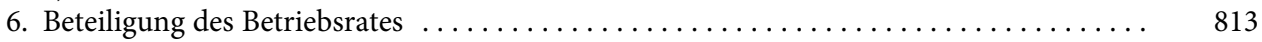

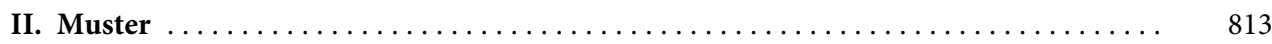

M 20.1 Änderungskündigung $\ldots \ldots \ldots \ldots \ldots \ldots \ldots \ldots \ldots \ldots \ldots \ldots \ldots \ldots \ldots$

M 20.2 Annahme/Annahme unter Vorbehalt/Ablehnung der Änderungs-

M 20.3 Anhörung des Betriebsrates zur ordentlichen Änderungskündigung

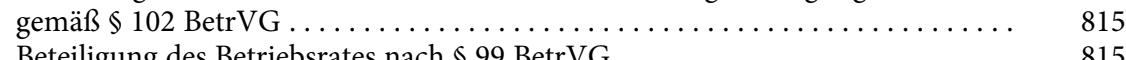

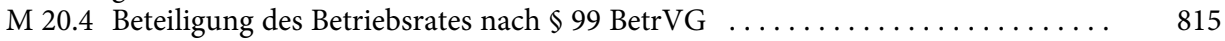

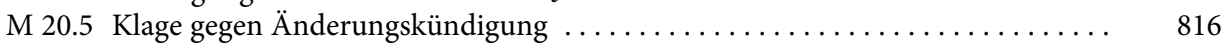

\section{Kap. 21 Eigenkündigung des Arbeitnehmers}

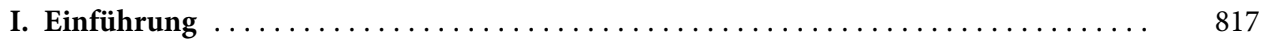

II. Muster $\ldots \ldots \ldots \ldots \ldots \ldots \ldots \ldots \ldots \ldots \ldots \ldots \ldots \ldots \ldots \ldots \ldots \ldots \ldots \ldots \ldots \ldots \ldots$

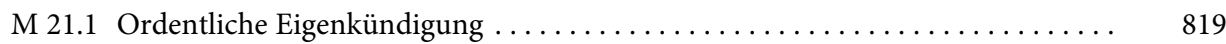

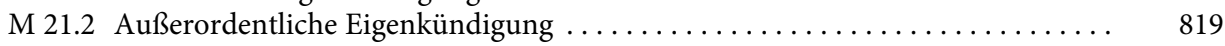

M 21.3 Anfechtung einer Eigenkündigung wegen Drohung $\ldots \ldots \ldots \ldots \ldots \ldots \ldots \ldots . . \ldots 20$

M 21.4 Klage des Arbeitnehmers wegen unwirksamer Eigenkündigung . . . . . . . . . 820

M 21.5 Klage des Arbeitnehmers wegen Anfechtung einer Eigenkündigung . . . . . . 822

\section{Kap. 22 Beendigungskündigung}

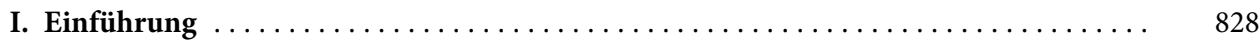

1. Allgemeines $\ldots \ldots \ldots \ldots \ldots \ldots \ldots \ldots \ldots \ldots \ldots \ldots \ldots \ldots \ldots \ldots \ldots \ldots \ldots \ldots \ldots \ldots$

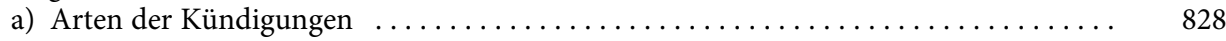

b) Kündigungserklärung $\ldots \ldots \ldots \ldots \ldots \ldots \ldots \ldots \ldots \ldots \ldots \ldots \ldots \ldots \ldots \ldots \ldots \ldots \ldots$

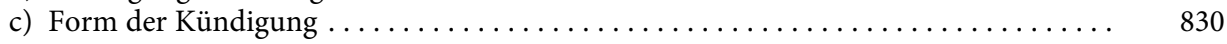

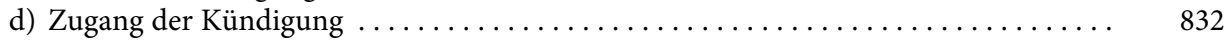

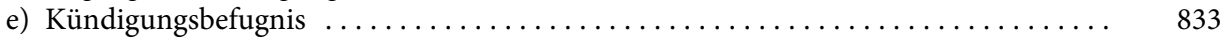

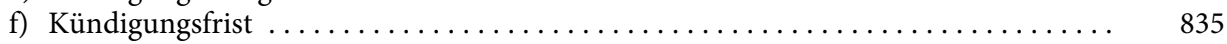

g) Anhörung des Betriebsrats gem. $₫ 102$ BetrVG $\ldots \ldots \ldots \ldots \ldots \ldots \ldots \ldots \ldots \ldots \ldots$

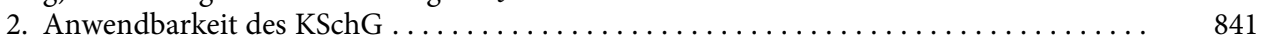

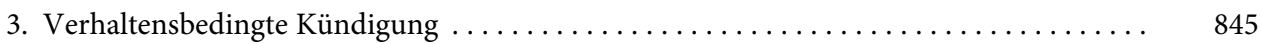

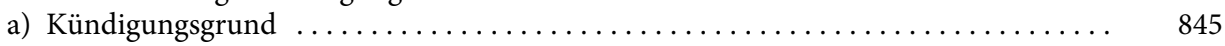

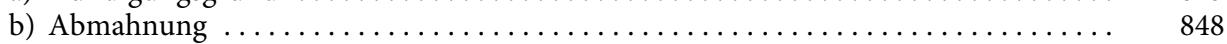

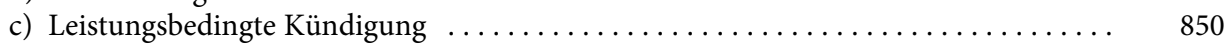

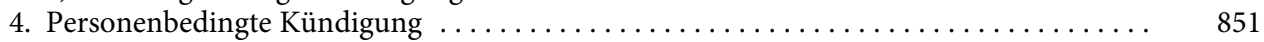

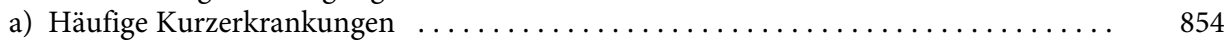

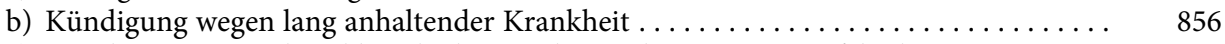

c) Kündigung wegen krankheitsbedingter dauernder Leistungsunfähigkeit . . . . . . . . 856

d) Kündigung wegen dauernder Leistungsminderung . . . . . . . . . . . . . . . 857

e) Kündigung wegen Suchterkrankungen $\ldots \ldots \ldots \ldots \ldots \ldots \ldots \ldots \ldots \ldots \ldots \ldots \ldots \ldots$ 
f) Betriebsratsanhörung $\ldots \ldots \ldots \ldots \ldots \ldots \ldots \ldots \ldots \ldots \ldots \ldots \ldots \ldots \ldots \ldots \ldots \ldots$

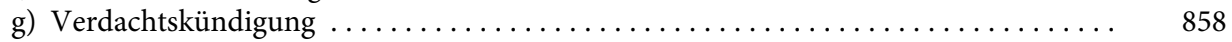

5. Betriebsbedingte Kündigung $\ldots \ldots \ldots \ldots \ldots \ldots \ldots \ldots \ldots \ldots \ldots \ldots \ldots \ldots \ldots \ldots \ldots$

a) Wegfall des bisherigen Arbeitsplatzes $\ldots \ldots \ldots \ldots \ldots \ldots \ldots \ldots \ldots \ldots \ldots \ldots \ldots . \ldots \ldots$

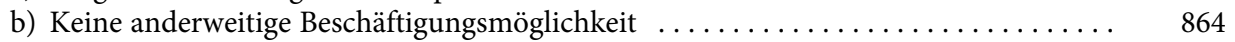

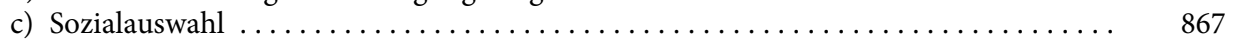

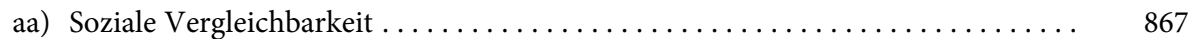

bb) Auswahlkriterien . . . . . . . . . . . . . . . . . . . . . . . . . . . . . 869

cc) Rechtsfolgen fehlerhafter Sozialauswahl . . . . . . . . . . . . . . . . . . . . 872

dd) Herausnahme aus der Sozialauswahl, $₫ 1$ Abs. 3 Satz 2 KSchG . . . . . . . . . . . 872

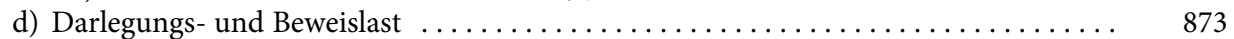

e) Interessenausgleich mit Namensliste $\ldots \ldots \ldots \ldots \ldots \ldots \ldots \ldots \ldots \ldots \ldots \ldots \ldots \ldots$

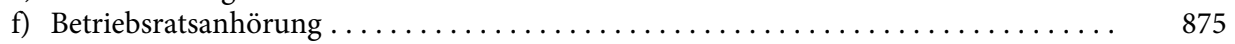

g) Abfindungsangebot nach $₫ 1 \mathrm{~K}$ KSchG $\ldots \ldots \ldots \ldots \ldots \ldots \ldots \ldots \ldots \ldots \ldots$

6. Außerordentliche Kündigung $\ldots \ldots \ldots \ldots \ldots \ldots \ldots \ldots \ldots \ldots \ldots \ldots \ldots \ldots \ldots \ldots \ldots \ldots$

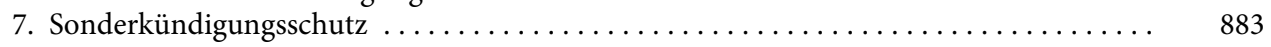

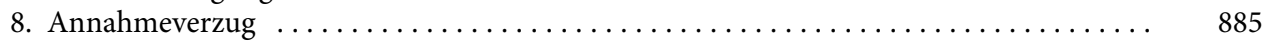

9. Massenentlassungsanzeige $\ldots \ldots \ldots \ldots \ldots \ldots \ldots \ldots \ldots \ldots \ldots \ldots \ldots \ldots \ldots \ldots \ldots \ldots$

10. Interessenausgleich und Sozialplan $\ldots \ldots \ldots \ldots \ldots \ldots \ldots \ldots \ldots \ldots \ldots \ldots \ldots \ldots \ldots$

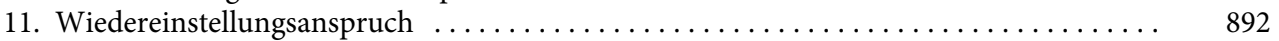

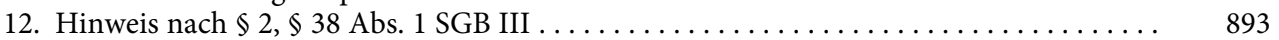

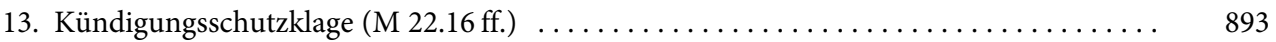

14. Auflösungsantrag ( $\mathrm{M} 22.20$ und $\mathrm{M} 22.21) \ldots \ldots \ldots \ldots \ldots \ldots \ldots \ldots \ldots$

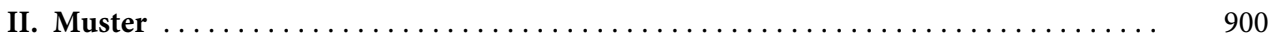

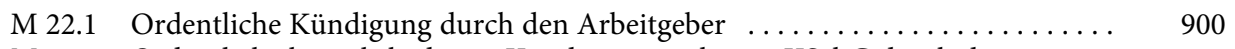

M 22.2 Ordentliche betriebsbedingte Kündigung nach $₫ 1$ a KSchG durch den

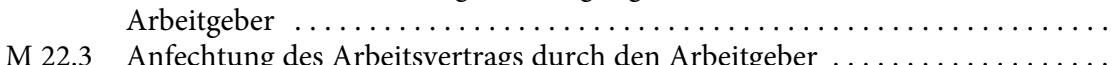

M 22.4 Außerordentliche Kündigung durch den Arbeitgeber . . . . . . . . . . . . . . . . . . 904

M 22.5 Außerordentliche sowie hilfsweise ordentliche Kündigung durch den

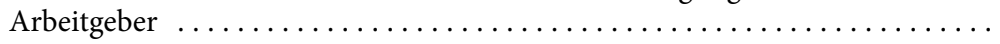

M 22.6 Außerordentliche sowie hilfsweise ordentliche Verdachtskündigung durch

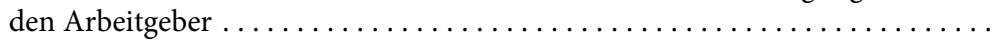

M 22.7 Aufforderung zur Mitteilung außerordentlicher Kündigungsgründe . . . . . . .

M 22.8 Kündigungszurückweisung wegen fehlender Vollmachtsvorlage . . . . . . . . .

M 22.9 Unternehmerentscheidung zur betriebsbedingten Kündigung . . . . . . . . . .

M 22.10 Anhörung des Betriebsrats zur außerordentlich fristlosen sowie hilfsweise ordentlich fristgemäßen verhaltensbedingten Kündigung gem. $\$ 102$ BetrVG .

M 22.11 Anhörung des Betriebsrats zur außerordentlich fristlosen sowie hilfsweise ordentlich fristgemäßen Verdachtskündigung gem. $\$ 102$ BetrVG $\ldots . \ldots \ldots$

M 22.12 Anhörung des Betriebsrats zur ordentlich fristgemäßen personenbedingten Kündigung gem. $₫ 102$ BetrVG $\ldots \ldots \ldots \ldots \ldots \ldots \ldots \ldots \ldots \ldots \ldots \ldots \ldots \ldots \ldots \ldots \ldots \ldots$

M 22.13 Anhörung des Betriebsrats zur ordentlich fristgemäßen betriebsbedingten Kündigung gem. $₫ 102$ BetrVG $\ldots \ldots \ldots \ldots \ldots \ldots \ldots \ldots \ldots \ldots \ldots \ldots \ldots \ldots \ldots \ldots \ldots \ldots$

M 22.14 Anhörung des Betriebsrates zur ordentlich fristgemäßen betriebsbedingten Änderungskündigung sowie alternativ zur ordentlich fristgemäßen betriebsbedingten Beendigungskündigung gem. $₫ 102$ BetrVG . . . . . . . . . . .

M 22.15 Stellungnahme des Betriebsrats zu einem Anhörungsschreiben . . . . . . . . . .

M 22.16 Kündigungsschutzklage mit Weiterbeschäftigungsantrag . . . . . . . . . .

M 22.17 Klage gegen Kündigung bei Unanwendbarkeit des KSchG . . . . . . . . . . . . . . . . . . . . . . . . . . . . . .

M 22.18 Kündigungsschutzklage bei betriebsbedingter Kündigung . . . . . . . . . . 
M 22.19 Antrag auf nachträgliche Zulassung der Kündigungsschutzklage .........

M 22.20 Auflösungsantrag des Arbeitnehmers $\ldots \ldots \ldots \ldots \ldots \ldots \ldots \ldots \ldots \ldots \ldots$

M 22.21 Auflösungsantrag des Arbeitgebers $\ldots \ldots \ldots \ldots \ldots \ldots \ldots \ldots \ldots \ldots \ldots \ldots$

M 22.22 Einstweilige Verfügung auf Weiterbeschäftigung bei offensichtlich unwirk-

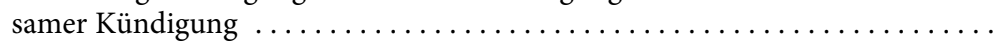

Seite

923

925

926

M 22.23 Einstweilige Verfügung auf Beschäftigung während der Kündigungsfrist . . . . .

M 22.24 Einstweilige Verfügung auf Weiterbeschäftigung nach $₫ 102$ Abs. 5 BetrVG . .

M 22.25 Einstweilige Verfügung des Arbeitgebers auf Entbindung von der Weiter-

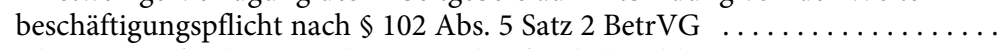

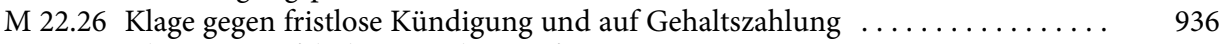

M 22.27 Klage wegen falscher Kündigungsfrist $\ldots \ldots \ldots \ldots \ldots \ldots \ldots \ldots \ldots \ldots \ldots \ldots \ldots$

M 22.28 Gesellschafterbeschluss zur Abberufung und Kündigung eines GmbH-

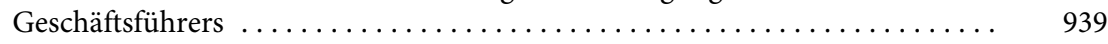

M 22.29 Einstweilige Verfügung auf Herausgabe von Arbeitspapieren . . . . . . . . . 941

M 22.30 Klage auf Wiedereinstellung nach Wegfall des Kündigungsgrundes . . . . . . . 942

M 22.31 Widerklage des Arbeitgebers auf Herausgabe des Dienstwagens und Schadensersatz

\section{Kap. 23 Einvernehmliche Beendigung}

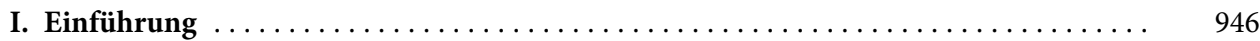

1. Aufhebungsvertrag $\ldots \ldots \ldots \ldots \ldots \ldots \ldots \ldots \ldots \ldots \ldots \ldots \ldots \ldots \ldots \ldots \ldots . \ldots \ldots \ldots$

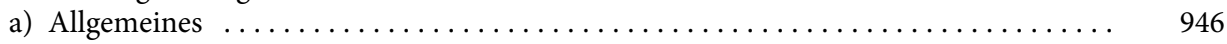

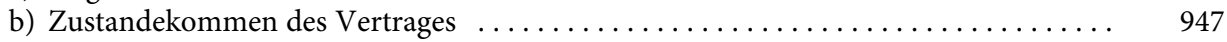

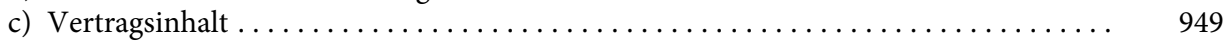

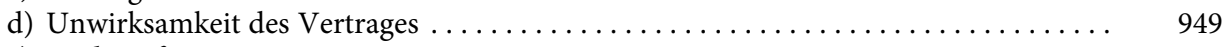

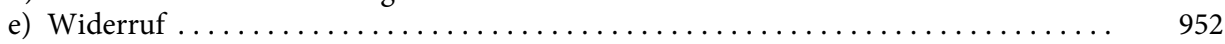

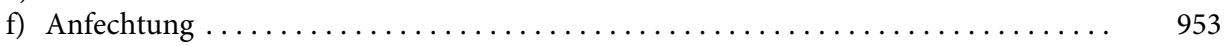

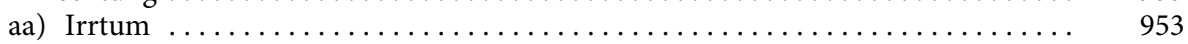

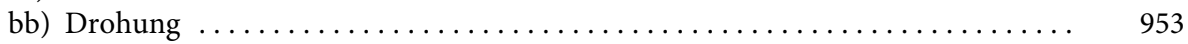

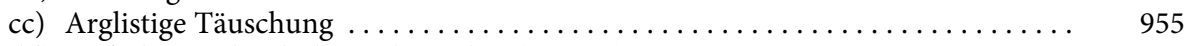

dd) Anfechtung durch den Arbeitgeber $\left(\begin{array}{l}M \\ 23.4)\end{array} \ldots \ldots \ldots \ldots \ldots \ldots \ldots \ldots \ldots\right.$

g) Verstoß gegen das "Gebot fairen Verhandelns" . . . . . . . . . . . . . . . . . . . 957

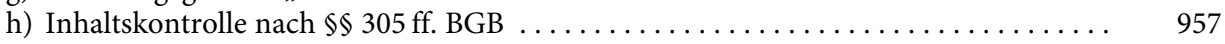

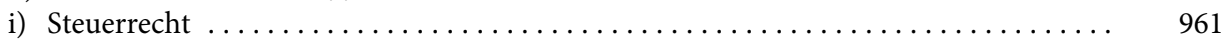

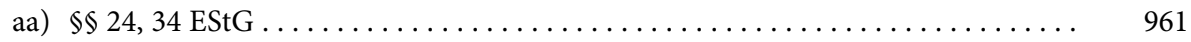

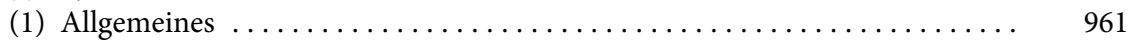

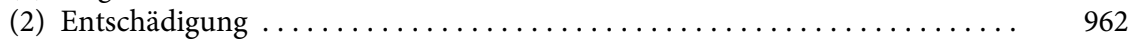

(3) Zusammenballung $\ldots \ldots \ldots \ldots \ldots \ldots \ldots \ldots \ldots \ldots \ldots \ldots \ldots \ldots \ldots \ldots$

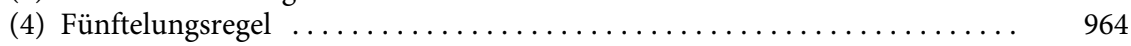

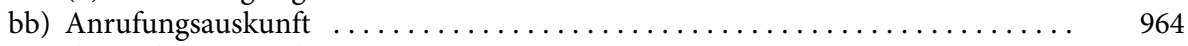

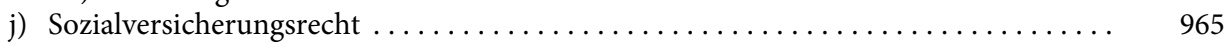

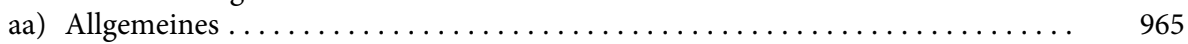

bb) Keine Beitragspflicht $\ldots \ldots \ldots \ldots \ldots \ldots \ldots \ldots \ldots \ldots \ldots \ldots \ldots \ldots \ldots$

cc) Anspruchsübergang auf die Bundesagentur für Arbeit . . . . . . . . . . . . . . . . . . . . . . 965

dd) Ruhen des Arbeitslosengeldes nach $\S 158$ SGB III . . . . . . . . . . . . . . . . . . . . . . . 965

(1) Entschädigungen iSv. $₫ 158$ Abs. 1 Satz 1 SGB III $\ldots \ldots \ldots \ldots \ldots \ldots \ldots \ldots$

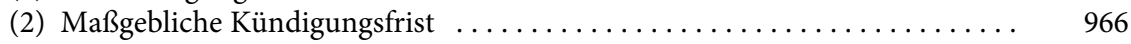

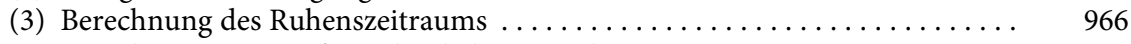

(4) Berechtigung zur außerordentlichen Kündigung . . . . . . . . . . . . . . . . . . . . . 967

(5) Folgen des Ruhens des Arbeitslosengeldanspruchs . . . . . . . . . . . . . 967

(6) Ruhen wegen anderweitiger Sozialleistungen $\ldots \ldots \ldots \ldots \ldots \ldots \ldots \ldots \ldots$ 


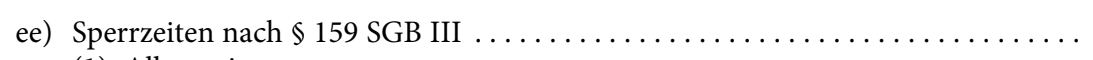

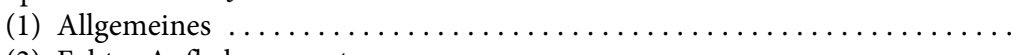

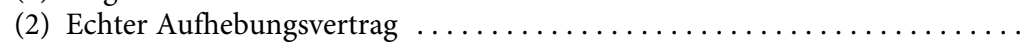

ff) Anrechnung von Abfindungen auf Arbeitslosengeld $\ldots \ldots \ldots \ldots \ldots \ldots \ldots \ldots$

gg) Kürzung bei nicht rechtzeitiger Meldung $\ldots \ldots \ldots \ldots \ldots \ldots \ldots \ldots \ldots$

hh) Erstattung von Arbeitslosengeld für ältere Arbeitslose nach $\$ 147$ a SGB III aF ..

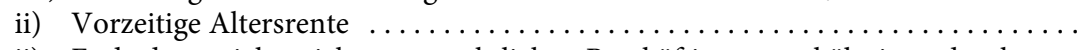

jj) Ende des sozialversicherungsrechtlichen Beschäftigungsverhältnisses durch einvernehmliche unwiderrufliche Freistellung? . $\ldots \ldots \ldots \ldots \ldots \ldots \ldots \ldots$

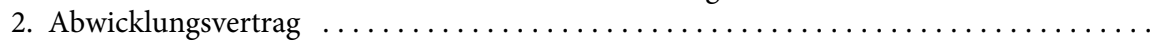

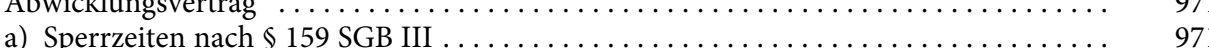

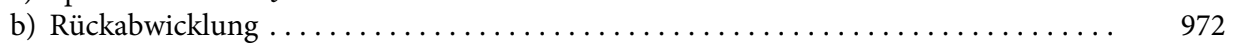

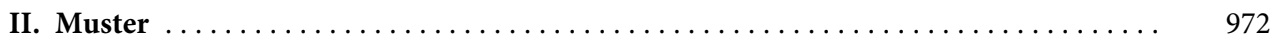

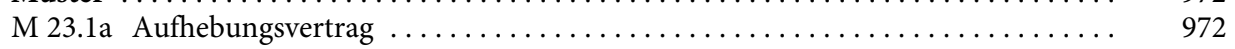

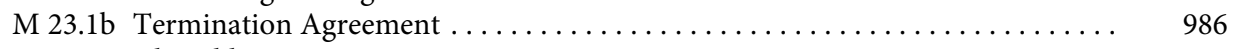

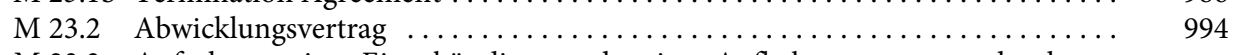

M 23.3 Anfechtung einer Eigenkündigung oder eines Aufhebungsvertrages durch

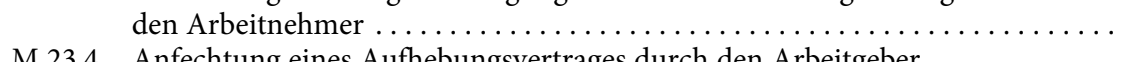

M 23.4 Anfechtung eines Aufhebungsvertrages durch den Arbeitgeber $\ldots \ldots \ldots \ldots$

M 23.5 Bestätigung eines anfechtbaren Aufhebungsvertrages durch den Arbeit-

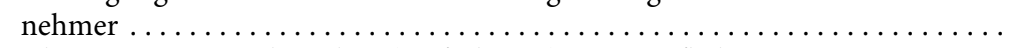

M 23.6 Klage wegen Unwirksamkeit (Anfechtung) eines Aufhebungsvertrages .....

M 23.7 Klage gegen einen Sperrzeitbescheid $\ldots \ldots \ldots \ldots \ldots \ldots \ldots \ldots \ldots \ldots \ldots \ldots \ldots$

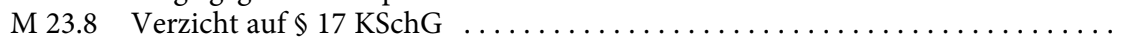

\section{Kap. 24 Zeugnis}

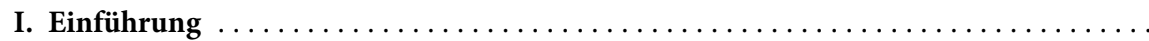

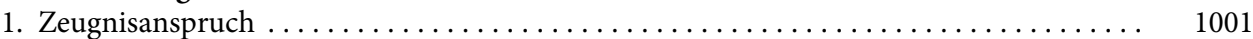

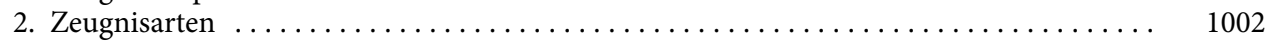

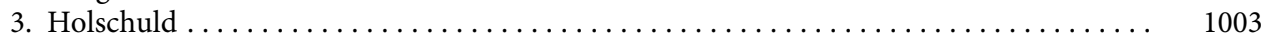

4. Verzicht, Verwirkung, Verjährung $\ldots \ldots \ldots \ldots \ldots \ldots \ldots \ldots \ldots \ldots \ldots \ldots \ldots \ldots \ldots \ldots \ldots$

5. Formalien . . . . . . . . . . . . . . . . . . . . . . . . . . . . . . . . . . . . 1004

6. Einfaches Zeugnis $(\$ 109$ Abs. 1 Satz 2 GewO $) \ldots \ldots \ldots \ldots \ldots \ldots \ldots \ldots \ldots \ldots \ldots$

7. Qualifiziertes Zeugnis $(\$ 109$ Abs. 1 Satz 3 GewO $) \ldots \ldots \ldots \ldots \ldots \ldots \ldots \ldots \ldots \ldots$

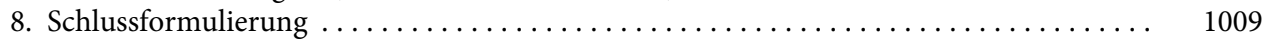

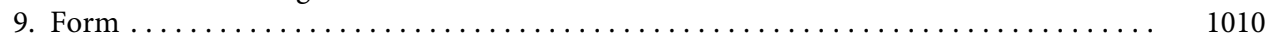

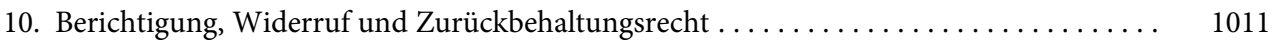

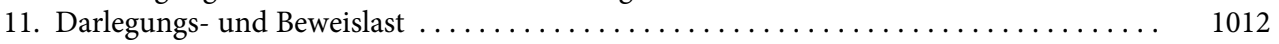

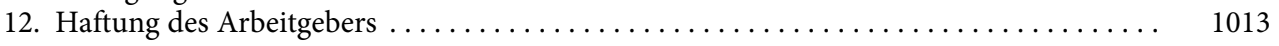

II. Muster $\ldots \ldots \ldots \ldots \ldots \ldots \ldots \ldots \ldots \ldots \ldots \ldots \ldots \ldots \ldots \ldots \ldots \ldots \ldots \ldots$

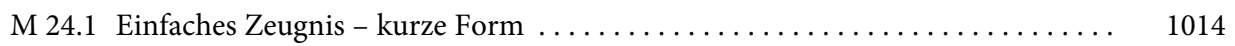

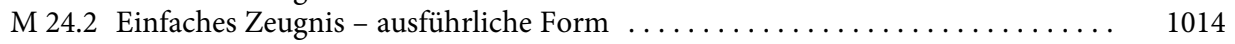

M 24.3 Zwischenzeugnis für Buchhalter-In mit guter Bewertung . . . . . . . . . . . 1014

M 24.4 Qualifiziertes Zeugnis mit guter Bewertung . . . . . . . . . . . . . . . . . . 1015

M 24.5 Qualifiziertes Zeugnis für Buchhalter-In mit guter Bewertung . . . . . . . . . 1015

M 24.6 Qualifiziertes Zeugnis für Leiter-In Controlling mit sehr guter Bewertung . . . 1016

M 24.7 Qualifiziertes Zeugnis für eine Assistentin mit unterdurchschnittlicher

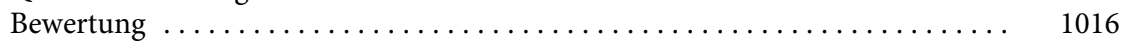

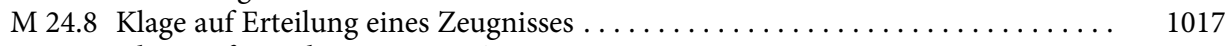

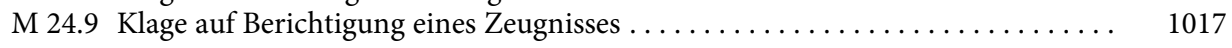




\section{Kap. 25 Nachvertragliches Wettbewerbsverbot}

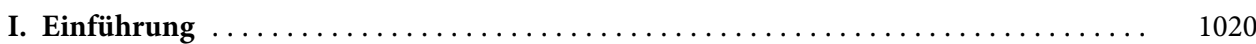

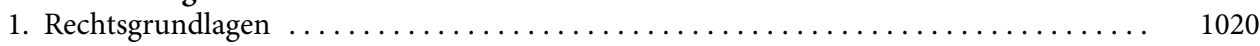

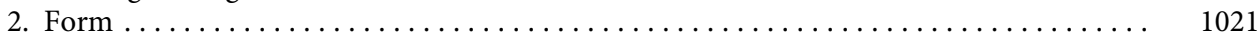

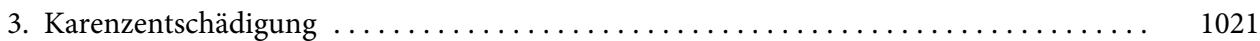

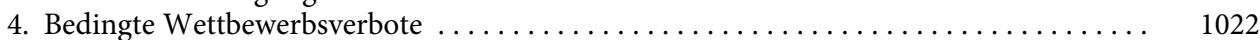

5. Berechtigtes Interesse des Arbeitgebers/unbillige Erschwerung . . . . . . . . . . . . . 1022

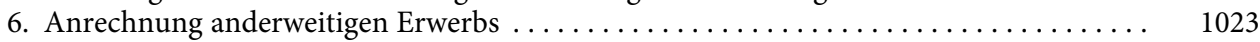

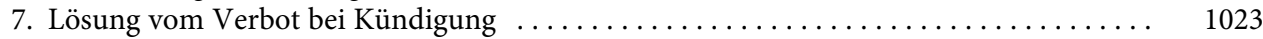

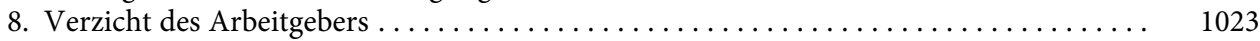

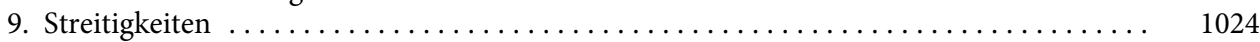

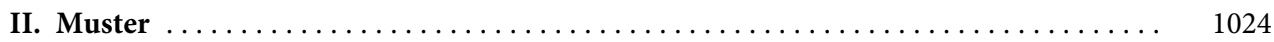

M 25.1.1 Wettbewerbsverbot mit einem Arbeitnehmer .................. 1024

M 25.1.2 Vorvertrag auf Abschluss eines nachvertraglichen Wettbewerbsverbots .... 1026

M 25.2 Wettbewerbsverbot mit einem Organmitglied $\ldots \ldots \ldots \ldots \ldots \ldots \ldots \ldots . \ldots 27$

M 25.3 Verzicht des Arbeitgebers gemäß $₫ 75$ a HGB $\ldots \ldots \ldots \ldots \ldots \ldots \ldots \ldots \ldots \ldots$

M 25.4 Lösungserklärung des Arbeitnehmers gemäß $₫ 75$ Abs. 1 oder 2 HGB . . . . . 1029

M 25.5 Angebot einer erhöhten Karenzentschädigung nach $₫ 75$ Abs. 2 HGB ...... 1031

M 25.6 Lösungserklärung des Arbeitgebers bei fristloser Kündigung nach

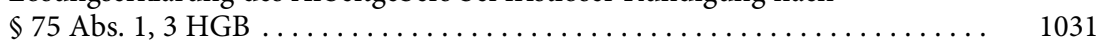

M 25.7 Aufforderung zur Mitteilung anderweitigen Erwerbs .............. 1032

M 25.8 Erfüllungsablehnung des Arbeitgebers nach Verstößen des Arbeitnehmers .. 1033

M 25.9 Fristsetzung/Ablehnungsandrohung des Arbeitnehmers bei Nichtzahlung

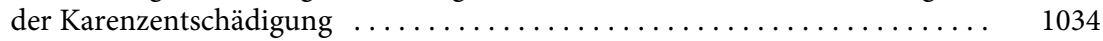

M 25.10 Klage auf Zahlung von Karenzentschädigung $\ldots \ldots \ldots \ldots \ldots \ldots \ldots \ldots \ldots$

M 25.11 Einstweilige Verfügung auf Unterlassung von nachvertraglichem Wettbewerb 1036

M 25.12 Schutzschrift gegen eine mögliche Unterlassungsverfügung wegen eines

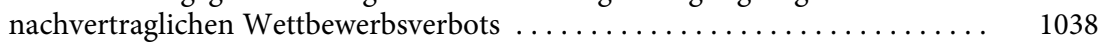

M 25.13 Klage auf Feststellung der Unwirksamkeit eines Wettbewerbsverbotes ..... 1039

\section{Kap. 26 Betriebliche Altersversorgung}

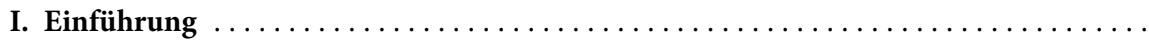

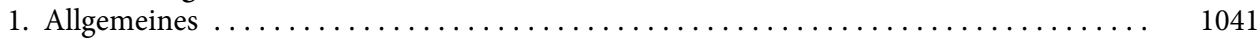

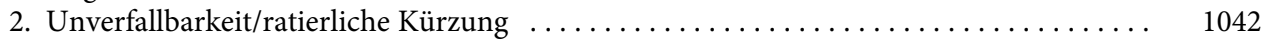

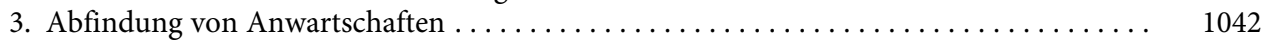

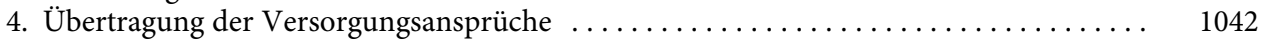

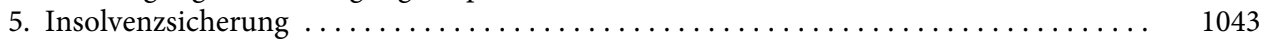

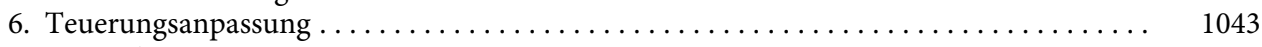

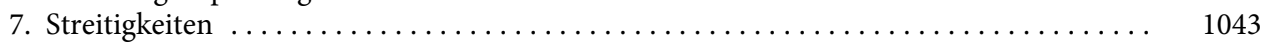

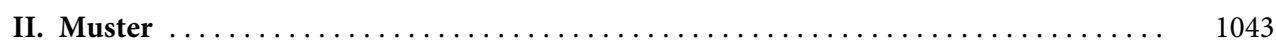

M 26.1 Einzelzusage auf betriebliche Altersversorgung für einen Geschäftsführer ... . 1043

M 26.2 Verpfändung einer Rückdeckungsversicherung ................... 1048

M 26.3 Betriebliche Versorgungsordnung (Gesamtzusage) ................. 1049

M 26.4 Satzung einer Unterstützungskasse in der Rechtsform eines e.V. . . . . . . . . 1052

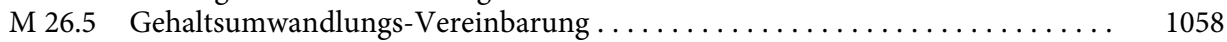

M 26.6 Unverfallbarkeitsbescheinigung nach $₫ 4$ a BetrAVG für unmittelbare

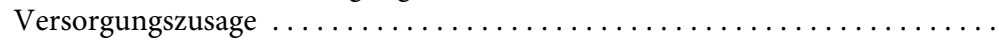

M 26.7 Abfindungserklärung des Arbeitgebers nach $\$ 3$ Abs. 2 BetrAVG ...........

M 26.8 Verlangen auf Übertragung von Versorgungsansprüchen des ausgeschiedenen Arbeitnehmers nach $₫ 4$ Abs. 3 BetrAVG auf den neuen Arbeitgeber ........ 
M 26.9 Dreiseitige Vereinbarung zur Übertragung des Anwartschaftsbarwerts auf

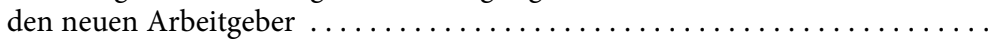

M 26.10 Dreiseitige Vereinbarung zur Übernahme der Versorgungszusage durch den

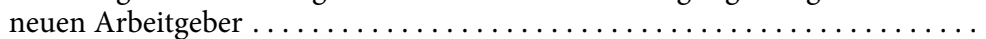

M 26.11 Erklärung des Arbeitgebers zur Anpassung einer aufrechterhaltenen

M 26.12 Klage auf Rentenzahlung gegen Unterstützungskasse $\ldots \ldots \ldots \ldots \ldots \ldots \ldots \ldots \ldots \ldots$

M 26.13 Klage auf Feststellung einer Rentenanwartschaft $\ldots \ldots \ldots \ldots \ldots \ldots \ldots \ldots$

M 26.14 Schreiben an den Arbeitnehmer wegen unterbliebener Anpassung nach

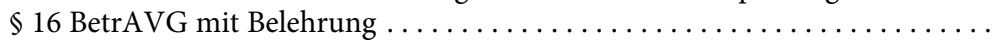

M 26.15 Klage nach $₫ 16$ BetrAVG auf Anpassung der Rente .

1062

1064

1067

1068

1070

Kap. 27-29 frei.

\section{Zweiter Teil \\ Betriebsverfassung/Personalvertretung}

\section{Kap. 30 Errichtung des Betriebsrats}

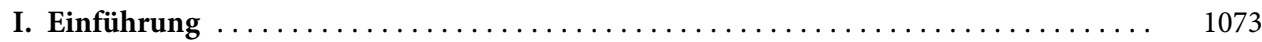

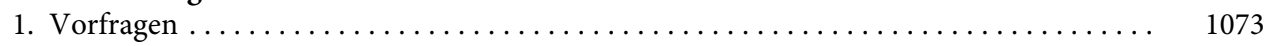

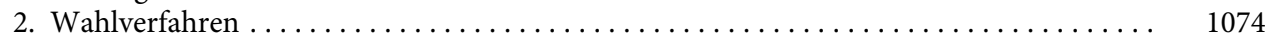

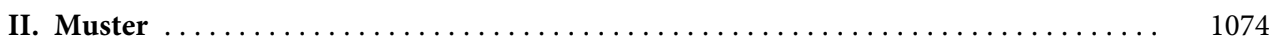

M 30.1 Einladung zur Betriebsversammlung zur Wahl eines Wahlvorstands . . . ... 1074

M 30.2 Antrag auf Bestellung eines Wahlvorstands .................. 1076

M 30.3 Antrag auf einstweilige Verfügung gegen die Durchführung einer Betriebsrats-

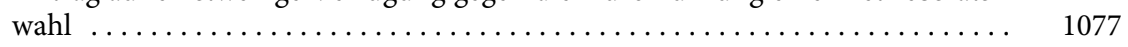

M 30.4 Antrag auf Klärung des Betriebsbegriffs . . . . . . . . . . . . . . . . . 1079

M 30.5 Anfechtung der Betriebsratswahl ......................... 1081

M 30.6 Strafanzeige wegen Wahlbehinderung nach $₫ 119$ BetrVG . . . . . . . . . . . 1083

\section{Kap. 31 Interne Organisation des Betriebsrats}

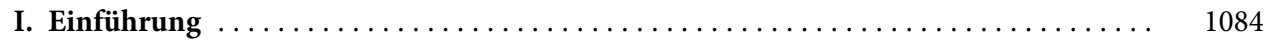

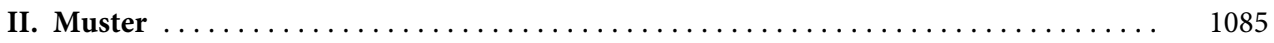

M 31.1 Anfechtung der Wahl des Betriebsratsvorsitzenden ............... 1085

M 31.2 Anfechtung der Wahl eines freigestellten Betriebsratsmitglieds . . . . . . . . 1086

\section{Kap. 32 Allgemeine Betriebsratsarbeit}

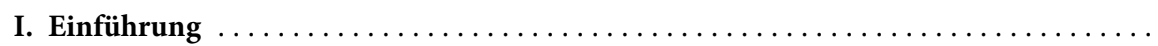

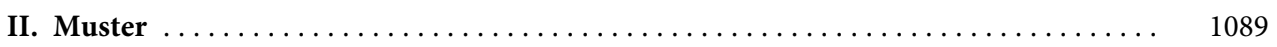

M 32.1 Einstweilige Verfügung wegen Zugangs eines Betriebsratsmitglieds zum

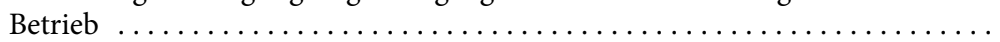

M 32.2 Antrag auf Feststellung des Status eines leitenden Angestellten ............

M 32.3 Antrag auf Duldung des Zugangs von Gewerkschaftsbeauftragten zum Betrieb

M 32.4 Antrag des Betriebsrats auf Freistellung/Übernahme von Sachmittelkosten ...

M 32.5 Antrag des Betriebsrats auf Erstattung von Schulungskosten .............

M 32.6 Antrag des Betriebsrats auf Gestattung der Hinzuziehung eines Rechtsanwalts

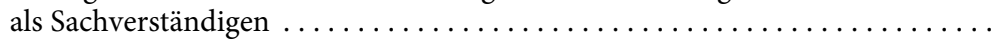


M 32.7 Antrag eines Rechtsanwalts auf Zahlung von Rechtsanwaltshonorar wegen

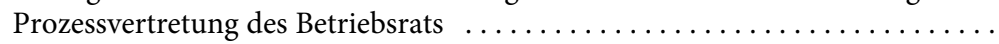

M 32.8 Klage des Rechtsanwalts gegen den Betriebsrat auf Beratungshonorar bei

eigenmächtiger Beauftragung $\ldots \ldots \ldots \ldots \ldots \ldots \ldots \ldots \ldots \ldots \ldots \ldots \ldots \ldots \ldots$

M 32.9 Antrag auf Unterlassung und Ordnungsgeld gegen den Arbeitgeber wegen grober Pflichtverletzung nach $₫ 23$ BetrVG $\ldots \ldots \ldots \ldots \ldots \ldots \ldots \ldots \ldots \ldots \ldots \ldots$

M 32.10 Antrag der Gewerkschaft auf Nicht-Durchführung einer tarifwidrigen

Betriebsvereinbarung $\ldots \ldots \ldots \ldots \ldots \ldots \ldots \ldots \ldots \ldots \ldots \ldots \ldots \ldots \ldots \ldots$
M 32.11 Antrag des Betriebsrats auf Durchführung einer Betriebsvereinbarung $\ldots \ldots$

Seite

M 32.12 Antrag des Betriebsrats auf Feststellung des Bestehens eines Mitbestimmungs-

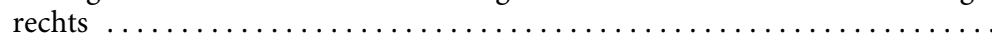

M 32.13 Antrag auf Feststellung eines Tendenzbetriebs $\ldots \ldots \ldots \ldots \ldots \ldots \ldots \ldots$

M 32.14 Einstweilige Verfügung auf Unterlassung einer mitbestimmungspflichtigen

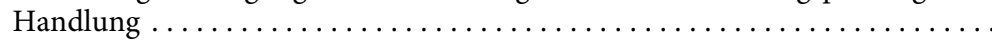

M 32.15 Strafanzeige wegen Behinderung der Betriebsratsarbeit $\ldots \ldots \ldots \ldots \ldots \ldots$

1099

1102

1104

1106

1107

1108

1109

1109

Kap. 33 Auflösung des Betriebsrats/Ausschluss von Mitgliedern

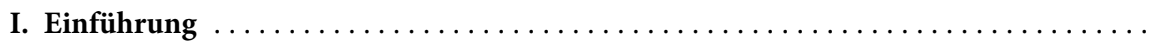

II. Muster $\ldots \ldots \ldots \ldots \ldots \ldots \ldots \ldots \ldots \ldots \ldots \ldots \ldots \ldots \ldots \ldots \ldots \ldots \ldots \ldots \ldots \ldots \ldots$

M 33.1 Antrag auf Auflösung des Betriebsrats wegen grober Pflichtverletzung . . . . . 1110

M 33.2 Antrag auf Ausschluss eines Betriebsratsmitglieds wegen Vorteilsannahme

\section{Kap. 34 Betriebsversammlung}

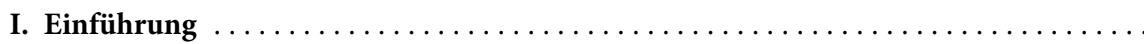

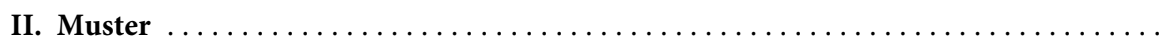

M 34.1 Einstweilige Verfügung gegen geplante Betriebsversammlung $\ldots \ldots \ldots \ldots \ldots$

M 34.2 Einstweilige Verfügung wegen Teilnahme eines Gewerkschaftsbeauftragten an

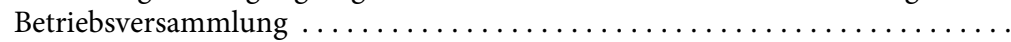

\section{Kap. 35 Mitbestimmung in sozialen Angelegenheiten - Arbeitszeit}

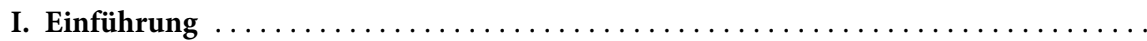

1. Vorrang von Gesetz und Tarifvertrag $(\$ 87$ Abs. 1 BetrVG $) \ldots \ldots \ldots \ldots \ldots \ldots \ldots$

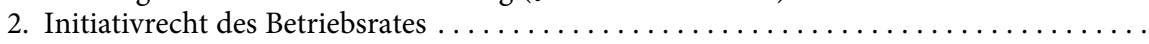

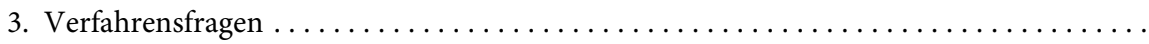

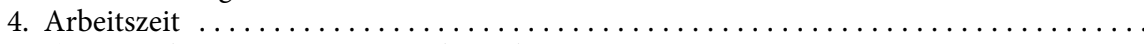

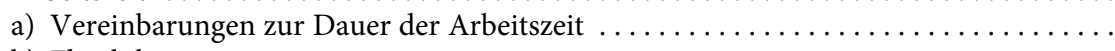

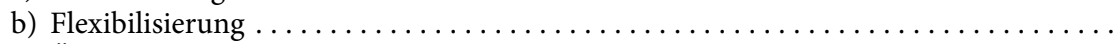

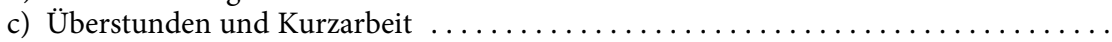

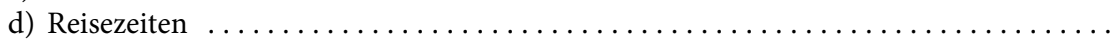

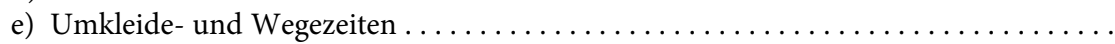

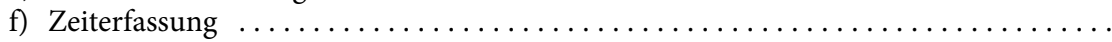

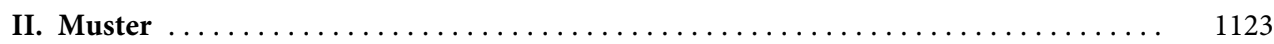

M 35.1 Betriebsvereinbarung zur Lage der Arbeitszeit . . . . . . . . . . . . . 1123

M 35.2 Betriebsvereinbarung zu flexibler Arbeitszeit ................... 1124

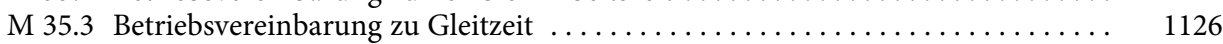

M 35.4 Betriebsvereinbarung zu Überstunden ......................... 1129

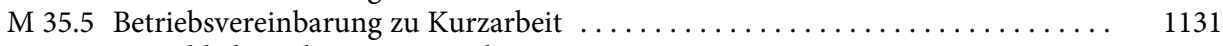

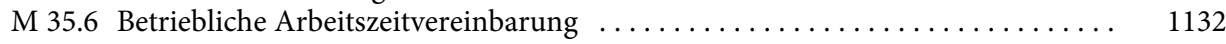


M 35.7 Einstweilige Verfügung wegen Unterlassung von Überstunden ohne

Zustimmung des Betriebsrats $\ldots \ldots \ldots \ldots \ldots \ldots \ldots \ldots \ldots \ldots \ldots \ldots \ldots$

Seite

\section{Kap. 36 Mitbestimmung in sozialen Angelegenheiten - Lohngestaltung}

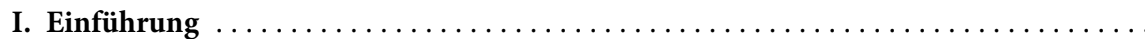

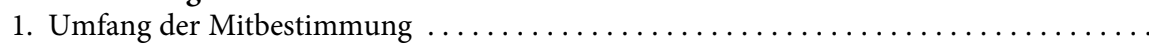

1137

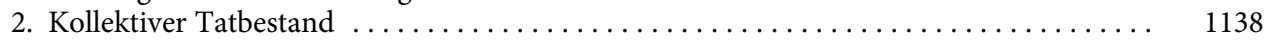

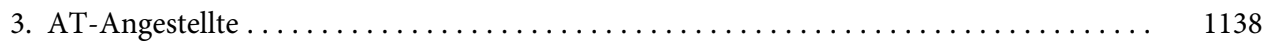

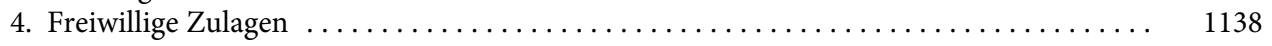

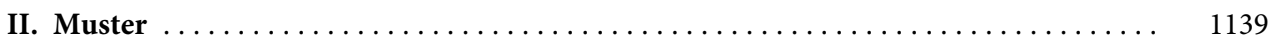

M 36.1 Betriebsvereinbarung Vergütung von AT-Angestellten .............. 1139

M 36.2 Betriebsvereinbarung Übertarifliche Zulagen .................... 1140

M 36.3 Betriebsvereinbarung Provisionen im Verkauf ................... 1141

M 36.4 Betriebsvereinbarung Erschwerniszulage im Vier-Schicht-Betrieb . . . . . . . 1141

M 36.5 Betriebsvereinbarung über zielvereinbarungsgestützte variable Vergütung .... 1142

M 36.6 Betriebsvereinbarung Gehaltsbandbreiten ...................... 1143

\section{Kap. 37 Mitbestimmung in sozialen Angelegenheiten - Technische Einrichtungen}

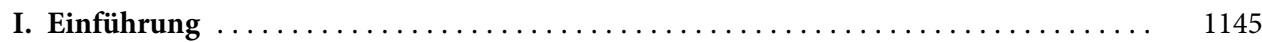

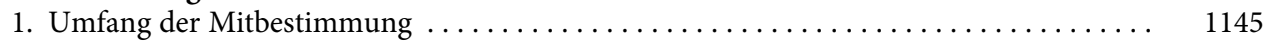

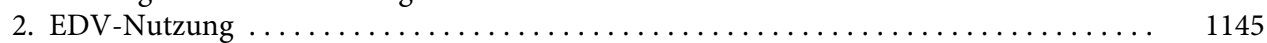

3. Telefondatenerfassung und Internet-/E-Mail-Nutzung $\ldots \ldots \ldots \ldots \ldots \ldots \ldots \ldots \ldots$

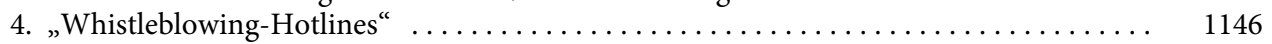

5. Zuständigkeit des Gesamt- oder Konzernbetriebsrates $\ldots \ldots \ldots \ldots \ldots \ldots \ldots \ldots \ldots$

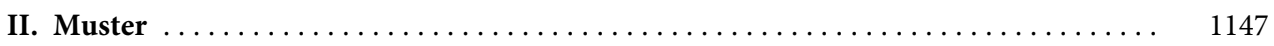

M 37.1 Regelungsabrede/Betriebsvereinbarung Einführung eines IT-Systems . . . . 1147

M 37.2 Gesamtbetriebsvereinbarung EDV-Systeme und Schutz personenbezogener

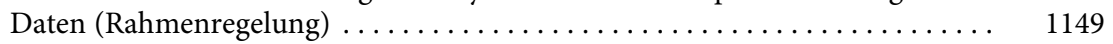

M 37.3 Betriebsvereinbarung Customer-Relation-Management ............. 1152

M 37.4 Betriebsvereinbarung zur Nutzung der Telefonanlage $\ldots \ldots \ldots \ldots \ldots \ldots \ldots . \ldots \ldots$

M 37.5 Betriebsvereinbarung zur Telefondatenerfassung ................. 1155

M 37.6 Betriebsvereinbarung zur elektronischen Zeiterfassung und Zeitwirtschaft ... 1156

M 37.7 Betriebsvereinbarung zur Nutzung von Internet und E-Mail . . . . . . . . . . . 1159

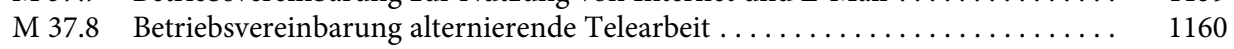

M 37.9 Betriebsvereinbarung „Bring your own device“ $\ldots \ldots \ldots \ldots \ldots \ldots \ldots \ldots . \quad 1162$

M 37.10 Einstweilige Verfügung wegen Unterlassung der Inbetriebnahme eines

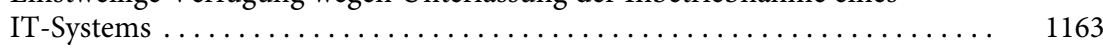

Kap. 38 Mitbestimmung in sozialen Angelegenheiten - Sozialeinrichtungen

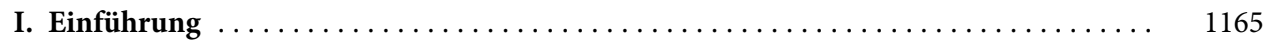

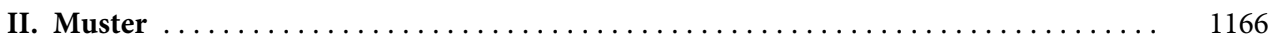

M 38.1 Betriebsvereinbarung zur Einrichtung eines Sozialfonds $\ldots \ldots \ldots \ldots \ldots \ldots \ldots$

M 38.2 Betriebsvereinbarung zu Konzern-Mitarbeiterdarlehen $\ldots \ldots \ldots \ldots \ldots \ldots \ldots \ldots . \ldots \ldots$

\section{Kap. 39 Mitbestimmung in sozialen Angelegenheiten - Betriebsordnung/ Verhaltensrichtlinien}

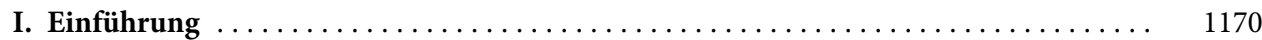

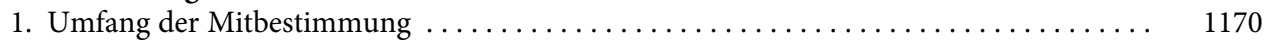

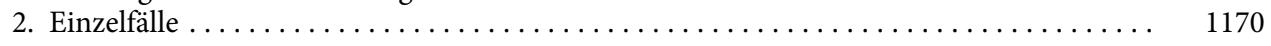


Seite

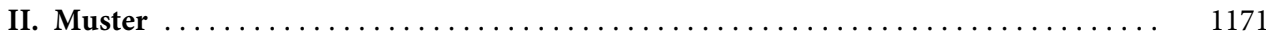

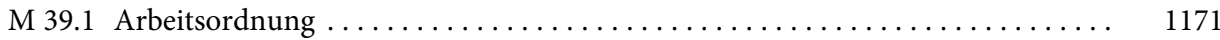

M 39.2 Betriebsvereinbarung zu Alkoholproblemen am Arbeitsplatz . . . . . . . . . 1178

M 39.3 Betriebsvereinbarung zur Einführung einer einheitlichen Arbeitskleidung . . . 1180

M 39.4 Betriebsvereinbarung über Arztbesuche während der Arbeitszeit . . . . . . . . 1181

M 39.5 Verhaltensrichtlinie zum Umgang mit Zuwendungen . . . . . . . . . . . . . 1182

Kap. 40 Mitbestimmung in sozialen Angelegenheiten - Betriebliches Vorschlagswesen

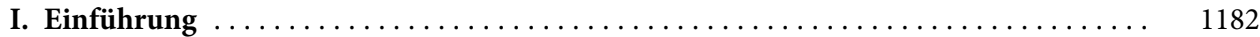

1. Begriff des betrieblichen Vorschlagswesens $\ldots \ldots \ldots \ldots \ldots \ldots \ldots \ldots \ldots \ldots \ldots \ldots \ldots \ldots \ldots$

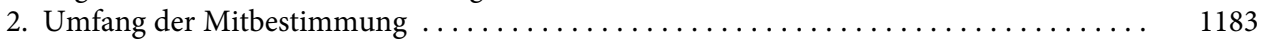

II. Muster $\ldots \ldots \ldots \ldots \ldots \ldots \ldots \ldots \ldots \ldots \ldots \ldots \ldots \ldots \ldots \ldots \ldots \ldots \ldots \ldots \ldots$

M 40.1 Betriebsvereinbarung zu Verbesserungsvorschlägen $\ldots \ldots \ldots \ldots \ldots \ldots \ldots \ldots$

Kap. 41 Mitbestimmung in sozialen Angelegenheiten - Urlaub

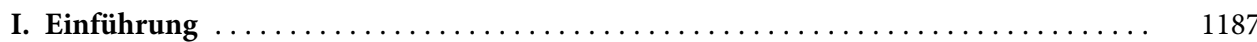

1. Umfang des Mitbestimmungsrechtes $\ldots \ldots \ldots \ldots \ldots \ldots \ldots \ldots \ldots \ldots \ldots \ldots \ldots \ldots \ldots \ldots \ldots$

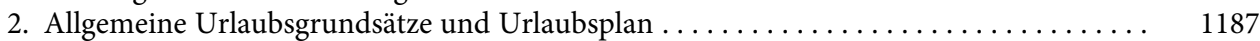

3. Lage des Urlaubs einzelner Arbeitnehmer $\ldots \ldots \ldots \ldots \ldots \ldots \ldots \ldots \ldots \ldots \ldots \ldots \ldots$

II. Muster $\ldots \ldots \ldots \ldots \ldots \ldots \ldots \ldots \ldots \ldots \ldots \ldots \ldots \ldots \ldots \ldots \ldots \ldots \ldots \ldots \ldots \ldots \ldots$

M 41.1 Betriebsvereinbarung Brückentage $\ldots \ldots \ldots \ldots \ldots \ldots \ldots \ldots \ldots \ldots \ldots \ldots \ldots \ldots$

M 41.2 Betriebsvereinbarung Betriebsferien $\ldots \ldots \ldots \ldots \ldots \ldots \ldots \ldots \ldots \ldots \ldots \ldots$

Kap. 42 Mitbestimmung in personellen Angelegenheiten

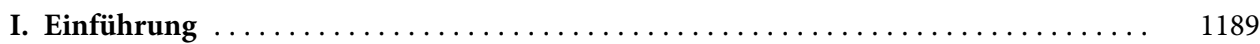

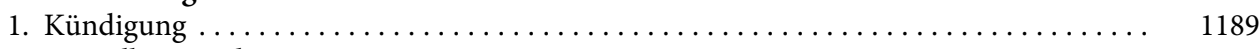

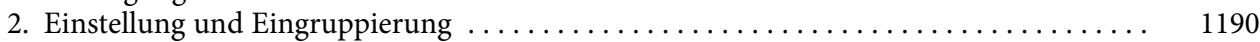

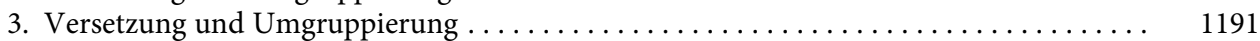

4. Stellenausschreibung ....................................... 1191

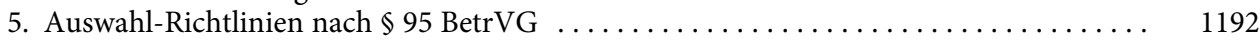

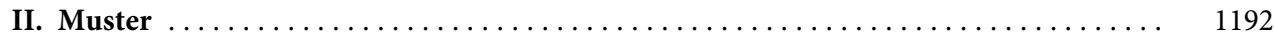

M 42.1 Anhörung des Betriebsrats gemäß $\$ 102$ BetrVG zur ordentlichen betriebs-

bedingten Kündigung ............................. 1192

M 42.2 Anhörung des Betriebsrats gemäß $\$ 102$ BetrVG zu betriebsbedingten

Kündigungen wegen Betriebsstilllegung .................... 1192

M 42.3 Anhörung des Betriebsrats gemäß $\$ 102$ BetrVG zur ordentlichen krankheitsbedingten Kündigung ............................. 1193

M 42.4 Antrag auf Zustimmung zur außerordentlichen Kündigung eines Betriebs-

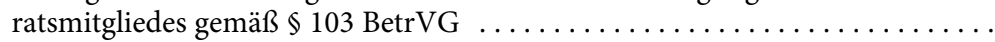

M 42.5 Antrag auf Ersetzung der Zustimmung des Betriebsrats zur außerordentlichen Kündigung eines Betriebsratsmitglieds gemäß $₫ 103$ BetrVG ........

M 42.6 Antrag auf Zustimmung zur Einstellung und Eingruppierung eines Bewerbers nach $₫ 99$ BetrVG .............................. 1196

M 42.7 Antrag auf Zustimmung zur Versetzung nach $\$ \$ 99,100$ BetrVG . . . . . . . 1197

M 42.8 Ablehnende Antwort des Betriebsrats auf einen Antrag nach $\$ \$ 99,100$ BetrVG ........................................... 1198

M 42.9 Antrag des Arbeitgebers an das Arbeitsgericht nach $\$ \$ 99,100$ BetrVG . . . . 1200

M 42.10 Antrag des Betriebsrats auf Aufhebung einer personellen Maßnahme nach

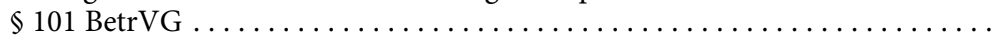


M 42.11 Einstweilige Verfügung wegen mitbestimmungswidriger Personal-

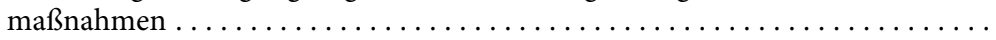

M 42.12 Antrag des Arbeitgebers auf Entbindung von der Übernahmeverpflichtung

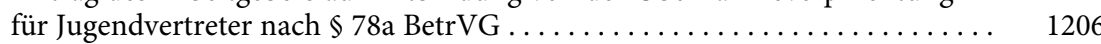

M 42.13 Betriebliche Regelung Stellenausschreibung . . . . . . . . . . . . . . . . . 1208

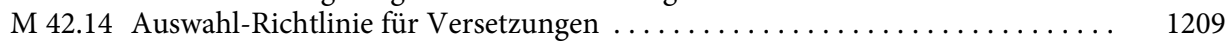

\section{Kap. 43 Mitbestimmung in wirtschaftlichen Angelegenheiten}

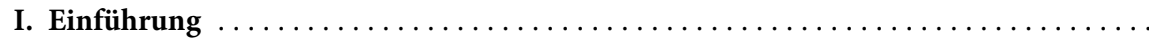

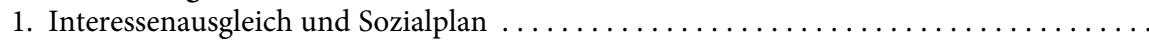

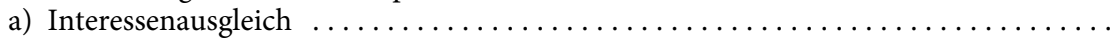

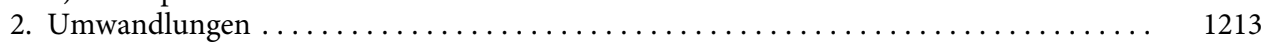

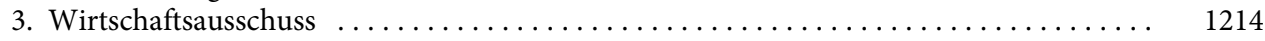

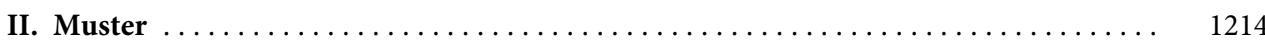

M 43.1 Interessenausgleich Betriebsverlegung . . . . . . . . . . . . . . . . . . . 1214

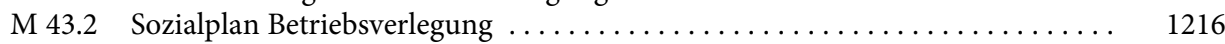

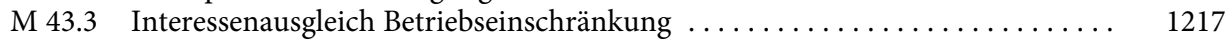

M 43.4 Sozialplan Betriebseinschränkung . . . . . . . . . . . . . . . . . . . . . . 1219

M 43.5 Negativer Interessenausgleich Werkschließung . . . . . . . . . . . . . . . . . . . . . 1222

M 43.6 Positiver Interessenausgleich Betriebsstilllegung (kurz) . . . . . . . . . . . . 1223

M 43.7 Positiver Interessenausgleich Betriebsstilllegung (ausführlich) $\ldots \ldots \ldots \ldots \ldots . .1223$

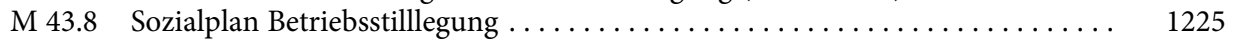

M 43.9 Vertrag über die Einrichtung einer Beschäftigungs- und Qualifizierungs-

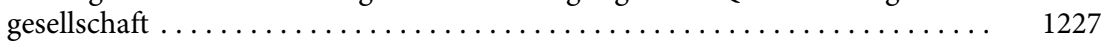

M 43.10 Einstweilige Verfügung gegen Kündigungen und weitere Maßnahmen vor Abschluss des Interessenausgleichs-Verfahrens . .............. 1232

M 43.11 Ordnungswidrigkeiten-Anzeige des Betriebsrats gegen den Arbeitgeber wegen mangelhafter Unterrichtung nach $\$ 111$ BetrVG . . . . . . . . . .

M 43.12 Angaben der Folgen der Verschmelzung für die Arbeitnehmer und ihre Vertretungen sowie die insoweit vorgesehenen Maßnahmen im Rahmen

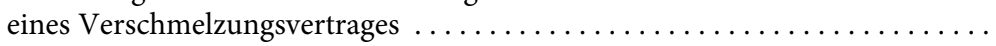

\section{Kap. 44 Einigungsstelle}

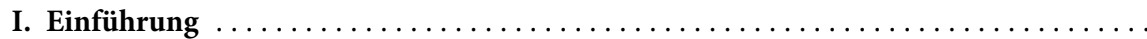

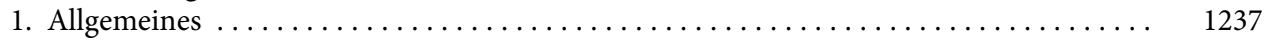

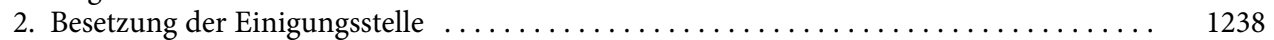

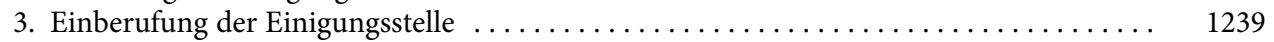

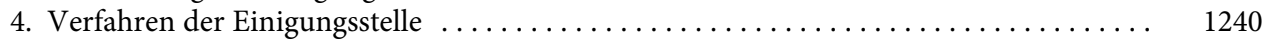

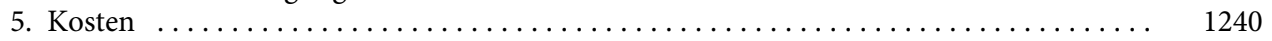

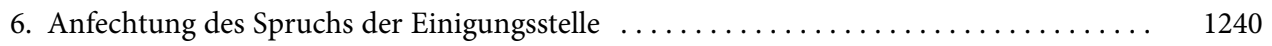

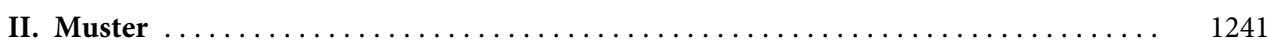

M 44.1 Antrag auf Errichtung der Einigungsstelle .................. 1241

M 44.2 Antrag an das Arbeitsgericht auf Errichtung der Einigungsstelle nach

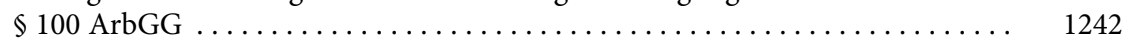

M 44.3 Einigungsstellenspruch ................................ 1244

M 44.4 Einstweilige Verfügung auf Untersagung der Durchführung eines Einigungs-

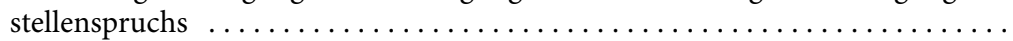

M 44.5 Anfechtung des Einigungsstellenspruchs nach $₫ 76$ Abs. 5 BetrVG . . . . . . . 1247 


\section{Kap. 45 Euro-Betriebsrat}

Seite

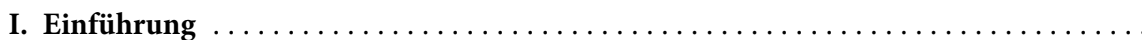

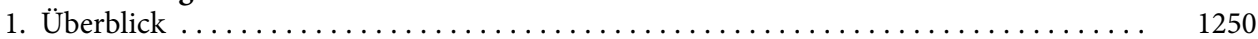

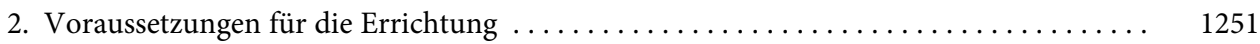

3. Auskunftsanspruch ........................................ 1251

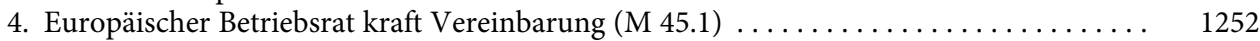

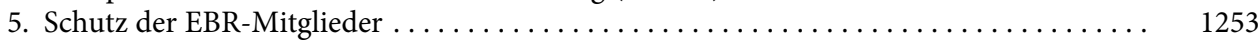

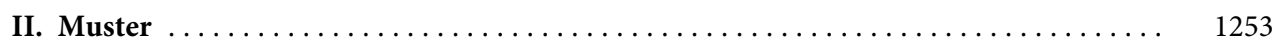

M 45.1 Vereinbarung über die Errichtung eines Europäischen Betriebsrats . . . . . . 1253

M 45.2 Klage des Betriebsrats auf Auskunftserteilung zwecks Errichtung eines

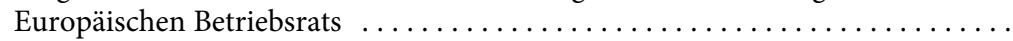

\section{Kap. 46 Personalvertretungsrecht}

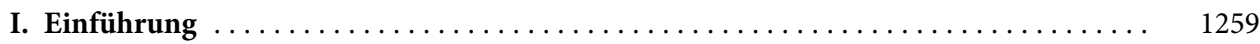

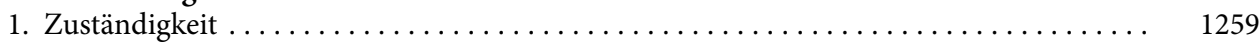

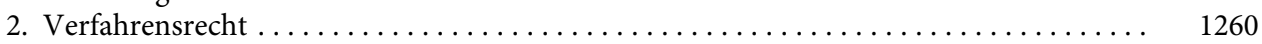

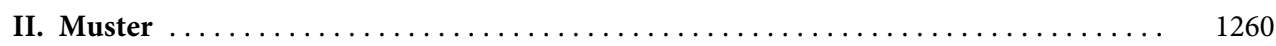

M 46.1 Antrag an das Verwaltungsgericht zur Einleitung eines Beschluss-

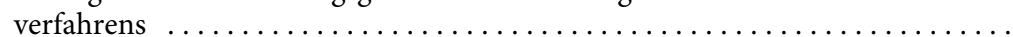

Kap. 47-49 frei.

\section{Dritter Teil \\ Tarifrecht/Arbeitskampfrecht}

\section{Kap. 50 Tarifverträge}

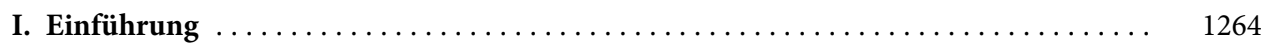

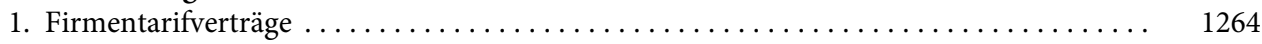

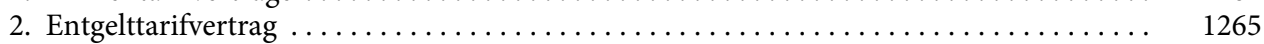

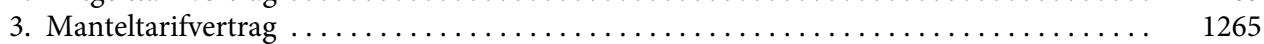

4. Tarifverträge über die betriebsverfassungsrechtlichen Strukturen $\ldots \ldots \ldots \ldots \ldots \ldots \ldots \quad 1266$

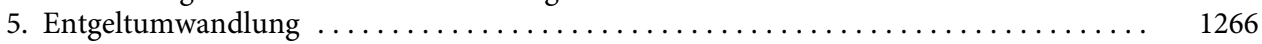

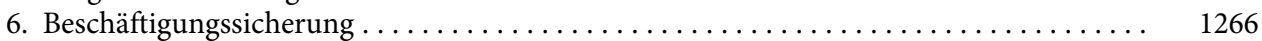

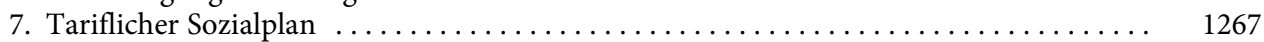

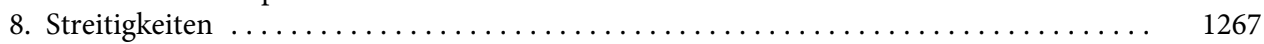

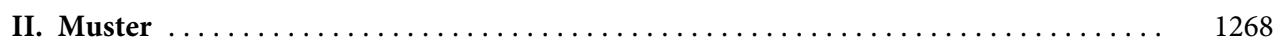

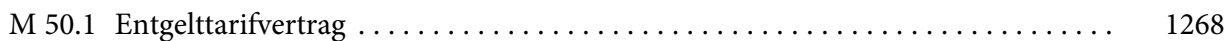

M 50.2 Firmentarifvertrag in Form eines Anerkennungstarifvertrages . . . . . . . . . 1269

M 50.3 Firmentarifvertrag nach Betriebsübergang/Gesellschafterwechsel ......... 1271

M 50.4 Tarifvertrag zur Bildung von Regionalbetriebsräten ................. 1272

M 50.5 Haustarifvertrag über einen gemeinsamen Gesamtbetriebsrat . . . . . . . . . . . 1274

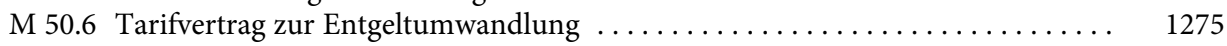

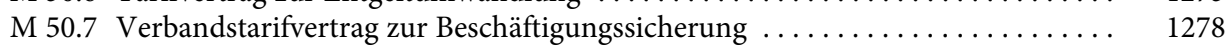

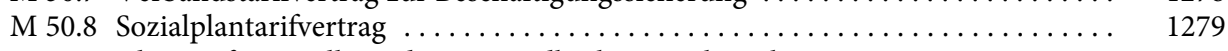

M 50.9 Klage auf Feststellung der Anwendbarkeit/Wirksamkeit eines 
Seite

Kap. 51 Arbeitskampf

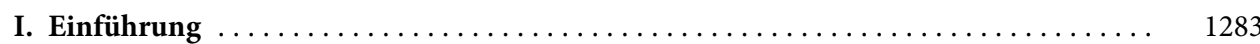

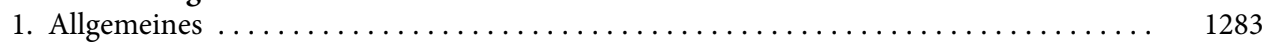

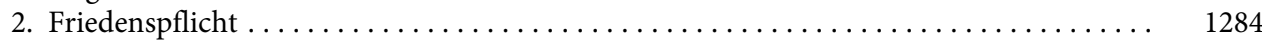

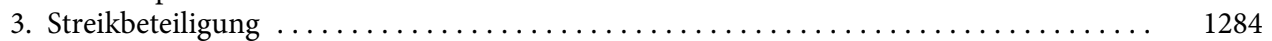

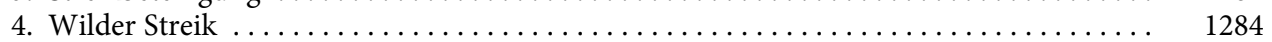

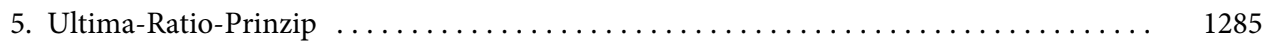

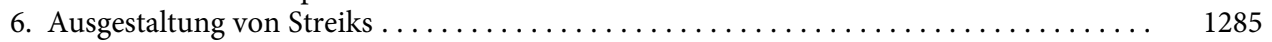

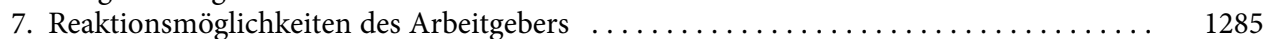

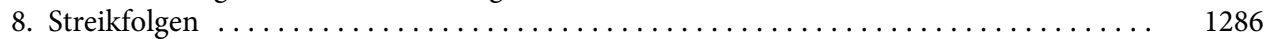

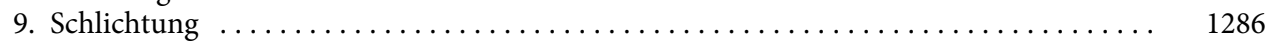

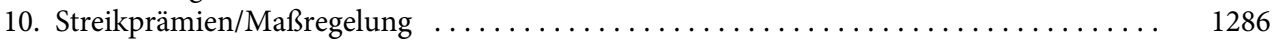

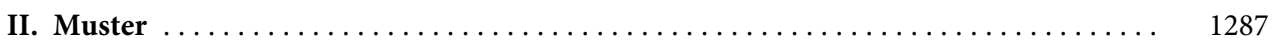

M 51.1 Einstweilige Verfügung gegen rechtswidrigen Streik ................ 1287

M 51.2 Einstweilige Verfügung gegen rechtswidrige Streikmaßnahmen .......... 1291

M 51.3 Einstweilige Verfügung wegen Einrichtung eines Notdienstes ............ 1293

M 51.4 Schlichtungsabkommen ................................ 1295

Kap. 52-59 frei.

\section{Vierter Teil \\ Betriebsübergang}

\section{Kap. 60 Betriebsübergang}

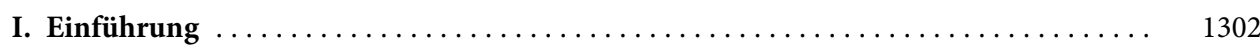

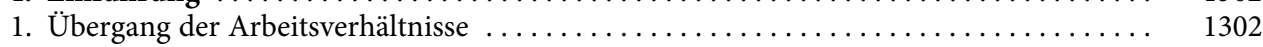

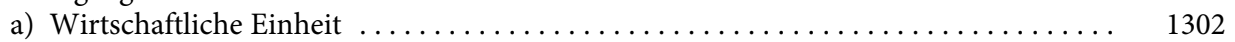

b) Übergang und Zuordnung der Arbeitsverhältnisse $\ldots \ldots \ldots \ldots \ldots \ldots \ldots \ldots \ldots \ldots \ldots \ldots$

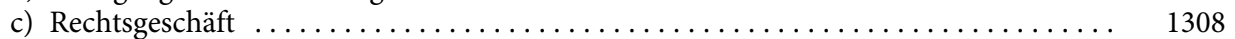

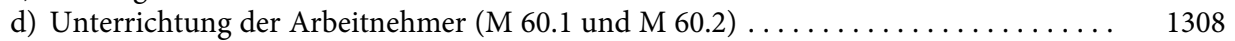

e) Widerspruchsrecht nach $₫ 613$ a Abs. 6 BGB ........................ 1319

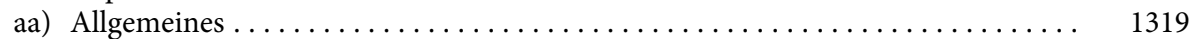

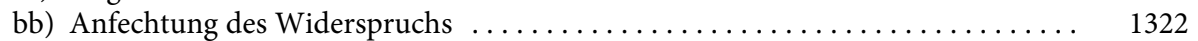

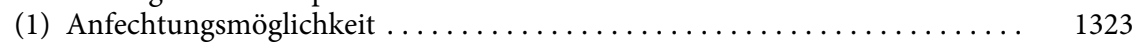

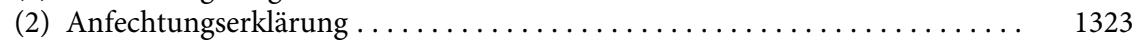

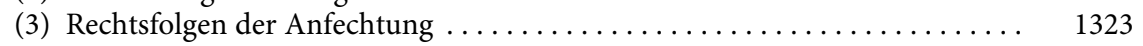

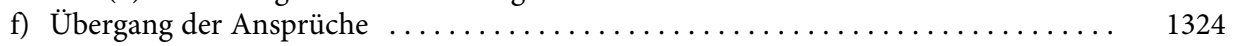

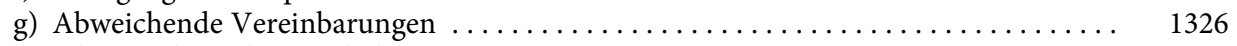

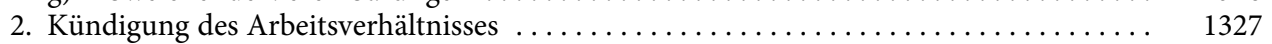

a) Wirksamkeit einer Kündigung bei Betriebsübergang ............... 1327

b) Kündigungsschutzklage gegen Kündigung wegen Betriebsübergangs

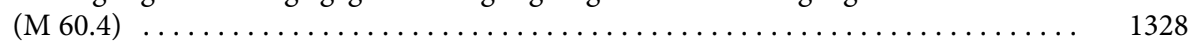

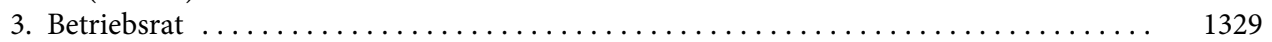

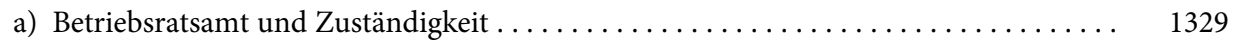

aa) Übergang des gesamten Betriebes . . . . . . . . . . . . . . . . . . . . . 1329

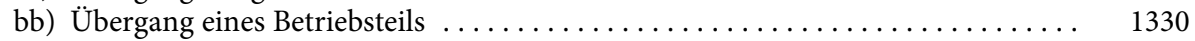

cc) Zusammenschluss mehrerer Betriebe oder Betriebsteile ............. 1330

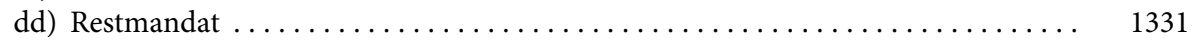

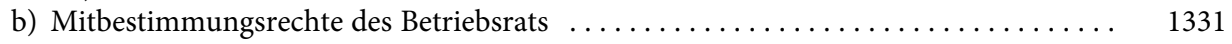


4. Auswirkungen auf Tarifverträge und Betriebsvereinbarungen $\ldots \ldots \ldots \ldots \ldots \ldots \ldots$

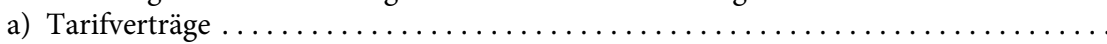

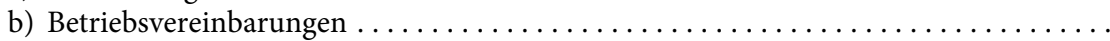

5. Sonderregelungen im Umwandlungsrecht $\ldots \ldots \ldots \ldots \ldots \ldots \ldots \ldots \ldots \ldots \ldots \ldots$

II. Muster $\ldots \ldots \ldots \ldots \ldots \ldots \ldots \ldots \ldots \ldots \ldots \ldots \ldots \ldots \ldots \ldots \ldots \ldots \ldots \ldots \ldots \ldots \ldots$

M 60.1 Unterrichtungsschreiben nach $\$ 613$ a Abs. 5 BGB - Übergang eines

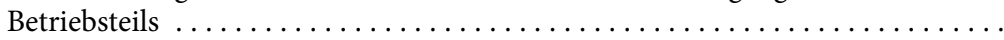

M 60.2 Unterrichtungsschreiben nach $\$ 613$ a Abs. 5 BGB - Übergang eines

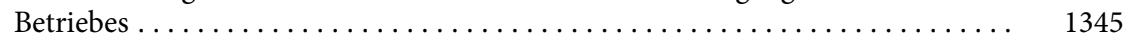

M 60.3 Widerspruch nach $₫ 613$ a BGB - Betriebsübergang . . . . . . . . . . . 1352

M 60.4 Anfechtung des Widerspruchs gegen den Übergang des Arbeitsverhältnisses . . 1353

M 60.5 Kündigungsschutzklage gegen Kündigung wegen Betriebsübergangs . . . . . . . . 1354

Kap. 61-69 frei.

\section{Fünfter Teil \\ Datenschutz/Compliance}

\section{Kap. 70 Compliance und Datenschutz}

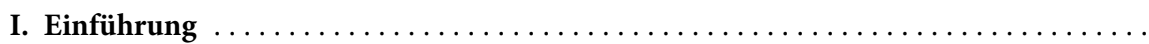

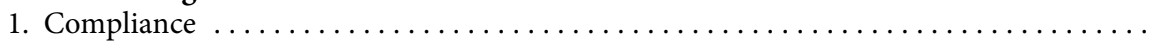

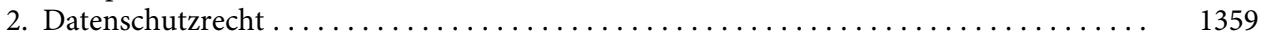

II. Muster $\ldots \ldots \ldots \ldots \ldots \ldots \ldots \ldots \ldots \ldots \ldots \ldots \ldots \ldots \ldots \ldots \ldots \ldots \ldots \ldots \ldots \ldots \ldots$

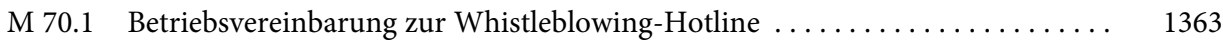

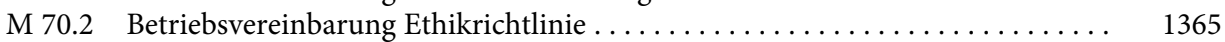

M 70.3 Belehrung zur Befragung durch den Arbeitgeber oder seine Anwälte . . . . . . 1366

M 70.4 Amnestieregelung für Mitwirkung bei Aufklärung . . . . . . . . . . . . . . . 1367

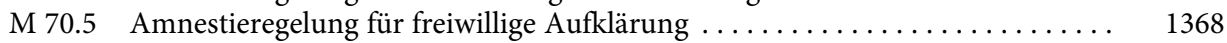

M 70.6 Einwilligung des Bewerbers in die Verarbeitung personenbezogener Daten . . 1369

M 70.7 Einwilligungserklärung des Mitarbeiters $\ldots \ldots \ldots \ldots \ldots \ldots \ldots \ldots \ldots \ldots \ldots$

M 70.8 Anschreiben zur Datenschutzorganisation im (Konzern-)Betriebsrat . . . . . . 1371

M 70.9 Mitarbeiterinformation zur Verarbeitung der Beschäftigtendaten . . . . . . . 1372

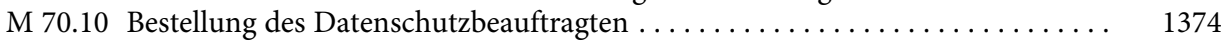

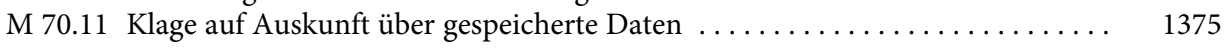

Kap. 71-79 frei.

\section{Sechster Teil Insolvenzarbeitsrecht}

\section{Kap. 80 Arbeitnehmeransprüche im Insolvenzverfahren}

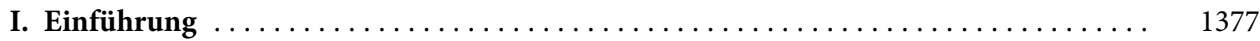

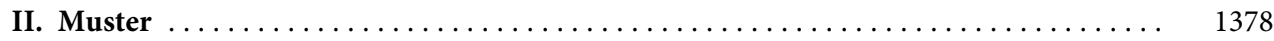

M 80.1 Klage auf Feststellung einer Insolvenzforderung $\ldots \ldots \ldots \ldots \ldots \ldots \ldots \ldots \ldots$

M 80.2 Wiederaufnahme eines wegen Insolvenzeröffnung unterbrochenen Rechtsstreits ..................................... 1379 


\section{Kap. 81 Betriebsänderungen im Insolvenzverfahren}

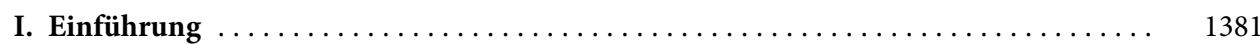

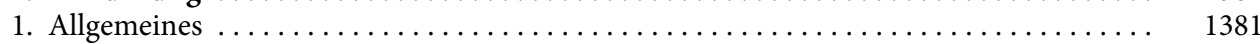

2. Beschlussverfahren nach $₫ 122$ InsO wegen Betriebsänderung ................ 1381

3. Beschlussverfahren wegen Kündigungsschutz nach $\$ \$ 125,126 \operatorname{Ins} \mathrm{O} \ldots \ldots \ldots \ldots \ldots \ldots$

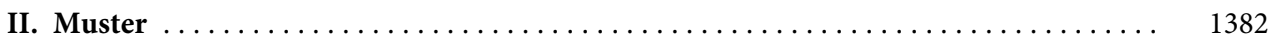

M 81.1 Antrag des Insolvenzverwalters wegen Durchführung einer Betriebs-

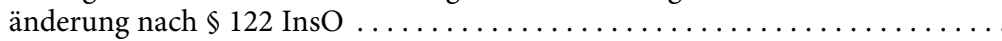

M 81.2 Antrag des Insolvenzverwalters wegen Zustimmung zu Kündigungen nach $\S 126 \mathrm{InsO}$

Kap. 82-89 frei.

\section{Siebter Teil \\ Unternehmensmitbestimmung}

\section{Kap. 90 Unternehmensmitbestimmung}

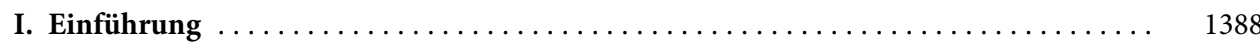

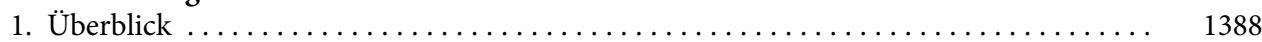

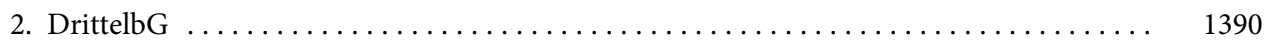

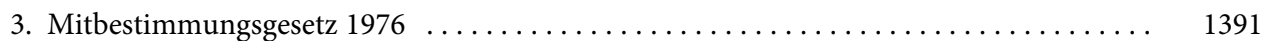

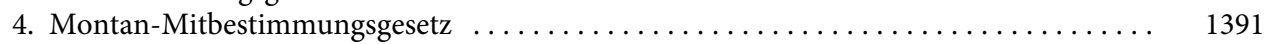

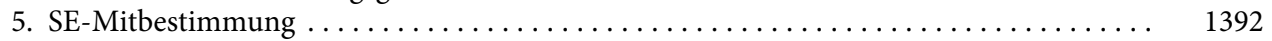

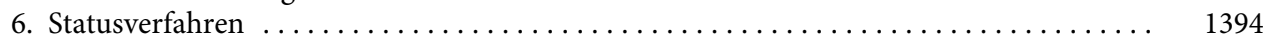

II. Muster . . . . . . . . . . . . . . . . . . . . . . . . . . . . . . . 1396

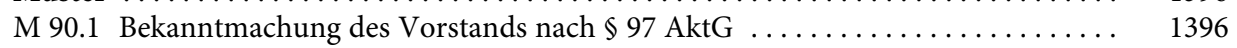

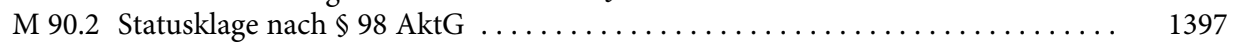

M 90.3 Vereinbarung über die Beteiligung der Arbeitnehmer in einer SE . . . . . . . . 1399

Kapitel 91-99 frei.

\section{Achter Teil \\ Arbeitsgerichtsverfahren}

\section{Kap. 100 Das arbeitsrechtliche Mandat}

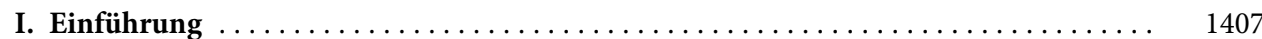

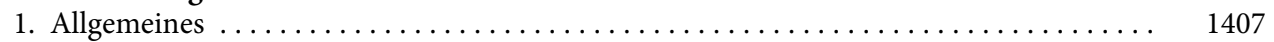

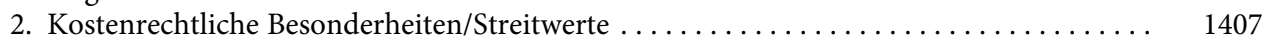

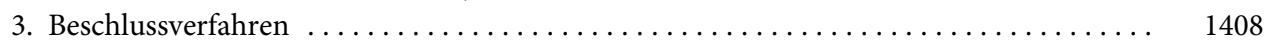

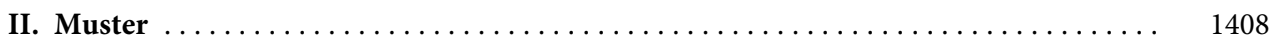

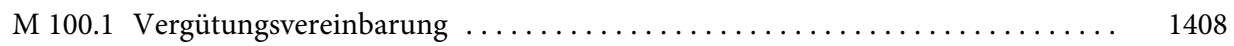

M 100.2 Belehrung nach $₫ 12$ a Abs. 1 ArbGG ....................... 1409

M 100.3 Antrag auf Bewilligung von Prozesskostenhilfe und Beiordnung eines Anwalts 1409 
Kap. 101 Urteilsverfahren erster Instanz

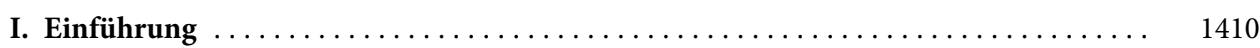

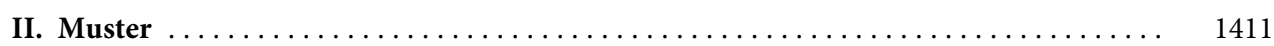

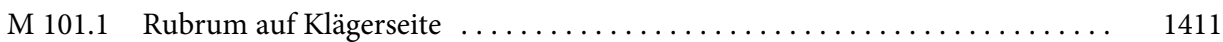

M $101.2 \quad$ Rubrum auf Beklagtenseite . . . . . . . . . . . . . . . . . . . . . 1412

M 101.3 Allgemeines Muster für Klagen/Zahlungsklagen vor dem Arbeitsgericht . . . 1415

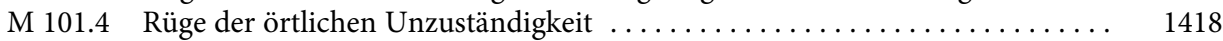

M 101.5 Rüge der Unzulässigkeit des Rechtsweges . . . . . . . . . . . . . . . . . . . . . 1419

M $101.6 \quad$ Klageerwiderung vor der Güteverhandlung ................... 1420

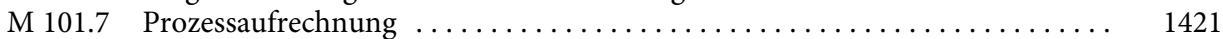

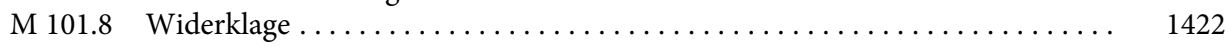

M 101.9 Sofortige Beschwerde gegen die Aussetzung der Kündigungsschutzklage

eines schwerbehinderten Menschen nach $₫ 148$ ZPO ............... 1424

M 101.10 Sofortige Beschwerde gegen die Aussetzung eines Kündigungsschutzverfahrens wegen vorgreiflichen Strafverfahrens nach $\$ 149 \mathrm{ZPO} \ldots \ldots \ldots \quad 1426$

M 101.11 Ablehnung eines Richters wegen Befangenheit . . . . . . . . . . . . . . . . 1427

M 101.12 Einspruch gegen Versäumnisurteil .................... 1430

M 101.13 Anhörungsrüge nach $\$ 78$ a ArbGG gegen nicht berufungsfähiges Urteil des

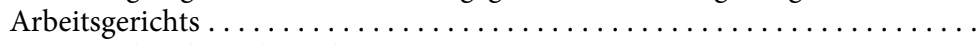

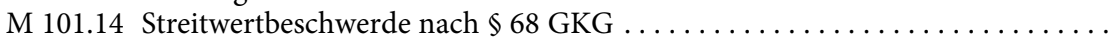

M 101.15 Verzögerungsrüge nach $₫ 198$ GVG, $\$ 9$ ArbGG $\ldots \ldots \ldots \ldots \ldots \ldots \ldots$

M 101.16 Klage auf Entschädigung wegen überlanger Verfahrensdauer $\ldots \ldots \ldots \ldots$.

\section{Kap. 102 Urteilsverfahren zweiter Instanz}

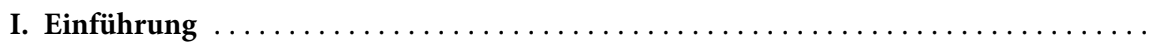

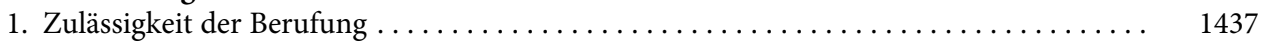

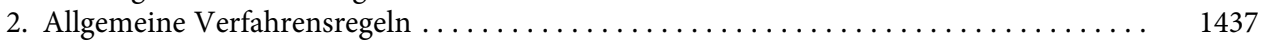

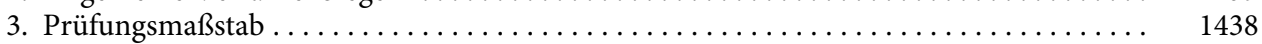

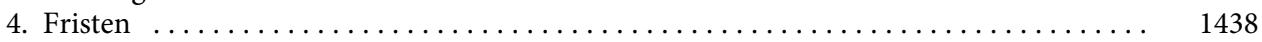

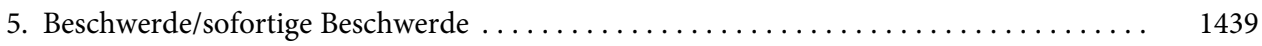

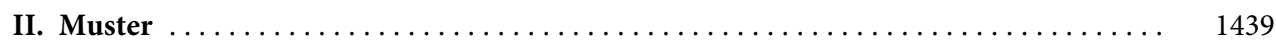

M 102.1 Berufung mit Berufungsbegründung und Antrag auf Einstellung der

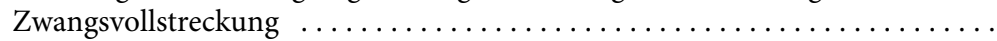

M 102.2 Berufungseinlegung ohne Begründung und mit Fristverlängerungsantrag . . . . 1442

M 102.3 Berufungserwiderung mit Anschlussberufung und Widerklage ........... 1444

M 102.4 Sofortige Beschwerde gegen Rechtswegentscheidung ................ 1445

\section{Kap. 103 Urteilsverfahren dritter Instanz}

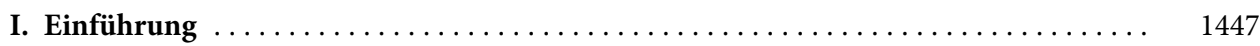

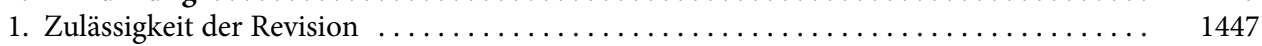

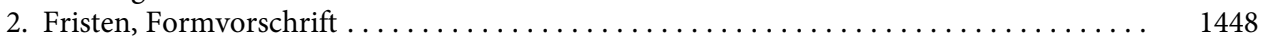

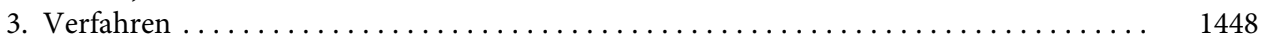

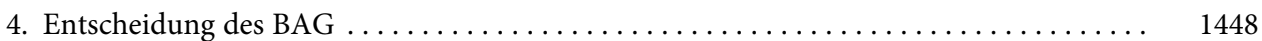

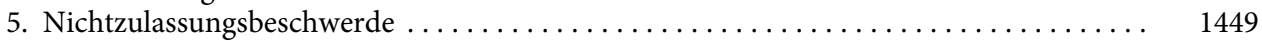

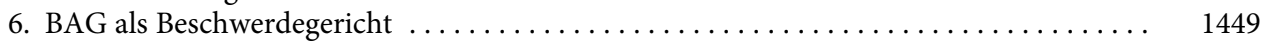

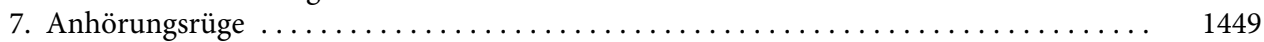

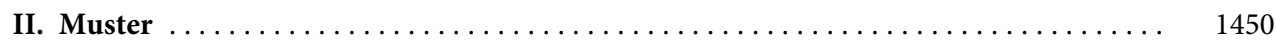

M 103.1 Einlegung der Revision mit Anträgen und Begründung . . . . . . . . . . 1450

M 103.2 Nichtzulassungsbeschwerde wegen Divergenz .................... 1454 


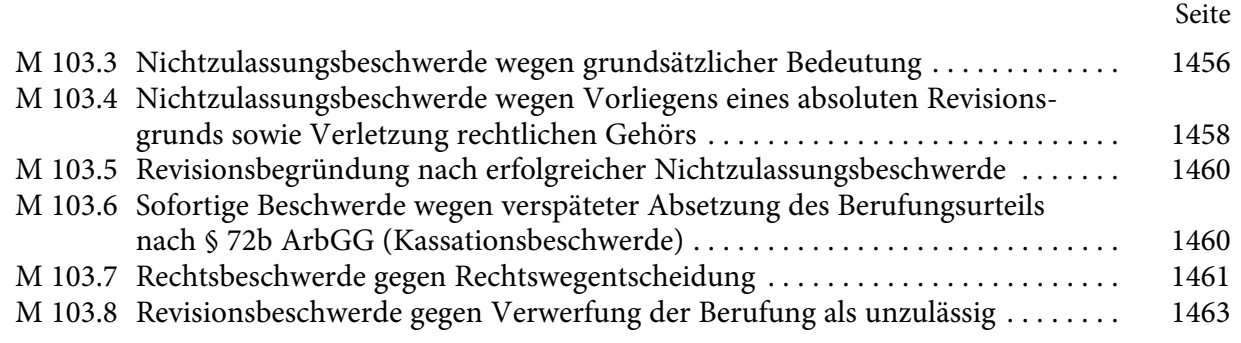

\section{Kap. 104 Beschlussverfahren erster Instanz}

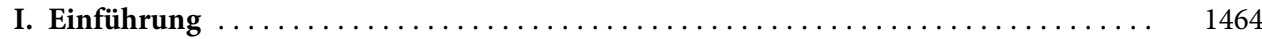

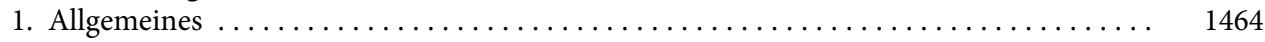

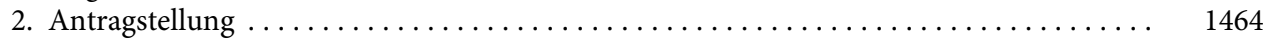

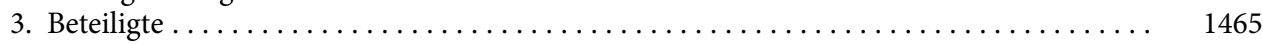

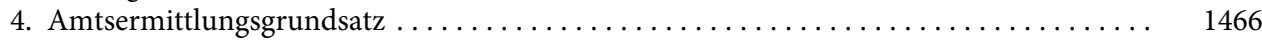

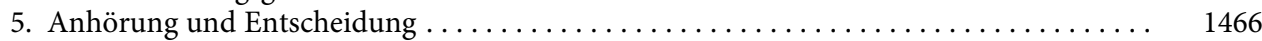

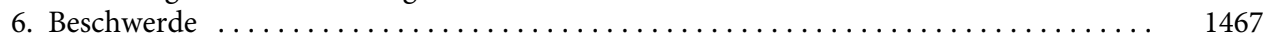

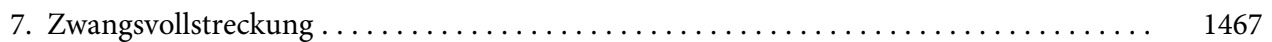

8. Einstweilige Verfügung $\ldots \ldots \ldots \ldots \ldots \ldots \ldots \ldots \ldots \ldots \ldots \ldots \ldots \ldots \ldots \ldots \ldots$

II. Muster $\ldots \ldots \ldots \ldots \ldots \ldots \ldots \ldots \ldots \ldots \ldots \ldots \ldots \ldots \ldots \ldots \ldots \ldots \ldots \ldots \ldots$

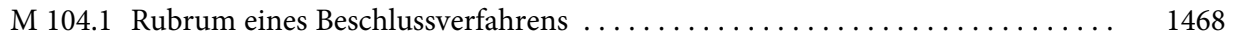

M 104.2 Antrag einer im Betrieb vertretenen Gewerkschaft (Beschlussverfahren) . . . . 1469

\section{Kap. 105 Beschlussverfahren zweiter Instanz}

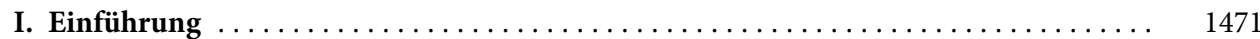

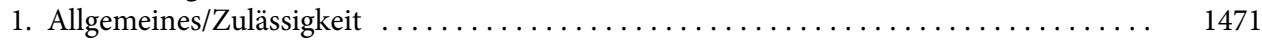

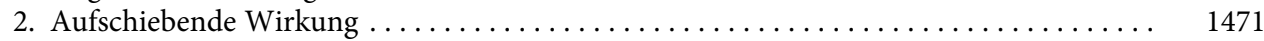

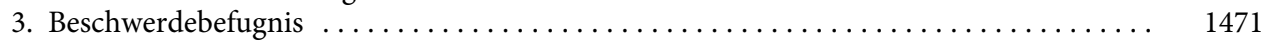

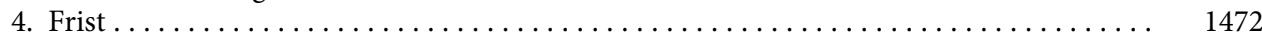

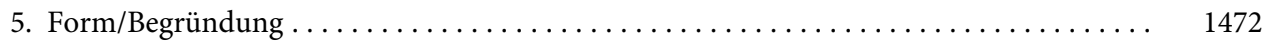

II. Muster $\ldots \ldots \ldots \ldots \ldots \ldots \ldots \ldots \ldots \ldots \ldots \ldots \ldots \ldots \ldots \ldots \ldots \ldots \ldots \ldots \ldots$

M 105.1 Beschwerde an das Landesarbeitsgericht . . . . . . . . . . . . . . . . . . . 1473

M 105.2 Beschwerde gegen Zwischenentscheidung des Arbeitsgerichts . . . . . . . . . . 1473

\section{Kap. 106 Beschlussverfahren dritter Instanz}

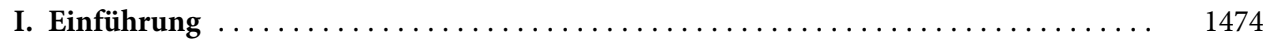

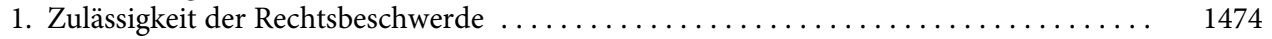

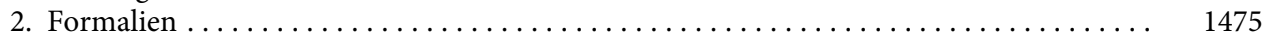

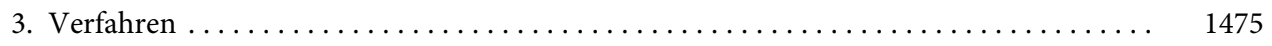

II. Muster $\ldots \ldots \ldots \ldots \ldots \ldots \ldots \ldots \ldots \ldots \ldots \ldots \ldots \ldots \ldots \ldots \ldots \ldots \ldots \ldots \ldots \ldots$

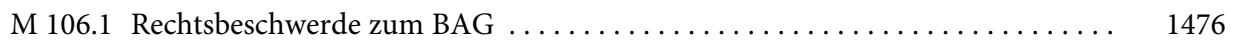

M 106.2 Nichtzulassungsbeschwerde zum BAG (Beschlussverfahren) . . . . . . . . . 1476

\section{Kap. 107 Einstweiliger Rechtsschutz}

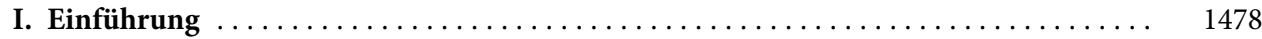

II. Muster . . . . . . . . . . . . . . . . . . . . . . . . . . . . . . . . . . . . . . . 1479

M 107.1 Antrag auf einstweilige Verfügung im Urteilsverfahren . . . . . . . . . . . . . 1479

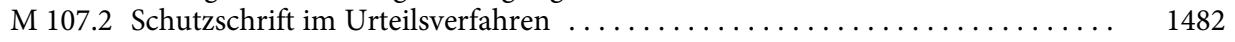


M 107.3 Widerspruch gegen erlassene einstweilige Verfügung $\ldots \ldots \ldots \ldots \ldots \ldots$

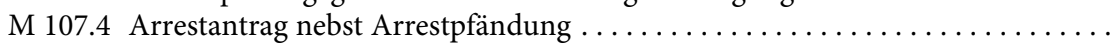

M 107.5 Antrag auf einstweilige Verfügung im Beschlussverfahren . . . . . . . . . .

M 107.6 Berufung gegen Abweisung eines Verfügungsantrags im Urteilsverfahren .... .

M 107.7 Beschwerde gegen Abweisung eines Verfügungsantrags im Beschluss-

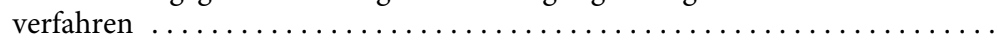

\section{Kap. 108 Zwangsvollstreckung}

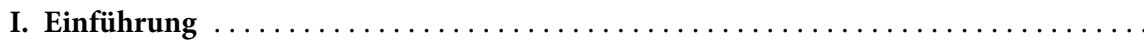

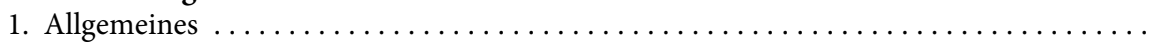

2. Vorläufige Vollstreckbarkeit im Urteilsverfahren $\ldots \ldots \ldots \ldots \ldots \ldots \ldots \ldots \ldots \ldots \ldots$

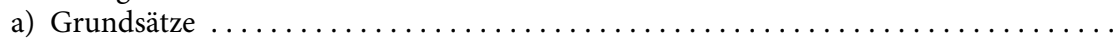

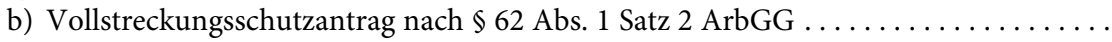

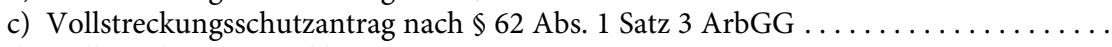

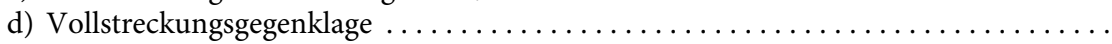

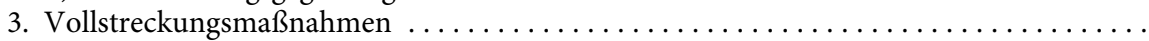

4. Entschädigungsantrag nach $₫ 61$ Abs. 2 ArbGG $\ldots \ldots \ldots \ldots \ldots \ldots \ldots \ldots \ldots$

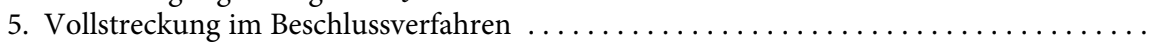

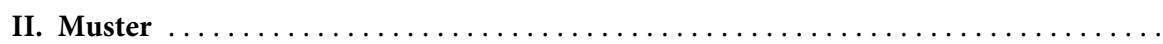

M 108.1 Antrag auf Erteilung der vollstreckbaren Ausfertigung . . . . . . . . . . .

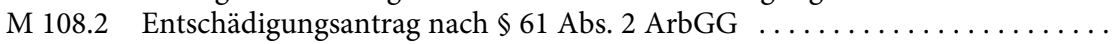

M 108.3 Antrag auf Ausschluss der vorläufigen Vollstreckbarkeit nach $\$ 62$ Abs. 1 Satz 2 ArbGG wegen nicht zu ersetzenden Nachteils ..........

M 108.4 Berufung mit Antrag auf nachträglichen Ausschluss der vorläufigen

Vollstreckbarkeit nach $₫ 62$ Abs. 1 Satz 3 ArbGG .................

M 108.5 Antrag auf Gerichtsvollzieherpfändung wegen Geldforderungen ..........

M 108.6 Antrag auf Zwangsvollstreckung wegen vertretbarer Handlung . . . . . . . .

M 108.7 Antrag auf Zwangsvollstreckung wegen unvertretbarer Handlung

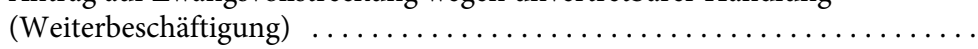

M 108.8 Antrag auf Zurückweisung eines Zwangsvollstreckungsantrags nach

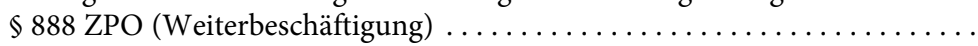

M 108.9 Antrag auf Androhung von Ordnungsmitteln nach $₫ 890$ ZPO bezüglich

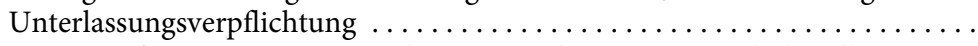

M 108.10 Antrag auf Festsetzung von Ordnungsmitteln wegen Zuwiderhandlungen gegen eine Unterlassungsverpflichtung $\ldots \ldots \ldots \ldots \ldots \ldots \ldots \ldots \ldots$

\section{Kap. 109 Verfahren vor dem EuGH nach Art. 267 AEUV}

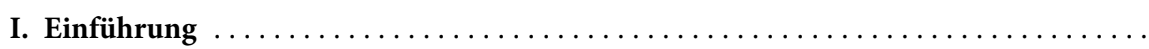

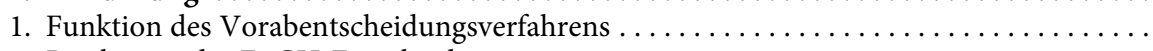

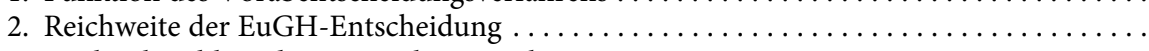

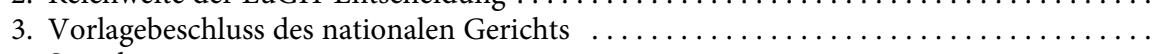

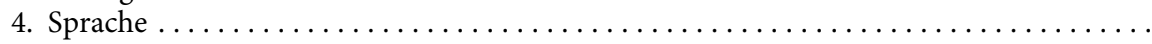

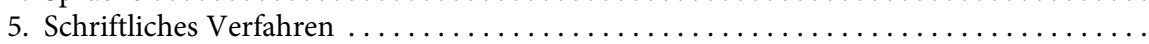

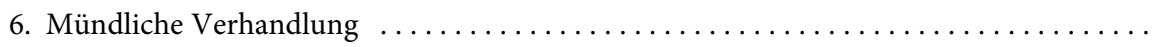

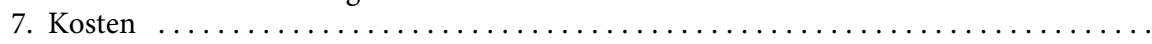

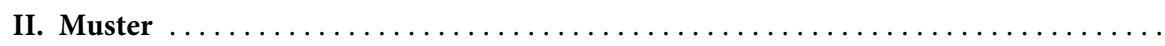

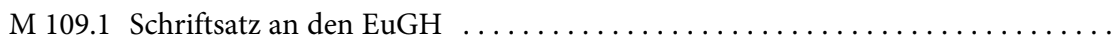


